\title{
Endocannabinoid modulation of secretory and inflammatory causes of gastric pathology
}

\author{
Molly S. Crowe
}

Follow this and additional works at: https://researchrepository.wvu.edu/etd

\section{Recommended Citation}

Crowe, Molly S., "Endocannabinoid modulation of secretory and inflammatory causes of gastric pathology" (2016). Graduate Theses, Dissertations, and Problem Reports. 5412.

https://researchrepository.wvu.edu/etd/5412

This Dissertation is protected by copyright and/or related rights. It has been brought to you by the The Research Repository @ WVU with permission from the rights-holder(s). You are free to use this Dissertation in any way that is permitted by the copyright and related rights legislation that applies to your use. For other uses you must obtain permission from the rights-holder(s) directly, unless additional rights are indicated by a Creative Commons license in the record and/ or on the work itself. This Dissertation has been accepted for inclusion in WVU Graduate Theses, Dissertations, and Problem Reports collection by an authorized administrator of The Research Repository @ WVU.

For more information, please contact researchrepository@mail.wvu.edu. 


\title{
Endocannabinoid modulation of secretory and inflammatory causes of gastric pathology
}

\author{
Molly S. Crowe, M.S. \\ Dissertation submitted to the Eberly College of Arts and Sciences \\ at West Virginia University \\ In partial fulfillment of the requirements for the degree of \\ Doctor of Philosophy in \\ Psychology/Behavioral Neuroscience
}

\author{
Steven G. Kinsey, Ph.D., Chair \\ Melissa D. Blank, Ph.D. \\ Jefferson C. Frisbee, Ph.D. \\ Kevin T. Larkin, Ph.D. \\ David P. Siderovski, Ph.D. \\ Department of Psychology
Morgantown, West Virginia
2016

Keywords: Gastric hemorrhage, stomach ulcer, endocannabinoid, mice, inflammation, MAGL, NSAID

Copyright 2016 Molly S. Crowe 


\title{
ABSTRACT \\ Endocannabinoid modulation of secretory and inflammatory causes of gastric pathology
}

\author{
Molly S. Crowe
}

Non-steroidal anti-inflammatory drugs (NSAIDs) are common analgesic drugs that also cause well-known, negative gastrointestinal (GI) side effects. The specific physiological mechanism(s) of NSAID-induced GI damage are unknown, and are likely due to multiple causes. The most studied components include: increased gastric acid secretions, inflammation of the gastric epithelium, and increased gastric motility. Currently, proton pump inhibitor (PPI) antacids are used by chronic NSAID users, with the expectation that decreasing gastric acid output will reduce gastric epithelial irritation. However, PPIs are associated with side effects like infection, gastric polyps, and dementia. Therefore, new gastroprotective treatments that prevent NSAID-induced gastropathy are needed. The endocannabinoid system has several possible targets to reduce NSAID-induced ulcers, including the endocannabinoid 2-AG (2-arachidonoylglycerol), and the primary enzyme that metabolizes 2-AG, monoacylglycerol lipase (MAGL). Blocking the MAGL enzyme increases stomach levels of 2-AG and reduces NSAID-induced ulcers in male mice. The present project was designed to determine which ulcerogenic effects of the NSAID diclofenac are reversed by MAGL inhibition. We hypothesized that MAGL inhibition would reverse the following effects of diclofenac: (1) increased gastric acid secretion; (2) increased gastric inflammation; and (3) increased gastric motility. Diclofenac induced gastric hemorrhages to a similar extent in both male and female mice. Diclofenac dose-dependently increased neutrophil infiltration in both male and female mice, indicating that diclofenac induces a cell-mediated inflammatory response. Gastric hemorrhage severity correlated with myeloperoxidase levels, an objective measure of immune cell infiltration, indicating its use as a potential biomarker of gastric damage. Diclofenac significantly increased inflammatory cytokines in male mice, whereas administration of JZL184, a MAGL inhibitor, prior to diclofenac had no effect in male mice and increased gastric inflammatory cytokine levels in female mice. Neither JZL184 nor diclofenac produced any changes on gastric acid secretions when evaluated during the gastric hemorrhage procedure. However, in the pentagastrin-stimulated acid model, JZL184 decreased gastric acid secretions in both basal and stimulated conditions. As hypothesized, JZL184 decreased gastric motility, although diclofenac, contrary to expectations, slowed gastric motility, indicating that diclofenac-induced ulcers most likely do not occur through increased gastric motility, at least not as measured in the present study. The present data indicate that MAGL inhibition may proffer gastroprotection through modulating the secretory pathway of gastric hemorrhage. These data underscore the importance of sampling multiple time points and using both sexes in research, in addition to multiple mechanistic targets, and contribute to the basic understanding of NSAIDinduced gastric inflammation. 
Dedicated to my husband, family, and friends who supported me throughout this journey. 
ENDOCANNABINOID MODULATION OF GASTROPATHY

\section{Acknowledgements}

Foremost, I would like to express my sincerest appreciation to my advisor and mentor, Dr. Steve Kinsey. I am truly thankful for his constant patience, encouragement, reassurance, and inspiration. Steve is the funniest and best advisor conceivable, whose advice and guidance I have truly cherished. He has allowed me freedom in my scientific creativity but has also provided insightful critiques, which has made me the lady scientist I am today. I whole-heartedly look forward to our continued and future collaborations.

In addition to Steve, I would like to thank my committee members, Drs. Melissa Blank, Jeff Frisbee, Kevin Larkin, and David Siderovski, who have supported me throughout graduate school and who improved my dissertation.

I would also like to thank the members of the Kinsey lab, who have always listened to my presentations and been an amazing support system throughout my time at WVU. Specifically, I want to thank Sara Nass and Kristen Trexler, who have assisted me in these experiments and I am forever grateful for their support and friendship.

Finally, I would like to thank my wonderful husband, Nick Arnhold, who has always kept me balanced and happy. 
ENDOCANNABINOID MODULATION OF GASTROPATHY

Table of Contents

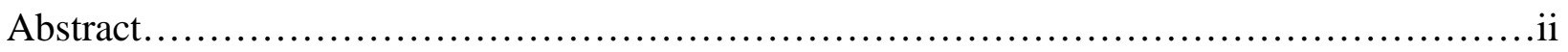

Abbreviations...................................................................... vii

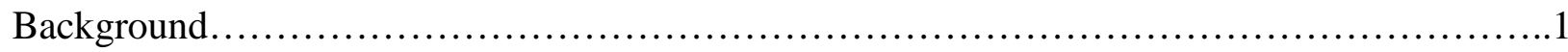

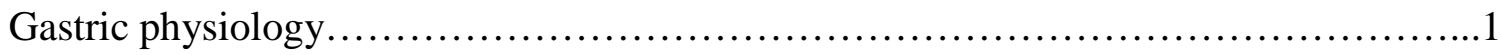

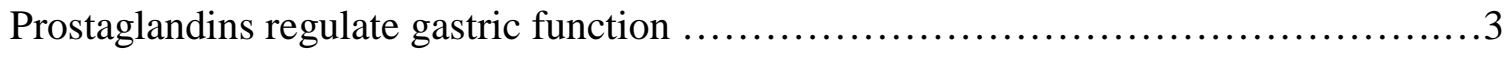

Nonsteroidal anti-inflammatory drugs are COX inhibitors...........................5

NSAID-induced gastric damage.............................................7

The endocannabinoid system.............................................

Endocannabinoids in the gastrointestinal system...............................13

Method.............................................................................. 16

Animals...................................................................16

Drugs....................................................................

Induction of gastric hemorrhage............................................17

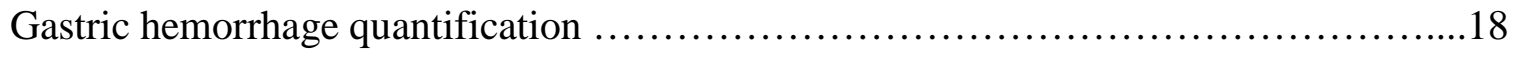

Biomarker and mediators quantification.......................................18

Gastric acid secretion.....................................................19

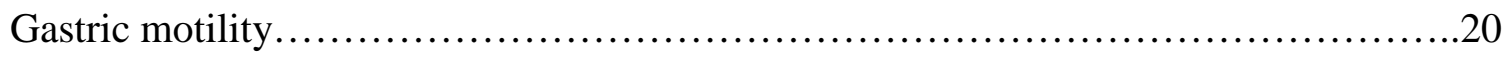

Statistical analysis........................................................21

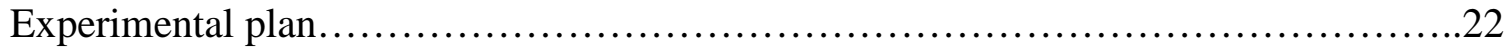

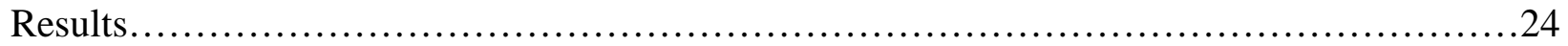

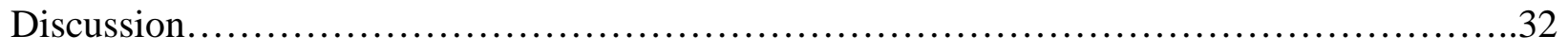

Mechanisms of gastric hemorrhage.......................................... 34

Alternative mechanisms of gastric hemorrhage $\ldots \ldots \ldots \ldots \ldots \ldots \ldots \ldots \ldots \ldots \ldots \ldots \ldots . . . \ldots 1$

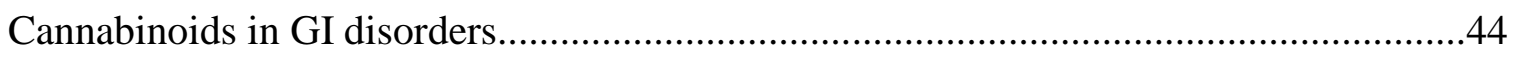


ENDOCANNABINOID MODULATION OF GASTROPATHY

\section{Table of Contents - Continued}

Parallel wound healing and pain models........................................46

Research limitations.........................................................48

Conclusion...................................................................... 50

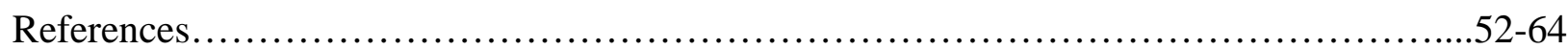

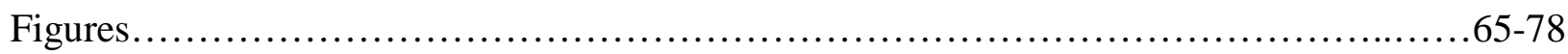


Abbreviations

2-arachidonylglycerol (2-AG)

Cannabinoid receptor subtype 1 (CB1)

Cannabinoid receptor subtype 2 (CB2)

Central nervous system (CNS)

Cranial nerve $(\mathbf{C N})$

Cyclooxygenase 1 and 2 (COX-1 and COX-2)

Diacylglycerol lipase $\alpha$ and $\beta$ (DAGL $\alpha$ and DAGL $\beta$ )

Diclofenac sodium salt (NSAID used in current study)

Endogenous cannabinoid (endocannabinoid; eCB)

Fatty acid amide hydrolase (FAAH)

Gastrointestinal (GI);

Inflammatory bowel disease (IBD)

Interleukin-1 (IL-1)

Interleukin-10 (IL-10)

Interleukin-1 $\beta$ (IL-1ß)

Interleukin-6 (IL-6)

Intraperitoneal (ip)

JZL184 (MAGL inhibitor)

Monoacylglycerol lipase (MAGL)

Monocyte Chemoattractant Protein-1 (MCP-1)

Myeloperoxidase (MPO)

$\mathrm{N}$-arachidonylethanolamine (anandamide)

Nonsteroidal anti-inflammatory drug (NSAID)

Per oral (po)

Prostaglandin $\mathrm{D}_{2}\left(\mathbf{P G D}_{2}\right)$

Prostaglandin $\mathrm{E}_{2}\left(\mathbf{P G E}_{2}\right)$

Prostaglandin $\mathrm{F}_{2 \alpha}\left(\mathbf{P G F}_{\mathbf{2 \alpha}}\right)$

Prostaglandin $\mathrm{I}_{2}$ (PGI 2$)$

Proton pump inhibitors (PPI)

Drug that stimulates gastric acid secretions (secretagogue)

Subcutaneous (sc)

$\Delta$ 9-tetrahydrocannabinol (THC)

Tumor necrosis factor $\alpha$ (TNF- $\alpha)$

Vascular endothelial factor A (VEGF-A) 


\section{Background}

Nonsteroidal anti-inflammatory drugs (NSAIDs), such as acetylsalicylic acid (aspirin), are used world-wide and remain the most commonly used pharmaceutical therapies for pain (Lanas, 2009). However, chronic pain can be resistant to NSAIDs, leading to more frequent administration and increased dosages (Adams et al., 2006). Approximately 20\% of all chronic NSAID users develop band-like lesions (i.e. gastric hemorrhages) in the stomach or duodenum that are, at some point, severe enough to require medical intervention (Wallace, 2001). The severity of gastric hemorrhaging and other negative side effects of NSAIDs increase with age and can be predicted to some degree by the patient's individual medical history (Raffa, 2001). For example, the incidence of NSAID-induced gastric hemorrhages can be as high as $45 \%$ in arthritis patients (Laine et al., 1999). Proton pump inhibitors (PPI) are regularly co-prescribed to prevent the ulcerogenic effect of NSAIDs by reducing gastric acid secretion (Mössner, 2016). However, chronic PPI use is associated with negative side effects including gastric polyps, tumors, infection, vitamin deficiencies, bone fractures, cancer, and dementia (Kuller, 2016; Lodato et al., 2010; Mössner, 2016). The negative side effects of both NSAIDs and PPIs emphasize the need for new gastroprotective therapeutics.

\section{Gastric physiology}

The gastrointestinal (GI) system is a continuous tube that is split into upper and lower tracts. The upper GI includes the esophagus, stomach, and duodenum, whereas the lower GI is composed of the small and large intestines (Gaskins, 1999). The main purpose of the GI system is to digest food, extract nutrients, and expel waste (Ermund et al., 2013). The GI system is composed of many different types of cells, enzymes, and microorganisms that are involved in the 


\section{ENDOCANNABINOID MODULATION OF GASTROPATHY}

physiological actions of the GI. The GI contains an independent nervous system, the enteric nervous system, which is known as "the brain of the gut" and can be influenced by the central nervous system (CNS) (DiPatrizio, 2016; Ermund et al., 2013; Goyal \& Hirano, 1996).

The enteric nervous system is responsible for many physiological processes of the gastrointestinal system, such as motility, immune and inflammatory responses, secretion, and microcirculation (Goyal \& Hirano, 1996). The myenteric plexus and submucosal plexus are the two main networks of afferent (sensory neurons) and efferent nerves (motor neurons) of the enteric nervous system (Aviello, Romano, \& Izzo, 2008). The myenteric plexus is involved in gastrointestinal motility, whereas the submucosal plexus function is not completely understood, but connects the mucosal layer of the stomach to deeper muscle layers (Aviello et al., 2008; Costa, Brookes, \& Hennig, 2000; Goyal \& Hirano, 1996). The plexuses are composed of (1) intrinsic sensory neurons that are activated by mechanical or chemical stimuli; (2) motor neurons that cause contraction (i.e., excitatory) mediated by the excitatory neurotransmitter acetylcholine, or relaxation (i.e., inhibitory), mediated predominantly via nitric oxide in the gastrointestinal system; as well as (3) interneurons, which relay signals between the sensory and motor neurons (Aviello et al., 2008; Sinn et al., 2010).

The enteric nervous system and the central nervous system communicate bi-directionally, and while each nervous system functions independently, there are many connections between them (DiPatrizio, 2016; Goyal \& Hirano, 1996). The most notable connection is the vagus nerve, also known as the pneumogastric nerve. The vagus nerve is the $10^{\text {th }}$ cranial nerve (i.e., CN X) and originates in the brain stem with peripheral nerve terminals innervating all layers of the gastrointestinal system, and has the densest expression in the stomach (Berthoud, Carlson, \& Powley, 1991; McMenamin, Travagli, \& Browning, 2016). 


\section{ENDOCANNABINOID MODULATION OF GASTROPATHY}

The stomach is composed of multiple physical layers and is divided into three topographical areas: the fundus, corpus, and antrum (Figure 1). Within each of these topographical areas, the tissue is subdivided into four layers: mucosa, submucosa, muscularis propria, and serosa (Figure 1). The surface layer of the stomach is the mucosa, which is lined with epithelial cells. A mucosal gel barrier, made of mucus and bicarbonate, covers the epithelium and provides a physical barrier between the epithelium and the contents of the stomach. In addition, the mucosal barrier helps maintain a neutral $\mathrm{pH}$ microenvironment around the epithelial cells, thereby protecting the cells from vast ranges of temperature and $\mathrm{pH}$ that regularly occur in the stomach (Laine, Takeuchi, \& Tarnawski, 2008). The epithelial cells are folded into gastric pits that give the empty stomach its characteristic "ridged" appearance (Dimaline \& Varro, 2007; Schubert \& Peura, 2008) (Figure 1). At the base of the gastric pits, mucus and gastric acid are excreted by the cells of the oxyntic and pyloric glands (Dimaline \& Varro, 2007; Schubert, 2008; Schubert \& Peura, 2008). The mucosa also contains a layer of connective tissue and a thin layer of muscle. The second layer of the stomach is the submucosa, which contains connective tissue, blood vessels, and nerves, and regulates peristalsis (i.e., rhythmic contraction and relaxation) of the smooth muscle (Laine et al., 2008). Adjacent to the submucosa is the muscularis propria, a three-layer muscle structure that also contributes to peristalsis of the stomach. The myenteric plexus is situated in this muscle layer. The serosa is the outer most layer of the stomach and is a thin layer of epithelia cells that covers the stomach.

\section{Prostaglandins regulate gastric function}

In addition to the layers of mucosa and muscle that protect the stomach, prostaglandins are a collection of signaling molecules that are essential for the defense systems in the stomach. Prostaglandins are synthesized from arachidonic acid by cyclooxygenase (COX-1 and COX-2) 


\section{ENDOCANNABINOID MODULATION OF GASTROPATHY}

enzyme activity and are produced throughout the body and modulate many physiological processes (Fitzpatrick, 2004). COX-1 is constitutively expressed and produces prostaglandins that provide homeostatic functions and regulate the gastric mucosa (Rouzer \& Marnett, 2009), whereas COX-2 is induced by tissue injury and produces prostaglandins involved in inflammation (Viegas, Manso, Corvo, Marques, \& Cabrita, 2011). Prostaglandins in the gastrointestinal tract regulate and maintain the gastric mucosal tissue layers and gastric acid secretions (Singh, 1998).

Prostaglandins of interest in the stomach include $\mathrm{E}_{2}\left(\mathbf{P G E _ { 2 } )}\right.$ and $\mathrm{I}_{2}\left(\mathbf{P G} \mathbf{I}_{2}\right)$, the highest expressed prostaglandins in the stomach, as well as prostaglandins $F_{2 \alpha}\left(\mathbf{P G F}_{2} \boldsymbol{\alpha}\right)$ and $\mathrm{D}_{2}\left(\mathbf{P G D}_{2}\right)$, which are also detected, although at much lower concentrations (Wallace, 2008). Although not much is known about the functions of $\mathrm{PGF}_{2 \alpha}$ and $\mathrm{PGD}_{2}$ in gastropathy, metabolites of $\mathrm{PGD}_{2}$ and $\mathrm{PGF}_{2 \alpha}$ are thought to be anti-inflammatory (Motilva, Alarcón De La Lastra, Bruseghini, Manuel Herrerias, \& Sánchez-Fidalgo, 2005). PGE 2 is the most abundant prostaglandin in the body and is the principal bioactive prostaglandin in the GI. $\mathrm{PGE}_{2}$ and $\mathrm{PGI}_{2}$ inhibit gastric acid secretions when produced by the COX-1 pathway (Nishio, Terashima, Nakashima, Aihara, \& Takeuchi, 2007; Wallace, 2008). However, $\mathrm{PGE}_{2}$ has dual effects on gastric secretions and can also stimulate acid output depending on the specific prostaglandin receptor to which it binds (Kato, Aihara, Yoshii, \& Takeuchi, 2005). Prostaglandins, specifically PGE 2 , maintain the gastric mucosal layer by stimulating surface epithelial cells to produce bicarbonate ions and mucus, which protect the stomach from luminal factors (e.g., low pH stomach acid) damaging the epithelium, as well as decreasing the permeability of the epithelium (Darling et al., 2004; Takezono et al., 2004; Wallace, 1989). Reducing the permeability of the epithelial lining of the 


\section{ENDOCANNABINOID MODULATION OF GASTROPATHY}

stomach stops gastric acid from penetrating and damaging deeper layers of the stomach, therefore reducing potential gastric impairment (Takezono et al., 2004).

Inflammation in the stomach can lead to gastric injury. Therefore, reducing inflammation within the stomach inhibits injury to the stomach itself. Prostaglandins can reduce inflammation in the stomach by decreasing the release of inflammatory mediators (Wallace, 2008). The production of $\mathrm{PGE}_{2}$ increases after COX-2 is upregulated in inflammatory conditions (Samuelsson, Morgenstern, \& Jakobsson, 2007) and PGE2 suppresses the immune response by inhibiting the release of proinflammatory mediators such as interleukin-1 (IL-1) and tumor necrosis factor $\alpha$ (TNF- $\alpha)$ (Martin \& Wallace, 2006; Tang, Libby, Vanhoutte, \& Xu, 2012; Wallace, 2008). On the other hand, reducing levels of PGE2 increases proinflammatory mediators in the stomach (Musumba, Pritchard, \& Pirmohamed, 2009).

\section{Nonsteroidal anti-inflammatory drugs are COX inhibitors}

Topical administration of salicylic acid relieves inflammatory pain and can be found in many plants, those of which have been used for over 3,500 years (Vane \& Botting, 1998). In the $19^{\text {th }}$ century, Felix Hoffman chemically acetylated salicylic acid, which came to be known as aspirin, in order to decrease pain and inflammation associated with rheumatism (i.e., inflammation of the joints) (Lanas, 2009). However, patients with rheumatism taking aspirin, including Hoffman’s father, found that the drug severely irritated their stomachs (Lanas, 2009). In the early 1970’s, John Vane discovered that aspirin inhibited COX, which subsequently decreased prostaglandin synthesis (Lanas, 2009; Martin \& Wallace, 2006; Vane, 1971). Vane’s finding created a paradigm shift and led him to win a Nobel Prize in medicine (Lanas, 2009). After the mechanism of action was discovered, many different types of COX inhibitors were 
ENDOCANNABINOID MODULATION OF GASTROPATHY

then synthesized, which are called nonsteroidal anti-inflammatory drugs (NSAIDs) (Lanas, 2009).

As mentioned above, NSAIDs are the most commonly used pharmaceutical therapies for pain (Lanas, 2009) and are especially useful in the treatment of inflammatory pain. NSAIDs decrease pain and inflammation by inhibiting both COX-1 and COX-2 enzyme activity (Figure 2), and subsequently blocking the production of prostaglandins (Rouzer \& Marnett, 2009). Specifically, NSAIDs reduce levels of PGE 2 and PGI (Crowe et al., 2015; Hecken et al., 2000; Musumba et al., 2009; Takeuchi, 2012; Wallace, 2013), which are involved in pain and vasodilation. Although inhibiting COX-1 has acute anti-inflammatory effects throughout the body, it also paradoxically causes GI irritation by altering the regulatory properties of prostaglandins. This alteration in prostaglandin levels can cause gastric tissue damage by hindering gastric epithelial cell renewal and delaying healing of the injury (Musumba et al., 2009). Conversely, administration of $\mathrm{PGE}_{2}$ blocks the formation of gastric hemorrhages, which further supports the protective role of prostaglandins in the stomach. Unfortunately, although the addition of exogenous prostaglandins can be beneficial to gastric health, prostaglandin treatments are generally not well tolerated by patients. Thus, only $2 \%$ of NSAIDs users are co-prescribed synthetic prostaglandins due to the need to take multiple doses a day as well as adverse side effects including diarrhea and abdominal pain (Laine et al., 2008; Rostom et al., 2011).

Due to the negative side effects of COX-1 inhibition by NSAIDs, coxibs were developed approximately 15 years ago. Coxibs are highly selective COX-2 isozyme inhibitors that circumvent the NSAID-induced gastrointestinal side effects by not inhibiting COX-1 (FitzGerald \& Patrono, 2001). Although coxibs effectively reduced pain and inflammation without GI side effects (FitzGerald \& Patrono, 2001; Laine et al., 1999; Patrono \& Baigent, 2009), in humans, 
ENDOCANNABINOID MODULATION OF GASTROPATHY

coxibs significantly increase the risk of major vascular complications, especially heart attacks

(Patrono \& Baigent, 2009). Given the controversy sparked by coxibs, essentially swapping the risk of gastric side effects for increased risk of cardiovascular events, it is not surprising that the enthusiasm for coxibs has weakened.

\section{NSAID-induced gastric damage}

NSAID administration can cause gastric hemorrhages (Figure 3; panel 2), which are found in the mucosal layer of the stomach (Laine et al., 2008). In the stomach, NSAID-induced hemorrhages are generally located in the antrum and corpus topographical areas of the stomach, and rarely occur in the fundus (Kamada et al., 2006; Takeuchi, Ueki, \& Okabe, 1986; Trevethick et al., 1994). NSAIDs not only cause gastric ulcers but also impair the healing of ulcers as they form.

NSAIDs damage the GI tract through multiple causes, which are generally grouped as either topical or systemic factors (Schubert, 2008). The most characterized effects include the inhibition of COX enzymes, which leads to topical epithelial irritation, thus activating proinflammatory mediators; increasing stomach contractions; and increasing gastric acid secretion (Figure 4) (Granger \& Kubes, 1994; Wallace, 2001; Wallace, Keenan, \& Granger, 1990). Considering prostaglandins play a protective role in the stomach, their inhibition leaves the gastric mucosa vulnerable to gastric damage. While a vulnerable mucosa does not necessarily result in gastric hemorrhages, the increased gastric secretions overwhelm the already susceptible mucosa, thereby causing ulcers (Wallace, 2001). Although many factors can contribute to gastropathy, gastric acid may be a major pathway of ulcer formation, as detailed below.

The many layers of the gastric mucosa (detailed above) defend the gastric epithelium against damage by gastric acid and topical irritants (Wallace, 2008). However, epithelial cells 


\section{ENDOCANNABINOID MODULATION OF GASTROPATHY}

can trap NSAID molecules intracellularly, leading to irritation and damage (Bastaki \& Wallace, 1999; Laine et al., 2008). NSAID-induced irritation also increases the epithelial permeability of the gastric mucosa, thereby impairing the defensive barrier against gastric acid (Brand et al., 1999). Therefore, NSAID administration can cause a cascade of events by deteriorating the protective barrier, thereby allowing luminal factors such as gastric acid and the NSAID itself to penetrate the protective barriers, increasing the chance of hemorrhage.

After the initial irritation, the damage to the epithelial cells recruits and activates white blood cells, including mast cells, macrophages, and neutrophils (Wallace, 2008). Neutrophils are the most abundant white blood cells that respond early in the innate immune response, and their infiltration contributes directly to gastric tissue damage. Myeloperoxidase (MPO) is an enzyme that is found within circulating neutrophils and is used to indirectly quantify neutrophil activity in tissue (Liu et al., 1998). Neutrophils and other activated white blood cells release proinflammatory cytokines, such as TNF- $\alpha$ and interleukin-1 $\beta$ (IL-1ß) to the site of the injury (Wallace, 2008). The resulting heightened immune response to these prototypical, proinflammatory cytokines causes further mucosal damage and inflammation. Conversely, blocking the activity of these proinflammatory cytokines attenuates gastric inflammation (Appleyard, McCafferty, Tigley, Swain, \& Wallace, 1996; Wallace, 2008). For example, NSAID administration significantly elevates plasma levels of TNF- $\alpha$ (Appleyard et al., 1996). However, deactivating TNF- $\alpha$ by administering anti-TNF- $\alpha$ antibodies prevented NSAID-induced gastric hemorrhages from forming in rats (Appleyard et al., 1996). These data suggest that inflammatory cytokines are an important mediator in NSAID-induced gastropathy.

Gastric motility, or stomach contractions, is another pathogenic factor in gastric hemorrhage development. NSAID administration increases gastric motility, which means there is 
ENDOCANNABINOID MODULATION OF GASTROPATHY

increased muscle contractions (Takeuchi, 2012; Takeuchi et al., 1986). As the muscles contract, the mucosa folds are compressed and cause the stomach to empty faster (Di Marzo et al., 2008; Takeuchi, 2012). The disturbance in the mucosal folds due to the mechanical compressions of the stomach may promote gastric hemorrhage development (Takeuchi, 2012; Yano, Akahane, \& Harada, 1978), because the mucosal ridges are exposed to gastric acid and may be less protected by a relatively thin coating of mucus and bicarbonate. The NSAID indomethacin increases gastric motility at ulcerogenic doses in rats (Mersereau \& Hinchey, 1982; Takeuchi et al., 1986; Tanaka, Araki, Komoike, Hase, \& Takeuchi, 2001). The effects of NSAIDs on gastric motility are modulated by the prostaglandin PGE (Tanaka et al., 2002). For example, a selective COX-2 inhibitor, rofecoxib, did not change basal motility, whereas a COX-1 inhibitor produced hypermotility (Tanaka et al., 2001), indicating that NSAID-induced increases in gastric motility are COX-1 mediated.

Despite increased inflammation and mucosal contractions, damage to the gastric mucosa does not always progress to the expression of overt gastric hemorrhages because of multiple mucosal defense mechanisms. One important defense is the process of tissue restitution, or the migration of healthy cells to the injury site (Wallace, 2001). However, this protective process is impaired when the wound is exposed to excessive gastric acid secretions. NSAIDs augment gastric acid secretions, increasing the acidity of gastric $\mathrm{pH}$, which leads to an interruption in stomach homeostasis (Playford \& Ghosh, 2005). The dysregulation of homeostasis caused by NSAIDs decreases tissue restitution and exacerbates mucosal damage, allowing for further ulcer development (Wallace, 2001). Therefore, it is plausible that suppression of gastric acid is critically essential to decreasing the incidence of NSAID-induced ulcers (Wallace, 2001). 
ENDOCANNABINOID MODULATION OF GASTROPATHY

\section{The endocannabinoid system}

Cannabis and its main component, $\Delta^{9}$-tetrahydrocannabinol (THC), have been studied in the gut and, to a lesser extent, gastric maladies in humans and nonhuman animal models. In a human study of gastric acid secretions, heavy Cannabis users, characterized by smoking Cannabis more than twice a week, had lower gastric acid secretions than light or non-users (Nalin et al., 1978). THC also protects the stomach against the development of gastric ulcers in multiple experimental animal models. For example, in rats, THC inhibited the hemorrhagic effect of pylorus ligation, in which the lower portion of the stomach is surgically tied off to prevent it from draining properly, thereby allowing stomach acid to accumulate (Sofia, Diamantis, Harrison, \& Melton, 1978). THC also strongly inhibits NSAID-induced gastric hemorrhages in mice (Kinsey et al., 2011; Kinsey \& Cole, 2013). After mice were administered a cannabinoid receptor subtype 1 ( $\left.\mathbf{C B}_{1}\right)$ antagonist, rimonabant, the gastroprotective effect of THC was blocked (Kinsey et al., 2011; Kinsey \& Cole, 2013). Importantly, the cannabinoid receptor subtype $2\left(\mathbf{C B}_{2}\right)$ selective antagonist SR144528 had no effect, indicating that THC proffers gastroprotection through a $\mathrm{CB}_{1}$ receptor-mediated mechanism of action. These data from human and experimental animal studies suggest that Cannabis may not only mediate gastric acid production, but that its main component, THC, provides a likely mechanism of gastroprotection.

Although THC has been used for thousands of years and has gastroprotective effects, unwanted behavioral and cognitive effects such as attention, memory, and motor deficits have dampened enthusiasm for its clinical use (Kogan \& Mechoulam, 2007). Due to these unwanted side effects of THC, researchers have targeted the endogenous cannabinoid (endocannabinoid; eCB) system. The endocannabinoid system comprises two receptors (i.e., $\mathrm{CB}_{1}$ and $\mathrm{CB}_{2}$ ), their endocannabinoid ligands, and the synthetic/catabolic enzymes that regulate endocannabinoids in 


\section{ENDOCANNABINOID MODULATION OF GASTROPATHY}

vivo. The two endogenous cannabinoids, $\mathrm{N}$-arachidonylethanolamine (anandamide) and 2arachidonylglycerol (2-AG), bind to and activate both cannabinoid receptors (Ahn, McKinney, \& Cravatt, 2008). The most abundant endogenous CB receptor ligand is 2-AG, which is produced on demand and immediately released (Ahn et al., 2008), in contrast to "traditional” neurotransmitters, which are stored in vesicles. Diacylglycerol lipase $\alpha$ and $\beta$ (DAGL $\boldsymbol{\alpha}$ and

DAGL $\beta$ ) synthesize 2-AG, and inhibition of the DAGL enzymes blocks the production of 2-AG, consequently reducing 2-AG levels (Bisogno et al., 2003; Silvestri \& Di Marzo, 2013).

Conversely, 2-AG is broken down by the catabolic enzyme monoacylglycerol lipase (MAGL), which breaks down 2-AG into arachidonic acid and glycerol, thereby decreasing pools of 2-AG available to bind to the cannabinoid receptors (Ahn et al., 2008). MAGL is abundant in brain tissue but can also be found in the muscular and mucosal layers of the gastrointestinal tract (Blankman, Simon, \& Cravatt, 2007; Duncan et al., 2008; Izzo \& Sharkey, 2010). Due to rapid degradation of 2-AG by MAGL, in vivo, genetic deletion or pharmacological inhibition of MAGL is used to indirectly increase levels of 2-AG (Kinsey et al., 2009; Long, Li, et al., 2009). In other words, blocking MAGL from degrading 2-AG allows 2-AG to activate the cannabinoid receptors. Because genetic manipulation is not feasible in humans, current research manipulating 2-AG typically explores the therapeutic efficacy of pharmacologically inhibiting MAGL.

JZL184 is a highly characterized pre-clinical MAGL inhibitor that increases levels of 2AG in the brain and stomach and blocks the development of NSAID-induced gastropathy (Figure 3; panel 3) (Kinsey et al., 2011; Long, Nomura, \& Cravatt, 2009). JZL184 reduces pain and inflammation by inhibiting the breakdown of 2-AG, thus allowing 2-AG to bind to CB receptors (Crowe et al., 2015; Ghosh et al., 2013; J. Guindon, Guijarro, Piomelli, \& Hohmann, 2011; Kinsey et al., 2009). JZL184 can also induce-CB1 dependent "THC-like” effects such as 


\section{ENDOCANNABINOID MODULATION OF GASTROPATHY}

analgesia and decreased locomotor activity (Long, Nomura, et al., 2009). JZL184 inhibits >90\%

of MAGL with an irreversible covalent bond, meaning JZL184 binds to MAGL and permanently

alters the chemical structure of the enzyme, subsequently inactivating the enzyme (Long,

Nomura, et al., 2009). Physiological activity of MAGL returns by "turn over" once the enzyme is reproduced. The permanent, irreversible bond between drug and enzyme leads to a long duration of action and reduces the frequency of dosing a drug, which is clinically attractive (Singh, Petter, Baillie, \& Whitty, 2011). However, an irreversible drug is also associated with a higher incidence of side effects (Cisneros et al., 2012; Tuccinardi et al., 2014).

Although JZL184 does not have overt toxicity effects (Nomura et al., 2010), using high doses of JZL184 can have unwanted side effects. Repeated administration of high dose JZL184 (i.e., $40 \mathrm{mg} / \mathrm{kg}$ ) reduces $\mathrm{CB}_{1}$ function and expression, which leads to functional antagonism of $\mathrm{CB}_{1}$ receptors (Schlosburg et al., 2010). In other words, chronic JZL184 administration reverses the anti-inflammation and antinociception properties of MAGL inhibition. While acute administration of JZL184 does not have off-target effects with other enzymes, repeated administration of high dose JZL184 can increase levels of anandamide, which is not catabolized by MAGL, suggesting that JZL184 can react with other enzymes besides MAGL (Schlosburg et al., 2010). A first-generation MAGL inhibitor with limited selectivity, URB602, interacts with multiple other enzymatic targets (Vandevoorde et al., 2007). Given its lack of specificity, URB602 inhibits COX-2 in vitro (Dong, Lu, Zou, \& Yang, 2015), which may indicate MAGL inhibition affects COX signaling. However, there is no evidence to suggest JZL184 interacts with the COX enzymes (Long, Li, et al., 2009; Long, Nomura, et al., 2009). Although chronic high dose JZL184 results in tolerance, lower doses still reduce pain, inflammation, and NSAIDinduced ulcers without negative side effects (Kinsey et al., 2013). 
ENDOCANNABINOID MODULATION OF GASTROPATHY

\section{Endocannabinoids in the gastrointestinal system}

While there are some conflicting reports on the specific locations of the DAGL isozymes (Bashashati et al., 2015), DAGL $\alpha$ is thought to be expressed on enteric nerves and surface epithelial cells in the GI (Bashashati et al., 2015; DiPatrizio, 2016) and DAGL $\beta$ is thought to be expressed on nerves in the myenteric plexus (Marquez et al., 2009). The presence of DAGL indicates bioavailability of 2-AG in the gastrointestinal system. For example, data from multiple labs, including my own data (Ignatowska-Jankowska et al., 2014; Kinsey et al., 2011, 2013; Nomura et al., 2011) indicate that inhibiting MAGL, thus increasing levels of 2-AG, blocks the formation of NSAID-induced ulcers (Figure 3), and requires $\mathrm{CB}_{1}$ receptors to block ulcer formation. MAGL inhibition does not block hemorrhage formation by increasing levels of prostaglandins in the stomach (Kinsey et al., 2011). Thus, JZL184 may have an effect on other pathogenic mechanisms of gastric hemorrhages. The following studies were designed to test the efficacy of the endocannabinoid system in the potential pathways in which NSAID-induced gastric hemorrhages develop, including gastric inflammation, motility, and acid secretion, as detailed below.

$\mathrm{CB}_{1}$ receptors are highly expressed throughout the stomach in humans and rodents, with the highest expression in the myenteric and submucosal plexuses and are co-localized with preand postganglionic cholinergic neurons, which respond to and release acetylcholine (Adami et al., 2002; Coruzzi et al., 2006; Izzo, Mascolo, \& Capasso, 2001; Izzo \& Sharkey, 2010). The neurons innervate the smooth muscle in the myenteric plexus, gastric mucosa, blood vessels in the submucosal plexus, and on vagal terminals innervating the walls of the stomach (Adami et al., 2002; Burdyga et al., 2004; Maccarrone et al., 2015; Pazos et al., 2008). Specifically, CB 1 receptors are found on intrinsic sensory neurons, interneurons, and excitatory motor neurons 
ENDOCANNABINOID MODULATION OF GASTROPATHY

(Anavi-Goffer \& Coutts, 2003; Aviello et al., 2008). Activation of $\mathrm{CB}_{1}$ receptors inhibits excitation and therefore reduces acetylcholine release (Aviello et al., 2008), which is generally considered to be the main site of action of cannabinoid effects in the GI.

Due to their inhibition of excitatory neurotransmission, cannabinoids are known to decrease motility in the gastrointestinal system in humans and other animals (Abalo, Vera, Lopez-Perez, Martnez-Villaluenga, \& Martin-Fontelles, 2012; Aviello et al., 2008; Izzo, Mascolo, Borrelli, \& Capasso, 1999; McCallum et al., 1999), including intestinal transit and stomach emptying (Di Marzo et al., 2008; Pinto et al., 2002). The cannabinoid-mediated decrease in motility was blocked after administration of the $\mathrm{CB}_{1}$ antagonist, rimonabant, or following ablation of the vagus nerve (Krowicki, Moerschbaecher, Winsauer, Digavalli, \& Hornby, 1999; Landi et al., 2002), indicating $\mathrm{CB}_{1}$ receptors facilitate this effect and suggests a potential CNS involvement.

As detailed above, blocking proinflammatory activity decreases gastric inflammation, potentially reducing hemorrhage. Cannabinoid receptor agonists block the NSAID-induced production of proinflammatory cytokines, such as TNF- $\alpha$ and IL-1 $\beta$ (Kinsey et al., 2011; Klein, 2005), suggesting that inhibiting proinflammatory cytokines is a gastroprotective mechanism of the endocannabinoid system. The current project sought to evaluate the role of MAGL inhibition on inflammatory mediators, such as cytokines and chemokines, in the mouse stomach using JZL184, and to extend these findings by examining the effects of JZL184 on MPO activity in the stomach.

$\mathrm{CB}_{1}$ receptors are expressed on human parietal cells in the gastric mucosa (Pazos et al., 2008). Parietal cells within the stomach secrete hydrochloric acid to facilitate digestion and absorption; however, the acid secretions can overpower mucosal defenses if not regulated 


\section{ENDOCANNABINOID MODULATION OF GASTROPATHY}

(Schubert, 2008). Parietal cells are located in the oxyntic gland and are stimulated by acetylcholine, histamine, or the hormone gastrin to increase acid output (Schubert \& Peura, 2008). Therefore, histamine and the gastrin analog, pentagastrin, are used experimentally to induce gastric acid secretions (i.e., secretagogue) in both animals (Gyires et al., 2014; Martinez et al., 1998; Shujaa et al., 2009) and humans (Rodriguez-Stanley, Redinger, \& Miner, 2006). Exogenous synthetic cannabinoid administration blocks gastric ulcer formation and suppresses gastric acid secretion in pentagastrin- and histamine-stimulated animal models. These gastroprotective effects are reversed by $\mathrm{CB}_{1}$ antagonism, suggesting that functioning $\mathrm{CB}_{1}$ receptors are required for the endocannabinoid system to be gastroprotective (Adami et al., 2002; Coruzzi et al., 2006; Coruzzi, Adami, Coppelli, Frati, \& Soldani, 1999; Pazos et al., 2008). Increased gastric acid output may be one of the primary mechanisms through which NSAIDs are thought to induce gastric ulcers, but it is unknown whether MAGL inhibition modulates gastric secretions. Therefore, the study examined the effect of MAGL inhibition on gastric acid output (Figure 4).

Despite their well-known gastrointestinal side effects, NSAIDs remain the most popular analgesic class. There are many potential pathways through which NSAIDs, like diclofenac sodium, cause gastric hemorrhages, including topical and systemic mechanisms. However, the specific mechanism(s) are not entirely understood. Recently, cannabinoids have been found to block the ulcerogenic effects of high-dose NSAID administration in mice. Therefore, the overall goals of the current study were to evaluate the mechanisms of diclofenac-induced gastric hemorrhages, as well as the gastroprotective mechanisms through which the MAGL inhibitor, JZL184, prevents the physiological events leading to diclofenac-induced gastropathy. Due to the breadth of pathogenic mechanisms, the current study evaluated the most characterized 
ENDOCANNABINOID MODULATION OF GASTROPATHY

components of gastric hemorrhages, which include changes in inflammation of the gastric epithelium, gastric acid secretions, and gastric motility (Figure 4). Although all published reports in this area have used male mice, exclusively, NSAIDs are used by both sexes, and it is therefore critically important to establish the NSAID-induced gastric hemorrhage model, as well as its attenuation by MAGL inhibition, in mice.

The ultimate goal of this research is to improve the lives of patients taking NSAIDs by informing the development of new, cannabinoid-based gastroprotective therapeutics.

\section{Method}

\section{Animals}

Adult male and female ICR mice (Harlan Laboratories, Indianapolis, IN) approximately 8 weeks old were used. The outbred ICR mice have genetic differences that are similar in many ways to human populations (Aldinger, Sokoloff, Rosenberg, Palmer, \& Millen, 2009), thus allowing for more variability and more conservative results than genetically identical strains. Mice were housed 3-5 in polysofone plastic cages (Allentown, Inc., Allentown, PA) with food and water offered ad libitum. Mice were housed in a temperature $\left(20-22^{\circ} \mathrm{C}\right)$ and humidity $(50 \pm 5 \%)$ controlled environment on a 12:12 h light cycle. The Animal Care and Use Committee at West Virginia University approved all experimental protocols (14-1007).

\section{Drugs}

The MAGL inhibitor JZL184 and the NSAID diclofenac sodium salt were purchased from Cayman Chemical (Ann Arbor, MI). The gastric acid secretagogue pentagastrin and the PPI (antacid) omeprazole were purchased from Sigma Aldrich (St. Louis, MO). All compounds were dissolved in a vehicle consisting of ethanol, Cremophor (Sigma-Aldrich), and saline in a ratio of 1:1:18 parts, as described previously (Crowe et al., 2015; Kinsey \& Cole, 2013). All solutions were warmed to room temperature and administered intraperitoneally (ip), subcutaneously (sc), 


\section{ENDOCANNABINOID MODULATION OF GASTROPATHY}

or per oral (po) at a volume of $10 \mu \mathrm{l} / \mathrm{g}$ body mass. Due to the multiple drugs administered to individual mice at the same time, different routes of administration were chosen to avoid fluid overload (Turner, Brabb, Pekow, \& Vasbinder, 2011). Diclofenac was given orally (po) to stay consistent with clinical use in that the NSAID comes into contact with the lining of the stomach. Omeprazole and JZL184 were administered intraperitoneally (ip), which may have similar pharmacokinetics to oral administration (Turner et al., 2011). With specific regard to diclofenac and JZL184, oral administration of diclofenac inhibits gastric prostaglandins and intraperitoneal JZL184 increases gastric 2-AG levels at the doses chosen here (Kinsey et al., 2011), indicating that both compounds are indeed active via the selected routes of administration. Pentagastrin was given subcutaneously because this route allows for injecting a relatively large volume into a small animal, reducing fluid overload.

\section{Induction of gastric hemorrhage}

Mice were randomly assigned to treatment groups. Gastric hemorrhages were induced based on previously published methods (Kinsey et al., 2011; Naidu, Booker, Cravatt, \& Lichtman, 2009). Mice were weighed, then food-deprived for $24 \mathrm{~h}$ with free access to water. A wire mesh barrier was placed on the bottom of each cage to prevent coprophagia (i.e., eating feces), with the goal of minimizing stomach contents. On the day of the hemorrhage induction, the mice were weighed, administered diclofenac or vehicle, and returned to the home cage. After $6 \mathrm{~h}$, the mice were euthanized via $\mathrm{CO}_{2}$ asphyxiation and their stomachs were harvested, photographed, and snap-frozen in liquid nitrogen. For a subset of mice (diclofenac dose response with MPO quantification and a separate cohort of mice for the multiplex assay) mucus was isolated by scraping with a metal spatula and frozen separately from the stomach. Tissues were stored at $80^{\circ} \mathrm{C}$ until assays were performed. 
ENDOCANNABINOID MODULATION OF GASTROPATHY

\section{Gastric hemorrhage quantification}

Gastric hemorrhages were quantified based on previously reported methods (IgnatowskaJankowska et al., 2014; Kinsey et al., 2011). Six hours after diclofenac treatment, stomachs were harvested, cut along the greater curvature, and rinsed with distilled water. The tissue was then placed on a lighted stage and photographed, along with a 1-mm reference, using a Canon EOS Rebel XS digital camera with a Canon 250D close-up lens (Adorama Inc., New York, NY). The images were pseudo randomized, renamed, and analyzed using Photoshop (Adobe Systems, Inc, San Jose, CA). The length of each hemorrhage and the reference was each marked with a 1pixel-wide line and compared, such that the total hemorrhage score in millimeters for each stomach was calculated using the following equation:

$$
\frac{\text { pixels of hemorrhages }}{\text { pixels of } 1 \mathrm{~mm} \text { reference }}=\text { Total hemorrhage length }
$$

The experimenter scoring gastric hemorrhages was blind to the treatment condition of each subject.

\section{Biomarker and mediators quantification}

Myeloperoxidase (MPO) is an enzyme produced by neutrophils, which are abundant white blood cells that are early responders of the innate immune system. MPO levels are commonly used to indirectly quantify neutrophils (Loria, Dato, Graziani, \& Biasucci, 2008). Gastric hemorrhages were induced with diclofenac $(0,11.11,33.33$, or $100 \mathrm{mg} / \mathrm{kg})$, as detailed above, and mucosal scrapings were isolated, using a metal spatula. Samples were homogenized using a Tissue Tearor (Bartlesville, OK) in $5 \mathrm{ml}$ phosphate-buffered saline and MPO activity was quantified by sandwich enzyme-linked immunosorbent assay (sandwich ELISA) per manufacturer's instructions (R\&D Systems, Minneapolis, MN). All samples were run in duplicate. 
ENDOCANNABINOID MODULATION OF GASTROPATHY

In order to determine the effects of diclofenac and MAGL inhibition on gastric inflammation, levels of the inflammatory mediators IL-1 $\beta$, TNF- $\alpha$, IL-6, IL-10, VEGF-A, and MCP-1 were measured using a Mouse Inflammatory Cytokines Multiplex kit (Meso Scale Diagnostics, Rockville, MD), per manufacturer's instructions, which measures multiple analytes simultaneously. In experiments using whole stomach analysis, mice were administered JZL184 (40 mg/kg) or vehicle $2 \mathrm{~h}$ prior to gastric hemorrhage induction via diclofenac (100 mg/kg) and subjected to the gastric hemorrhage protocol, as detailed above. In the subset of experiments using mucosal scraping samples, mice were administered JZL184 (8 mg/kg) or vehicle 2 h prior to gastric hemorrhage induction via diclofenac $(100 \mathrm{mg} / \mathrm{kg})$ and subjected to the gastric hemorrhage protocol, as detailed above. On the day of assay, samples were homogenized in $5 \mathrm{ml}$ phosphate-buffered saline using a Tissue Tearor (Bartlesville, OK). All samples were run in duplicate.

Whole stomach samples were also evaluated for MPO and IL-6 activity using separate sandwich ELISAs, per manufacturer's instructions (R\&D Systems, Minneapolis, MN). All samples were run in duplicate.

\section{Gastric acid secretion}

Mice were subjected to the gastric hemorrhage procedure, and gastric secretions were collected 6 h after diclofenac administration (i.e., at the same time as hemorrhages were photographed). For evaluation of basal vs. pentagastrin-stimulated gastric acid secretions, mice were administered JZL184 (40 mg/kg), omeprazole (positive antacid control), or vehicle 2 h prior to vehicle (basal condition) or pentagastrin $(0.25 \mathrm{mg} / \mathrm{kg}$; stimulated condition). Mice were euthanized via $\mathrm{CO}_{2}$ asphyxiation $1 \mathrm{~h}$ after pentagastrin administration, then gastric secretions were collected. 
ENDOCANNABINOID MODULATION OF GASTROPATHY

Gastric acid secretions were collected using gastric lavage, as described previously (Martinez et al., 1998), with minor modifications. After euthanasia, the stomach was clamped at the lower esophageal sphincter and the pyloric region to block stomach emptying, and $200 \mu \mathrm{l}$ of normal saline was injected into the stomach. The stomach was then harvested and its contents were collected in a test tube. After gastric lavage, the samples were centrifuged for 7 min at $13000 \mathrm{~g}$ and the supernatant was aliquoted into a new tube and stored at $-80^{\circ} \mathrm{C}$ until $\mathrm{pH}$ analysis. The stomach fluid was assessed for $\mathrm{pH}$ using a $\mathrm{pH}$ microelectrode (Thermo Scientific, PerpHecT ROSS microelectrode 8220BNWP).

It is noteworthy that the current study measured the $\mathrm{pH}$ of gastric secretions mixed with saline, and therefore did not directly measure acid secretion but the amount of acidity in the stomach. The changes in gastric $\mathrm{pH}$ were inferred as changes in gastric secretions. However, gastric acid secretion is the primary determinant of gastric $\mathrm{pH}$ (Fuchs et al., 1991). For simplicity, I will refer hereafter to the alterations in $\mathrm{pH}$ samples as alterations in gastric acid secretion.

\section{Gastric motility}

Gastric emptying was performed as described previously (Di Marzo et al., 2008), with minor modifications. Mice were weighed, placed on a wire barrier, and fasted for $24 \mathrm{~h}$. The mice were administered JZL184 (40 mg/kg) or vehicle, then 2 h later, diclofenac sodium (100 mg/kg) or vehicle was administered $1 \mathrm{~h}$ before oral administration by gavage of $0.3 \mathrm{ml}$ solution of 0.5 mg/ml Phenolsulfonphthalein (phenol red; Sigma-Aldrich, St. Louis, MO) dissolved in a vehicle of distilled water and 1.5\% volume of Carboxymethylcellulose (CMC). The CMC vehicle is useful for oral administration because its high viscosity allows for an even suspension of the phenol red. At 20 min post phenol red administration, the mice were euthanized and the stomach was quickly clamped at the lower esophageal sphincter and pyloric region. Mice in the baseline 


\section{ENDOCANNABINOID MODULATION OF GASTROPATHY}

group were administered phenol red and immediately euthanized. Samples recovered from these mice were used as a standard baseline ( $0 \%$ emptying). The stomach was then injected with 0.2 ml of Nanopure filtered (Barnstead NANOpure Water Purification System), deionized water, to aid the removal of its contents. The stomach was removed, opened along the greater curvature, and its contents were poured into a test tube and the stomach was rinsed with $3.8 \mathrm{ml}$ Nanopure filtered, deionized water to remove and collect all remaining phenol red from stomach ridges. Prior to assay, $2 \mathrm{ml}$ of a $1 \mathrm{~mol}$ sodium hydroxide $(\mathrm{NaOH})$ solution was added to each tube to develop the maximum intensity of the phenol red color. The optical density of each sample was read on a microplate reader (Molecular Devices, Vmax kinetic microplate reader) at $560 \mathrm{~nm}$ wavelength. As the stomach empties, the phenol red exits the stomach. Thus, a saturated color indicates slower gastric motility, whereas unsaturated color indicates hypermotility. The percentage of gastric emptying was calculated according to the following formula:

$$
100 \times\left[\frac{1-\text { OD of phenol red at } 20 \mathrm{~min}}{\text { OD of phenol red at } 0 \mathrm{~min}}\right]
$$

\section{Statistical analysis}

Diclofenac dose-response data were analyzed using one-way analysis of variance (ANOVA), followed by Dunnett's post hoc comparisons. To evaluate sex differences in gastric hemorrhages, diclofenac dose-response data were analyzed using a two-way ANOVA with sex and drug treatment as the independent variables and hemorrhage length or MPO level as the dependent variable. As a higher body weight may indicate a larger stomach, thus affecting gastric hemorrhages, analysis of covariance (ANCOVA) was also used to determine the influence of sex and drug treatment after controlling for body weight. Inflammatory marker assays, gastric acid secretion with diclofenac, and gastric motility data were analyzed using a two-way ANOVA with pretreatment (vehicle, JZL184) and drug treatment (vehicle, diclofenac). Gastric acid secretion 
ENDOCANNABINOID MODULATION OF GASTROPATHY

with pentagastrin data were analyzed using a two-way ANOVA with pretreatment (vehicle, JZL184, omeprazole) and drug treatment (vehicle, pentagastrin). Two-way ANOVAs were followed by Tukey’s post hoc comparisons. Correlations between gastric hemorrhage length and MPO or inflammatory mediators were analyzed using the Pearson's correlation coefficient. Differences were considered statistically significant if $\alpha<.05$.

\section{Experimental plan}

Experiment 1. The goal of the first experiment was to determine the doses of diclofenac that induce gastric hemorrhage and to quantify hemorrhages using MPO as an objective biomarker. Gastric hemorrhage induction was evaluated with varying doses of diclofenac (11.11, 33.33, or $100 \mathrm{mg} / \mathrm{kg}$, po), with another group of mice receiving vehicle, and subjected to the gastric hemorrhage protocol, as described above. There were 32 male mice and 33 female mice used for this experiment. Gastric hemorrhages were quantified by photographic analysis and confirmed by using MPO activity ELISA, as described in the "Biomarker and mediators quantification” procedure. Gastric hemorrhage length and MPO levels were then correlated.

Experiment 2. The goal of the second experiment was to quantify inflammatory mediators. 31 male mice and 32 female mice were administered JZL184 (40 mg/kg, ip) or vehicle $2 \mathrm{~h}$ prior to gastric hemorrhage induction via diclofenac (100 mg/kg, po) or vehicle and subjected to the gastric hemorrhage protocol, as detailed above. The whole stomachs were evaluated for protein levels of cytokines (IL-1 $\beta$, TNF- $\alpha$, IL-6, IL-10, VEGF-A, and MCP-1) using a multiplex assay and using IL-6 and MPO ELISAs, as described in the "Biomarker and mediators quantification” procedure.

Using a separate cohort of mice, 39 male mice and 40 female mice were administered JZL184 (8 $\mathrm{mg} / \mathrm{kg}$, ip) or vehicle $2 \mathrm{~h}$ prior to gastric hemorrhage induction via diclofenac (100 mg/kg, po) or 


\section{ENDOCANNABINOID MODULATION OF GASTROPATHY}

vehicle and subjected to the gastric hemorrhage protocol, as detailed above. The mucus scrapings from the stomach were evaluated for protein levels of cytokines (IL-1 $\beta$, TNF- $\alpha$, IL-6, IL-10, VEGF-A, and MCP-1) using a multiplex assay, as described in the "Biomarker and mediators quantification” procedure.

Experiment 3. The goal of the third experiment was to determine the efficacy of endocannabinoid attenuation of NSAID-induced gastric acid secretion. 40 male mice and 40 female mice were subjected to the gastric hemorrhage procedure, with JZL184 (8 mg/kg) administered $2 \mathrm{~h}$ prior to diclofenac (100 mg/kg). Gastric secretions were collected $6 \mathrm{~h}$ after diclofenac administration (i.e., at the same time as hemorrhages were photographed) and analyzed for $\mathrm{pH}$, as described above in the "Gastric acid secretion” procedure.

For evaluation of basal vs. pentagastrin-stimulated gastric acid secretions, a separate cohort of 48 male mice were administered JZL184 (40 mg/kg), omeprazole (20 mg/kg), or vehicle $2 \mathrm{~h}$ prior to vehicle (basal condition) or pentagastrin $(0.25 \mathrm{mg} / \mathrm{kg}$; stimulated condition). Samples were collected $1 \mathrm{~h}$ after pentagastrin administration, then gastric secretions were collected and analyzed for $\mathrm{pH}$, as described above in the "Gastric acid secretion” procedure.

Experiment 4. The goal of the fourth experiment was to assess the efficacy of endocannabinoid attenuation of NSAID-induced hypermotility, as described above in the "Gastric motility” procedure. 32 male mice were subjected to the gastric motility procedure, with JZL184 (40 mg/kg) administered 2 h prior to diclofenac (100 mg/kg), and phenol red administration $1 \mathrm{~h}$ after diclofenac. Gastric contents were collected 20 min after phenol administration. Samples were measured for optical density using a plate reader. 
ENDOCANNABINOID MODULATION OF GASTROPATHY

\section{Results}

\section{Diclofenac induces gastric hemorrhages and increases MPO activity in both male and}

\section{female mice}

In both male and female mice, gastric hemorrhages were induced using various doses of diclofenac $(0,11.11,33.33$, or $100 \mathrm{mg} / \mathrm{kg}$, po), and subjected to the gastric hemorrhage protocol, as detailed above. Diclofenac sodium caused a significant increase in gastric hemorrhages in male $[\mathrm{F}(3,28)=10.72, \mathrm{p}<.01$; Figure 5A $]$ and female $[\mathrm{F}(3,29)=8.45, \mathrm{p}<.01$; Figure 5C $]$ mice, compared to vehicle treated mice. Post hoc analyses revealed that diclofenac induced gastric hemorrhages at doses of $\geq 33.33 \mathrm{mg} / \mathrm{kg}$ in male mice and $100 \mathrm{mg} / \mathrm{kg}$ in female mice. Sex differences of gastric hemorrhage development were also evaluated. There was no interaction between sex and drug treatment $[\mathrm{F}(3,57)=.917, \mathrm{p}=.44$; data not shown]. There was a main effect of treatment $[F(3,57)=18.36, \mathrm{p}<.01]$, such that diclofenac increases gastric hemorrhage formation. There was a main effect of $\operatorname{sex}[\mathrm{F}(1,57)=4.27, \mathrm{p}<.05]$, such that male mice had increased gastric hemorrhage length. After controlling for body weight, there was no interaction between sex and drug treatment $[F(3,56)=.89, \mathrm{p}=.45]$. There was a main effect of drug treatment $[\mathrm{F}(3,56)=17.87, \mathrm{p}<.01]$, such that diclofenac increases gastric hemorrhage formation. However, there was not a main effect of $\operatorname{sex}[F(1,56)=2.67, p=.11]$.

MPO activity, an indirect measure of neutrophils, was quantified by ELISA. Gastric hemorrhage length was quantified by photographic analysis and correlated with gastric MPO activity. Diclofenac dose-dependently induced gastric hemorrhages regardless of sex. Diclofenac significantly increased MPO level in male $[\mathrm{F}(3,28)=3.53, \mathrm{p}<.05$; Figure 5B] and female $[\mathrm{F}(3$, 29) $=4.19, \mathrm{p}<.05 ;$ Figure 5D] mice. Post hoc analyses indicated that diclofenac increased MPO at $\geq 33.33 \mathrm{mg} / \mathrm{kg}$ in male mice and $100 \mathrm{mg} / \mathrm{kg}$ in female mice. Sex differences of gastric MPO 


\section{ENDOCANNABINOID MODULATION OF GASTROPATHY}

levels were also evaluated. There was no interaction between sex and drug treatment $[\mathrm{F}(3,57)=$ $.95, \mathrm{p}=.42$; data not shown]. There was a main effect of treatment $[\mathrm{F}(3,57)=6.48, \mathrm{p}<.05]$, such that diclofenac increases gastric MPO concentration. There was a main effect of sex $[\mathrm{F}(1$, $57)=5.25, \mathrm{p}<.05]$, such that male mice had higher levels of MPO. After controlling for body weight, there was no interaction between sex and drug treatment $[F(3,56)=.93, p=.44]$. There was a main effect of drug treatment $[\mathrm{F}(3,56)=6.34, \mathrm{p}<.01]$, such that diclofenac increases gastric MPO concentration. However, there was not a main effect of $\operatorname{sex}[F(1,56)=3.10, p=$ .08].Because neutrophil infiltration contributes directly to gastric tissue damage, MPO could be used as an objective biomarker for gastric hemorrhage severity. Therefore, a Pearson’s correlation coefficient was computed to elucidate the relationship between blind-scored total gastric hemorrhage length and gastric MPO level. There was a positive correlation between gastric hemorrhage length and gastric MPO level in male [ $\mathrm{r}=0.37, \mathrm{~N}=32, \mathrm{p}<.05]$, but not in

female $[\mathrm{r}=0.33, \mathrm{~N}=33, \mathrm{p}=.059]$ mice. However, there was one outlier in the male data (33.33 $\mathrm{mg} / \mathrm{kg}$ treated mouse) and two outliers in the female data (100 mg/kg treated mice), as defined as a data point more than 2 standard deviations from the mean. With outliers removed, the correlation between gastric hemorrhage and MPO level remained significant in male mice $[\mathrm{r}=$ 0.57, $\mathrm{N}=31, \mathrm{p}<.01]$, and there was a significant correlation in female mice $[\mathrm{r}=0.54, \mathrm{~N}=31, \mathrm{p}$ $<$.01], indicating MPO may be used as an objective biomarker for gastric damage.

\section{Diclofenac increases gastric inflammatory mediators differently in male and female mice}

To evaluate the effect of JZL184 on inflammatory markers as a mechanism of gastroprotection, mice were pretreated with JZL184 (40 mg/kg) or vehicle 2 h prior to administration of diclofenac $(100 \mathrm{mg} / \mathrm{kg})$ or vehicle. Whole stomachs were harvested $6 \mathrm{~h}$ after diclofenac administration. In male mice, the interaction of the pretreatment and drug treatment 
ENDOCANNABINOID MODULATION OF GASTROPATHY

was significant $[\mathrm{F}(1,27)=22.69, \mathrm{p}<.01$; Figure 6A]. There was a main effect of pretreatment, such that JZL184 pretreatment significantly decreased gastric hemorrhages $[\mathrm{F}(1,27)=27.42$, $\mathrm{p}<$ .01]. There was a main effect of drug, such that diclofenac significantly increased gastric hemorrhage length $[\mathrm{F}(1,27)=26.82, \mathrm{p}<.01]$. Post hoc analysis revealed that administration of JZL184 prior to diclofenac significantly decreased ulcer formation $(\mathrm{p}<.01)$. In female mice, the interaction between pretreatment and drug treatment was significant $[\mathrm{F}(1,28)=31.58, \mathrm{p}<.01$;

Figure 6B]. There was a main effect of pretreatment, such that JZL184 pretreatment significantly decreased gastric hemorrhages $[\mathrm{F}(1,28)=31.58, \mathrm{p}<.01]$. There was a main effect of drug, indicating that diclofenac significantly increased gastric hemorrhage length $[\mathrm{F}(1,28)=$ 49.40, $\mathrm{p}<.01$ ]. Post hoc analysis revealed that pretreatment of JZL184 prior to diclofenac significantly reduced gastric hemorrhages $(\mathrm{p}<.01)$. Dexamethasone was used as a positive, antiinflammatory control (Nakamura, Murai, \& Ogawa, 1996) and has been shown to reduce inflammation in the stomach (Kinsey et al., 2011). However, gastric hemorrhages for that experiment were uncharacteristically low (data not shown) and there were no treatment differences in male $[\mathrm{F}(1,14)=.77, \mathrm{p}=.40]$ or female $[\mathrm{F}(1,14)=1.67, \mathrm{p}=.22]$ mice. Therefore, dexamethasone was not included in the inflammatory marker assays.

Whole stomachs were then assayed for concentration levels of inflammatory markers by multiplex assay. Tumor necrosis factor- $\alpha$ (TNF- $\alpha)$ is the main mediator for acute inflammation and recruits neutrophils and monocytes to the injury site. In male mice, the interaction was not significant $[\mathrm{F}(1,27)=2.35, \mathrm{p}=.15$; Figure 7A $]$. However, there was a main effect of drug, indicating that diclofenac significantly increased TNF- $\alpha[F(1,27)=7.82, \mathrm{p}<.01]$, whereas there was no main effect of pretreatment $[F(1,27)=3.35, p=.08]$. In female mice, the interaction was significant $[\mathrm{F}(1,28)=11.41, \mathrm{p}<.01$; Figure 8A $]$. There was a main effect of drug and a main 


\section{ENDOCANNABINOID MODULATION OF GASTROPATHY}

effect of pretreatment, such that diclofenac $[\mathrm{F}(1,28)=14.15, \mathrm{p}<.01]$ and JZL184 pretreatment $[\mathrm{F}(1,28)=14.05, \mathrm{p}<.01]$ significantly increased TNF- $\alpha$. Post hoc analysis revealed that JZL184 administration prior to diclofenac significantly increased levels of TNF- $\alpha(\mathrm{p}<.01)$.

Interleukin-1 $\beta$ (IL-1ß) has biological actions very similar to TNF- $\alpha$, in that it mediates local inflammation. In male mice, the interaction was not significant $[\mathrm{F}(1,27)=.01, \mathrm{p}=.94$;

Figure 7B]. There was a main effect of drug, indicating that diclofenac significantly increased IL-1 $\beta[F(1,27)=11.76, p<.01]$, whereas there was no main effect of pretreatment was not significant $[\mathrm{F}(1,27)=1.18, \mathrm{p}=.29]$. In female mice, the interaction was significant $[\mathrm{F}(1,28)=$ 7.78, $\mathrm{p}<.01$; Figure 8B]. There was a main effect of drug and a main effect of pretreatment, indicating that diclofenac $[\mathrm{F}(1,28)=14.44, \mathrm{p}<.01]$ and JZL184 pretreatment $[\mathrm{F}(1,28)=15.55$, $\mathrm{p}<.01$ ] significantly increased IL-1 $\beta$, respectively. Post hoc analysis revealed that JZL184 administration prior to diclofenac significantly increased levels of IL-1 $\beta$ ( $p<.01)$.

Interleukin-6 (IL-6) production is stimulated by IL-1 and TNF- $\alpha$ and contributes to systemic effects of inflammation. In male mice, the interaction was not significant $[F(1,27)=$ 1.66, $\mathrm{p}=.21$; Figure 7C]. However, there was a main effect of drug treatment, in that diclofenac significantly increased IL-6 $[\mathrm{F}(1,27)=13.44, \mathrm{p}<.01]$, whereas pretreatment had no significant main effect $[F(1,27)=.67, p=.42]$. In female mice, the interaction was not significant $[F(1,28)$ $=3.09, \mathrm{p}=.09$; Figure 8C]. However, there was a main effect of drug treatment and a main effect of pretreatment, indicating that diclofenac $[\mathrm{F}(1,28)=6.77, \mathrm{p}<.05]$ and JZL184 pretreatment $[\mathrm{F}(1,28)=4.49, \mathrm{p}<.05]$ significantly increased IL-6, respectively.

The anti-inflammatory cytokine, interleukin-10 (IL-10) is a negative feedback regulator for macrophage activity. In male mice, the interaction was not significant $[F(1,27)=.08, p=$ .78; Figure 7D]. However, there was a main effect of drug treatment, such that diclofenac 
ENDOCANNABINOID MODULATION OF GASTROPATHY

significantly increased IL-10 in male mice $[F(1,27)=11.56, \mathrm{p}<.01]$. There was no main effect of pretreatment on IL-10 $[\mathrm{F}(1,27)=.44, \mathrm{p}=.51]$. In female mice, the interaction was not significant $[F(1,28)=3.76, p=.06$; Figure 8D]. However, there was a significant main effect of drug treatment and a main effect of pretreatment, in that diclofenac $[\mathrm{F}(1,28)=4.97, \mathrm{p}<.05]$ and JZL184 pretreatment $[\mathrm{F}(1,28)=9.17, \mathrm{p}<.01]$ significantly increased IL-10, respectively.

Vascular endothelial factor A (VEGF-A) is a protein that promotes angiogenesis and increases vascular permeability. In male mice, the interaction between JZL184 and diclofenac was not significant $[\mathrm{F}(1,27)=2.17, \mathrm{p}=.15$; Figure 7E $]$. However, there was a main effect of drug treatment, such that diclofenac significantly increased VEGF-A in male mice $[\mathrm{F}(1,27)=$ 6.77, $\mathrm{p}<.05]$. There was no main effect of pretreatment on VEGF-A $[F(1,27)=3.94, p=.06]$. Similarly, in female mice, the interaction was not significant $[\mathrm{F}(1,28)=.88, \mathrm{p}=.36$; Figure $\mathbf{8 E}]$. There was no main effect of drug treatment $[\mathrm{F}(1,28)=3.42, \mathrm{p}=.08]$ or pretreatment $[\mathrm{F}(1$, 28) $=1.00, \mathrm{p}=.33]$ on VEGF-A.

Monocyte Chemoattractant Protein-1 (MCP-1) regulates migration and infiltration of monocytes and macrophages. In male mice, the interaction between JZL184 and diclofenac was not significant $[\mathrm{F}(1,27)=.30, \mathrm{p}=.59$; Figure 7F $]$. However, there was a main effect of drug, indicating that diclofenac significantly increased MCP-1 $[F(1,27)=23.63, p<.01]$. There was no effect of pretreatment on MCP-1 $[\mathrm{F}(1,27)=.31$, $\mathrm{p}=.58]$. In female mice, the interaction was significant $[\mathrm{F}(1,28)=5.52, \mathrm{p}<.05$; Figure $\mathbf{8 F}]$. There was a significant main effect of drug and main effect of pretreatment, indicating that diclofenac $[F(1,28)=9.16, p<.01]$ and JZL184 pretreatment $[\mathrm{F}(1,28)=9.87, \mathrm{p}<.01]$ significantly increased MCP-1, respectively. Post hoc analysis revealed that JZL184 administration prior to diclofenac significantly increased levels of $\operatorname{MCP}-1(\mathrm{p}<.01)$ 


\section{ENDOCANNABINOID MODULATION OF GASTROPATHY}

In male mice, gastric hemorrhage length is positively correlated with levels of IL-6 [ $\mathrm{r}=$ $.62, \mathrm{~N}=31, \mathrm{p}<.01]$ and MCP-1 $[\mathrm{r}=.41, \mathrm{~N}=31, \mathrm{p}<.05]$, but there was no correlation between hemorrhages and IL-1 $\beta[r=.35, N=31, p=.052]$, TNF- $\alpha[r=.05, N=31, p=.79]$, IL-10 $[r=$ $.31, \mathrm{~N}=31, \mathrm{p}=.09]$, or VEGF-A $[\mathrm{r}=.08, \mathrm{~N}=31, \mathrm{p}=.68]$. In female mice, none of the inflammatory markers were significantly correlated with gastric hemorrhages, IL-1 $\beta[\mathrm{r}=-.10, \mathrm{~N}$ $=32, \mathrm{p}=.60]$, TNF- $\alpha[\mathrm{r}=-.11, \mathrm{~N}=32, \mathrm{p}=.54], \mathrm{IL}-6[\mathrm{r}=-.01, \mathrm{~N}=32, \mathrm{p}=.97], \mathrm{IL}-10[\mathrm{r}=-.11$, $\mathrm{N}=32, \mathrm{p}=.54], \mathrm{MCP}-1[\mathrm{r}=-.08, \mathrm{~N}=32, \mathrm{p}=.68]$, or VEGF-A $[\mathrm{r}=.15, \mathrm{~N}=32, \mathrm{p}=.41]$.

Because of the unexpected results reported above, the same samples used for the multiplex assay were assayed using separate IL-6 and MPO ELISAs, to confirm the unexpected IL-6 results and to indirectly quantify neutrophils, respectively. In male mice, there was no interaction between pretreatment and drug treatment for IL-6 $[F(1,27)=.23$, $p=.64$; Figure 9A $]$. In contrast to the multiplex data, there was no main effect of drug for IL-6 $[F(1,27)=.18$, p $=$.67] but now there is a main effect of pretreatment, in that JZL184 significantly decreased IL-6 $[F(1,27)=6.40, \mathrm{p}<.05]$. In female mice, there was no interaction between JZL184 and diclofenac for IL-6 $[\mathrm{F}(1,28)=1.24, \mathrm{p}=.28$; Figure 9C], there was a main effect of drug treatment but, opposite to the multiplex data, diclofenac significantly decreased IL-6 levels [F(1, $28)=5.43, \mathrm{p}<.05]$, whereas there was no main effect of pretreatment had no effect $[F(1,28)=$ $.01, \mathrm{p}=.92]$. The IL-6 data from the multiplex and ELISA assay do not correspond with one another. Therefore, the results are still inconclusive. In male mice, there was an interaction between diclofenac and JZL184 for MPO $[\mathrm{F}(1,27)=21.40, \mathrm{p}<.01$; Figure 9B]. There was a main effect of drug and a main effect of pretreatment, indicating that diclofenac $[\mathrm{F}(1,27)=$ 31.54, $\mathrm{p}<.01]$ and JZL184 $[\mathrm{F}(1,27)=7.18, \mathrm{p}<.05]$ significantly increased MPO levels, respectively. Post hoc analysis revealed that diclofenac by itself and JZL184 with and without 


\section{ENDOCANNABINOID MODULATION OF GASTROPATHY}

diclofenac significantly increased MPO levels compared to vehicle. In female mice, there was not an interaction $[F(1,28)=.28, \mathrm{p}<.60$; Figure 9D]. There was no main effect of drug treatment on MPO levels $[\mathrm{F}(1,28)=.80, \mathrm{p}<.38]$. However, there was a main effect of pretreatment, in that JZL184 significantly increased MPO levels $[\mathrm{F}(1,28)=15.84, \mathrm{p}<.01]$.

In a different cohort of mice, mucus samples were quantified using a multiplex for inflammatory marker concentration in order to cut down on the potential "noise" of using the full stomach sample. Mice were pretreated with JZL184 (8 mg/kg) or vehicle 2 h prior to administration of diclofenac $(100 \mathrm{mg} / \mathrm{kg})$ or vehicle. Mucus samples were collected $6 \mathrm{~h}$ after diclofenac administration. There was an interaction of diclofenac and JZL184 in male $[\mathrm{F}(1,35)=$ 8.50, $\mathrm{p}<.01$; Figure 10A $]$ and female $[\mathrm{F}(1,36)=5.27, \mathrm{p}<.05$; Figure 10D] mice. There was a main effect of drug treatment, such that diclofenac significantly increased gastric hemorrhage in male $[\mathrm{F}(1,35)=15.33, \mathrm{p}<.01]$ and female $[\mathrm{F}(1,36)=17.74, \mathrm{p}<.01]$ mice. There was a main effect of pretreatment, such that JZL184 decreased gastric hemorrhages in male $[F(1,35)=8.50$, $\mathrm{p}<.01]$ and female $[\mathrm{F}(1,36)=5.27, \mathrm{p}<.05]$ mice. Post hoc analyses revealed that JZL184 administration prior to diclofenac significantly decreased gastric hemorrhages in male $(\mathrm{p}<.01)$ and female $(\mathrm{p}<.05)$ mice.

Mucus samples were then assayed for concentration levels of inflammatory markers by multiplex assay. However, all cytokines, except VEGF-A and MCP-1, were below the detection point for the assay and therefore, not viable for analysis. In male mice, there was no interaction for VEGF-A $[F(1,35)=1.74, p=.20$; Figure 10B $]$. There was no main effect of drug treatment $[\mathrm{F}(1,35)=.01, \mathrm{p}=.94]$ or pretreatment $[\mathrm{F}(1,35)=.30, \mathrm{p}=.59]$ on VEGF-A. In female mice, there was no interaction for VEGF-A $[F(1,36)=.32$, $\mathrm{p}=.58$; Figure 10E]. There was no main effect of drug treatment $[F(1,36)=.02, p=.89]$ or pretreatment $[F(1,36)=1.3, p=.27]$ on 
ENDOCANNABINOID MODULATION OF GASTROPATHY

VEGF-A. In male mice, there was no interaction for $\operatorname{MCP}-1[\mathrm{~F}(1,35)=1.26, \mathrm{p}=.20$; Figure

10C]. However, there was a main effect of drug treatment, such that diclofenac significantly increased levels of MCP-1 $[\mathrm{F}(1,35)=4.44, \mathrm{p}<.05]$. There was no main effect of pretreatment on MCP-1 $[\mathrm{F}(1,35)=.45, \mathrm{p}=.51]$. In female mice, there was no interaction for MCP-1 $[\mathrm{F}(1,36)$ $=3.50, \mathrm{p}=.07$; Figure 10F]. However, there was a main effect of drug treatment, in that diclofenac significantly increased levels of MCP-1 $[\mathrm{F}(1,36)=10.87, \mathrm{p}<.01]$. There was no main effect of pretreatment on MCP-1 $[F(1,36)=.29, p=.60]$. Considering the data was not detectable using the mucus samples and the inconsistent data, the effects on inflammatory mediators is still inconclusive.

\section{JZL184 reduces pentagastrin-stimulated gastric acid secretions}

The goal of this experiment was to determine the efficacy of endocannabinoid attenuation of induced gastric acid secretion. Mice were subjected to the gastric hemorrhage procedure, with JZL184 (8 mg/kg) administered $2 \mathrm{~h}$ prior to diclofenac, as described in the Methods. In male mice, there was a significant interaction between pretreatment and drug treatment $[F(1,34)=$ 5.51, $\mathrm{p}<.05$; Figure 11A]. However, the post hoc analysis revealed no statistically significant differences between treatment groups. There were no main effects of pretreatment $[\mathrm{F}(1,34)=$ 0.28, $p=0.60$; Figure 11A $]$ or drug treatment $[F(1,34)=0.57, p=.46$; Figure $11 \mathrm{~A}]$ on acid secretions. In female mice, there were no main effects of pretreatment $[F(1,34)=0.03, p=.86$;

Figure 11B] or drug treatment $[F(1,34)=0.16, p=.70]$ and there was not a significant interaction $[\mathrm{F}(1,34)=0.52, \mathrm{p}=.48]$ on acid secretions.

The effects of JZL184 on basal and stimulated acid secretions were determined in the absence or presence of the acid-stimulating drug, pentagastrin, respectively, in male mice. There was an interaction between pretreatment (JZL184, omeprazole, vehicle) and drug treatment 
ENDOCANNABINOID MODULATION OF GASTROPATHY

(pentagastrin, vehicle) $[\mathrm{F}(2,42)=9.46, \mathrm{p}<.01$; Figure 12]. There was a main effect of drug, pentagastrin $(0.25 \mathrm{mg} / \mathrm{kg})$ significantly decreased gastric $\mathrm{pH}[\mathrm{F}(1,42)=13.18, \mathrm{p}<.01]$, indicating pentagastrin stimulated gastric acid output. There was a main effect of pretreatment, JZL184 (40 mg/kg) and omeprazole (20 mg/kg) pretreatments significantly increased gastric pH $[F(2,42)=21.07, \mathrm{p}<.01]$, which indicates that both drugs decreased gastric acid output. Post hoc analysis revealed JZL184 $(\mathrm{p}<.05)$ and omeprazole $(\mathrm{p}<.01)$ significantly decreased pentagastrin-stimulated gastric acid secretions and JZL184, but not omeprazole, decreased unstimulated gastric acid secretions $(\mathrm{p}<.01)$.

\section{JZL184 decreases gastric motility}

The goal of this experiment was to determine the efficacy of endocannabinoid attenuation of induced gastric motility. There was an interaction of JZL184 (40 mg/kg) and diclofenac (100 $\mathrm{mg} / \mathrm{kg})[\mathrm{F}(1,28)=6.11, \mathrm{p}<.05$; Figure 13]. There was a main effect of drug treatment and a main effect of pretreatment, such that diclofenac $[F(1,28)=6.85, \mathrm{p}<.05]$ and JZL184 $[\mathrm{F}(1,28)$ $=9.76, \mathrm{p}<.01$ ] significantly decreased gastric emptying, respectively. Post hoc analysis revealed that diclofenac administered prior to vehicle decreased gastric motility $(\mathrm{p}<.01)$, which was unexpected. Similarly, JZL184 decreased gastric motility in the absence $(\mathrm{p}<.01)$ and presence $(\mathrm{p}<.01)$ of diclofenac, as compared to controls.

\section{Discussion}

The results stated here replicate previous reports that the NSAID, diclofenac sodium, induces gastric hemorrhages, whereas the MAGL inhibitor, JZL184, stops the formation of these hemorrhages. The current study expanded the investigation by determining that sex does not modulate these gastric hemorrhages when controlling for body weight. In addition, the present data found significant correlations between published hemorrhage quantification methods and neutrophil levels, as assessed by MPO activity. The current study explored the primary 


\section{ENDOCANNABINOID MODULATION OF GASTROPATHY}

mechanisms through which NSAID-induced gastric hemorrhaging is suspected to occur, which are characterized by topical and systemic mechanisms. Although neither the mechanisms of NSAID-induced ulcers nor the mechanisms of gastroprotection proffered by MAGL inhibition are known, there are many potential mechanisms through which gastric hemorrhages are produced and prevented. Therefore, in the current study, the most characterized potential mechanisms were evaluated: gastric inflammation, acid secretion, and motility. Although diclofenac did not increase gastric acid output, JZL184 reduced pentagastrin-stimulated gastric acid secretion, while also reducing basal secretions. However, MAGL inhibition did not decrease proinflammatory markers as expected. MAGL inhibition slowed gastric motility, which supports previous research, but did not further reduce motility when given prior to diclofenac.

Diclofenac dose-dependently increased gastric hemorrhage length and MPO concentration in both male and female mice. MPO concentration significantly correlated with hemorrhage length, which indicates MPO may be used as an objective biomarker for gastric damage. Researchers have used multiple methods to measure gastric hemorrhages, including using a semi-quantitative clinical scale scoring gastric damage severity (e.g., a 5-point scale with factors such as ulcer count and redness contributing to a higher score), as well as the objective, visual quantitative method used in the current study, in which the length of the hemorrhage is measured compared to a standard. All of the scoring methods presently used may be open to bias even when blinded, whereas the use of an objective biomarker may increase the reliability and validity of results. While using MPO as a biomarker of gastric hemorrhage may be helpful to measure gastric hemorrhages in the lab, MPO is found throughout the body which may hinder its use as a specific molecular diagnostic for gastric hemorrhages in humans (Loria et al., 2008). Thus, current diagnostic tools such as endoscopy will likely remain preferred in humans. However, the 
ENDOCANNABINOID MODULATION OF GASTROPATHY

translational potential of the present study is in the manipulation of endocannabinoid levels by inhibiting MAGL, not measuring a particular marker in gastric biopsies.

\section{Mechanisms of gastric hemorrhage}

Diclofenac has previously been shown to increase proinflammatory markers in the stomach (Kinsey et al., 2011; Wallace, Caliendo, Santagada, Cirino, \& Fiorucci, 2007), whereas MAGL inhibition reduces gastric inflammatory markers (Kinsey et al., 2011). However, the present study pretreatment of JZL184 prior to diclofenac did not decrease proinflammatory cytokines in male mice, as previously reported. In female mice, administration of diclofenac, as well as JZL184, significantly increased proinflammatory cytokines including IL-1 $\beta$ and TNF- $\alpha$, which suggests sex differences in the immune response to gastric wounds. JZL184 reduced MCP-1 levels in a pathological state in the colon (Alhouayek, Lambert, Delzenne, Cani, \& Muccioli, 2011). The present data indicate diclofenac increased MCP-1 levels but found no attenuation with JZL184 administration in male mice. Conversely, JZL184 increased levels of MCP-1 in female mice when administered prior to diclofenac, which further supports sex differences in immune response. Because of the surprising results, the same samples were quantified for a second time using an IL-6 ELISA. However, there were no treatment interactions in male and female mice in IL-6 levels and the results did not replicate the results found using the multiplex assay.

In order to reduce the potential cytokine "noise” of the whole stomach assay, mucus scrapings collected from a separate cohort of mice were also assayed for inflammatory markers. Considering NSAID-induced gastric hemorrhages form in the mucosal layer, using mucosal samples potentially allows for a more focused measurement of gastric inflammation. Unfortunately, all of the assayed cytokines, except VEGF-A and MCP-1, fell below detection 


\section{ENDOCANNABINOID MODULATION OF GASTROPATHY}

range and could not be analyzed. There were no treatment differences of VEGF-A levels in male or female mice. In male mice, diclofenac significantly increased MCP-1 in the mucus samples, which corroborates the whole stomach data. In female mice, diclofenac increased MCP-1 in mucus samples, which differs from the JZL184/diclofenac increase in MCP-1 as shown in the whole stomach data. Because of the conflicting results of the multiple assays, the effect of JZL184 on inflammatory markers remains unclear.

As mentioned in the Introduction, NSAIDs not only induce gastric damage but can also impair the healing of the injury. The present study evaluated the levels of two gastroprotective cytokines, IL-10 and VEGF-A, which may promote healing of gastric lesions. IL-10 is produced by monocytes and is an anti-inflammatory cytokine that suppresses pro-inflammatory cytokine release (De Waal Malefyt, Abrams, Bennett, Figdor, \& Vries, 1991; Roncarolo et al., 2006). VEGF-A is important in the immune response because it stimulates new blood vessel growth, which fosters healing (Salgado et al., 2001; Takahashi, 2011; Wallace, 2008). In the present study, neither VEGF-A nor IL-10 levels were reduced after diclofenac administration, indicating that a reduction in these signaling molecules may not be a main contributor to diclofenacinduced ulcers. However, pretreatment with JZL184 increased IL-10 levels in female mice, which may suggest MAGL inhibition stimulates healing of NSAID-induced gastric damage by increasing levels of IL-10. However, IL-10 increases after proinflammatory cytokine elevation (Figure 14), so it is still unclear if JZL184 exerts its gastroprotection through anti-inflammatory mediators without first determining the proinflammatory cytokine signaling in the samples.

Cytokines are dynamic signaling proteins that work in concert with one another, interacting in a complex network that can alter immune cell signaling and function. A multiplex immunoassay is a strong tool for quantifying multiple cytokines in a small sample, with the goal 


\section{ENDOCANNABINOID MODULATION OF GASTROPATHY}

of getting a better picture of the response of a whole network of inflammatory cells (BurgosRamos, Martos-Moreno, Argente, \& Barrios, 2012; Kingsmore, 2006). However, it is difficult to fully understand the context of the cytokine levels when looking at one time point, as was chosen for the design of the present study. Therefore, an important follow-up study would include multiple time points for evaluating cytokine levels. Such a design would help elucidate whether the cytokine and chemokine levels we observed are actively rising or declining. Considering immune cells, such as monocytes, macrophages, neutrophils, and T cells, secrete many different cytokines, another possible future direction would be to use fluorescence-activated cell sorting (FACS; flow cytometry) or immunohistochemistry to determine the different immune cell populations involved in the response to NSAID-induced gastric hemorrhage. Another interesting follow-up would be to potentially isolate and culture gastric neutrophils and macrophages from diclofenac-treated mice and stimulate the cells, in vitro, with JZL184 to determine which cytokines are synthesized. Delineating the changes in cell populations at the injury site might provide more insight into the immune response, as well as the sex differences in cytokine levels reported above.

Although many advances have been made in biomedical research, a major shortcoming of preclinical research is the overreliance on male subjects and the assumption that data from male mice will generalize to all humans. This shortcoming has received a fair amount of recent scrutiny and is reflected in the new NIH guidelines, which urge including both sexes in research. Published reports in gastrointestinal research have used male mice, exclusively; therefore, the current study used both male and female mice and analyzed data. The difference between the sexes reported here emphasizes the importance of using both sexes in research. Although there were no sex differences observed in the ulcerogenic effects of diclofenac after controlling for 


\section{ENDOCANNABINOID MODULATION OF GASTROPATHY}

body weight (i.e., no effect of sex on gastric hemorrhage length), there were sex differences in the immune response to NSAID-induced gastric damage. The sex effects may be due to a difference in immune response to the injury. Estrogens and prolactin, which are hormones more predominant in female mice, can be stimulated by cytokines to increase cellular (i.e., cytokines) and humoral (i.e., antibody production) immune reactions (Bouman, Jan Heineman, \& Faas, 2005; Cai et al., 2016; Orbach \& Shoenfeld, 2007), which may account for the higher incidence of autoimmune disorders in females (Cai et al., 2016). Because these hormones elicit a more vigorous inflammatory response in females, cutaneous wounds heal faster in women, whereas testosterone, the primary male sex hormone, mainly suppresses macrophage function, which corresponds to delayed wound healing in men (Cai et al., 2016; Darnall \& Suarez, 2009). Gastric samples from female mice reported here had higher concentrations of the proinflammatory cytokines tested, which may be a result of hormone-stimulated immune response. In other words, the elevated proinflammatory cytokines levels in female mice may stimulate gastric hemorrhage healing more so than male mice (Figure 14). A potential follow-up study would determine the effects of specific hormones on gastric inflammation caused by diclofenac. For example, given the substantial data that estrogens and prolactin modulate immune function, using ovariectomized female mice and administering specific exogenous hormones may provide further understanding into the altered immune response to gastric inflammation.

An increase in gastric acid secretion is thought to be a main pathogenic mechanism of NSAID-induced gastric hemorrhages (Wallace, 2008). However, assessing gastric acid levels was particularly more challenging than originally proposed in the current study. The goal of measuring gastric acid was to assess acid secretions continuously over a $4 \mathrm{~h}$ period. During this time, a secretagogue, such as pentagastrin or diclofenac, would be administered to increase 


\section{ENDOCANNABINOID MODULATION OF GASTROPATHY}

gastric acid output, and then the addition of JZL184 would elucidate the role of MAGL

inhibition in gastric acid alterations. The main issues with the procedure were that the many anesthetics we tried worked either too well or not well enough (thus no data collection occurred) and that blood pooled near the pyloric sphincter where the stomach contents were collected (thus contaminating the baseline samples). Although the surgical techniques and anesthetic issues improved after consulting with the Clinical Veterinarian, the veterinary technicians, and an expert in small animal surgery, the other main issues of the procedure continued unimpeded. Therefore, stomach contents were collected at one time point (i.e., gastric lavage procedure) to determine the effect of JZL184 on gastric secretions, in place of a continuous measurement of gastric secretions.

NSAIDs in vivo increase baseline and stimulated gastric acid secretion, and support the idea that gastric acid is involved with ulcer formation (Salvatella et al., 2004). However, there are conflicting reports on whether diclofenac itself alters acid secretions. Diclofenac decreased $\mathrm{pH}$ and increased total acidity, as compared to vehicle treated rats (Khan \& Khan, 2013). However, other reports did not find treatment differences between diclofenac- and vehicle-treated rats (Reuter, Davies, \& Wallace, 1997). Conversely, diclofenac significantly decreased basal- and stimulated-gastric acid output in isolated rabbit gastric glands, whereas aspirin and indomethacin increased stimulated acid output (Salvatella et al., 2004), which suggests that specific NSAIDs may have different modulatory effects on gastric acid secretion. In the current study, diclofenac did not increase gastric acid secretions, indicating diclofenac may cause hemorrhage formation through a nonacidic mechanism. These conflicting reports underscore differences across species, collection methods, as well as differences of in vitro and in vivo contexts (Devi et al., 2007; Reuter et al., 1997; Rodriguez-Stanley et al., 2006; Salvatella et al., 2004). Still, acute 


\section{ENDOCANNABINOID MODULATION OF GASTROPATHY}

administration the of NSAID naproxen did not change basal or stimulated levels of $\mathrm{pH}$ in humans, but decreased the total volume of gastric fluid released, ultimately increasing acid concentration (Rodriguez-Stanley et al., 2006). It is plausible that diclofenac works through a similar mechanism to increase acid concentration in humans that we were unable to capture in mice because of differences related to species or methodology.

In the present study, JZL184 significantly decreased gastric acid secretion (i.e., JZL184 increased $\mathrm{pH}$ of stomach contents) in both basal and pentagastrin-stimulated conditions $1 \mathrm{~h}$ after pentagastrin administration. However, JZL184 did not alter gastric acid in the absence or presence of diclofenac following the "Induction of Gastric Hemorrhage" procedure outlined in the Methods. The different pretreatment times of JZL184 administration prior to euthanasia in the gastric acid collections ( $1 \mathrm{~h}$ when using pentagastrin compared to $6 \mathrm{~h}$ when using diclofenac) suggest that JZL184 may initially decrease acid secretions within the first few hours after administration. As with the cytokine study, a follow-up study may focus on evaluating the effects of MAGL inhibition at multiple time points. Currently, it remains unclear whether diclofenac alters gastric acid output. However, JZL184 does reduce acid early on, and it is plausible that MAGL inhibition proffers gastroprotection through an antacid mechanism.

In addition to gastric acid secretions, one of the primary, suspected mechanisms through which NSAIDs cause gastric hemorrhages is by increasing mechanical compressions of the stomach (i.e., increasing gastric motility) (Takeuchi, 2012; Wallace, 2008). Considering that cannabinoids reduce gastrointestinal motility in animals, including humans (Esfandyari et al., 2006; Izzo \& Sharkey, 2010; Maccarrone et al., 2015; McCallum et al., 1999), we hypothesized that JZL184 would attenuate NSAID-induced increases in stomach contractions. As hypothesized, JZL184 decreased gastric motility in the current study, whereas diclofenac, 
ENDOCANNABINOID MODULATION OF GASTROPATHY

contrary to expectations, slowed gastric motility. JZL184 did not further reduce the gastric emptying of diclofenac, suggesting that the gastroprotection of MAGL inhibition does not occur through gastric motility changes.

In previous reports, gastric motility was increased using a different NSAID, indomethacin. Hypermotility is cause by the inhibition of COX-1 and while diclofenac inhibits both COX-1 and COX-2, it is more selective for COX-2, whereas indomethacin is more selective for COX-1 (Patrono \& Baigent, 2009). The difference in COX selectivity may alter which mechanisms significantly contribute to pathophysiology (Rodriguez-Stanley et al., 2006; Smecuol et al., 2001). A future direction may be to evaluate indomethacin in the gastric motility protocol used here. In addition, motility is generally assessed in rats (as opposed to mice used here) and is quantified by inserting a balloon into the stomach and recording changes in pressure to determine gastric contractions (Mersereau \& Hinchey, 1982; Takeuchi et al., 1986; Tanaka et al., 2001). The gastric motility assay used in the current study focused more on overall function and may not be sensitive enough to see alterations in stomach contractions caused by diclofenac. For example, measuring pressure changes using balloon manometry in the stomach may reveal a more subtle mucosal compression than can be determined in whole stomach movement, as measured by gastric emptying in the present study.

\section{Alternative mechanisms of gastric hemorrhage}

Due to the numerous possible mechanisms that may be involved in the formation of NSAID-induced ulcers, not all of the potential pathways were examined in the current study. A proposed pathway that was not evaluated here is deficient wound healing, caused by NSAIDinduced hindering of microcirculation of the gastric mucosa (Ma et al., 2001; Wallace, 2008). Specifically, COX inhibition is proposed to alter neutrophil activation and gastrointestinal 


\section{ENDOCANNABINOID MODULATION OF GASTROPATHY}

permeability, thereby increasing ulceration (Reuter et al., 1997; Rodriguez-Stanley et al., 2006).

The present data indicate that diclofenac dose-dependently increases MPO, indirectly suggesting that diclofenac increases neutrophil infiltration into the stomach. In other words, as compared to controls, the stomachs of mice treated with diclofenac had more neutrophil activation.

An alternative model involving neutrophils relates less to their proinflammatory effects than on their physical interaction with capillaries. Neutrophils are thought to contribute to NSAIDinduced gastric damage by adhering to the vascular endothelium, thereby inhibiting the ability of capillaries to maintain normal blood flow to the mucosa (by physically blocking the movement of red blood cells), and by producing oxygen-derived free radicals, which cause tissue damage (Beck et al., 2000; Wallace \& Vong, 2008). Through the activation of neutrophils, NSAIDs foster oxygen metabolite free radical synthesis and also decrease the antioxidizing enzymes that defend against reactive oxygen metabolites (Pohle et al., 2001), thus further increasing free radical activity. Free radicals cause oxidative degradation of lipids, which damages endothelial cells, subsequently forming gaps in the cell membrane (Beck et al., 2000; Kwiecien, Brzozowski, \& Konturek, 2002). The free radical induced damage increases permeability of the stomach barrier, which reduces the protective lining of the gastrointestinal system (Kwiecien et al., 2002; Pohle et al., 2001). NSAIDs dose-dependently increase extravasation in the intestines (Beck et al., 2000; Reuter et al., 1997), indicating the intestinal barrier is compromised after administration. Using mice with genetically reduced free radical production, but having normal neutrophil adhesion properties, showed a significant decrease in barrier permeability and indomethacin-induced gastric hemorrhages (Beck et al., 2000). Protection against barrier deficiency and hemorrhagic effects of the mutant mice indicate the neutrophil-dependent release of oxides may play a bigger role in hemorrhage formation than neutrophil adhesion to the 


\section{ENDOCANNABINOID MODULATION OF GASTROPATHY}

endothelium itself. Thus, a potential future direction would be to evaluate MAGL inhibition on free radical production.

Another pathway of NSAID-induced microcirculation disruption could be due to inhibition of platelet function. Aggregation of platelets causes clotting and therefore acts as a "brake" for bleeding, which is critically important for wound reparation (Wallace, 2008). Platelets can also be protective because VEGF-A is mainly concentrated in platelets, which promotes blood vessel growth. The prevention of platelet function and aggregation can decrease VEGF while also increasing bleeding at the injury site (Ma et al., 2001), thereby contributing to the risk of death in chronic NSAID users (Sung et al., 2010). Platelet accumulation is stimulated by thromboxane, which is produced by COX-1 (Wallace, 2008). COX-2 inhibition does not affect platelets, which may explain why COX-2 selective inhibition is not associated with gastropathy (Wallace, 2008). Following COX-1 inhibition by NSAIDs, thromboxane is decreased and platelet function is subsequently reduced (Smith, Garavito, \& Dewitt, 1996; Wallace, 2013). Increasing thromboxane levels stimulates gastric healing (Ma et al., 2001), suggesting that thromboxane is important for wound reparation. Cleavage of 2-AG via MAGL leads to an increase in free arachidonic acid, which activates platelets in vitro (Brantl, Khandoga, \& Siess, 2014). However, inhibiting MAGL (for example, with JZL184) blocks the catabolism of 2-AG into arachidonic acid, and this drop in arachidonic acid reduces platelet aggregation (Brantl et al., 2014). Thus, increased platelet accumulation is most likely not the gastroprotective mechanism of MAGL inhibition.

While the current study focused on MAGL inhibition, experiments from our lab (Ignatowska-Jankowska et al., 2014; Kinsey et al., 2011; Kinsey \& Cole, 2013), and others (Gyires et al., 2014; Izzo et al., 2001; Sasso et al., 2012) indicate that inhibiting the catabolic 
ENDOCANNABINOID MODULATION OF GASTROPATHY

enzyme fatty acid amide hydrolase (FAAH), which then increases levels of the endocannabinoid anandamide, blocks the formation of NSAID-induced ulcers through a $\mathrm{CB}_{1}$ mechanism of action. Administration of anandamide directly into the brain prevents gastric hemorrhage formation (Shujaa et al., 2009). Surprisingly, the peripherally restricted FAAH inhibitor (i.e., inhibiting FAAH in peripheral tissues only), URB937, also blocks gastric hemorrhages (Sasso et al., 2012). Thus, there are discrepancies between possible central and peripheral, as well as neural and nonneural mechanisms. Therefore, a possible future direction would be to evaluate the central and peripheral effects of the endocannabinoid system's involvement in NSAID-induced gastropathy. Using mice genetically deficient in FAAH either globally, which have ubiquitously elevated anandamide levels [i.e., FAAH(-/-)], or mice expressing FAAH in neural tissue only, which have elevated anandamide levels only in non-neural tissue (i.e., stomach) [i.e., FAAH-NS], as well as wild-type control mice [i.e., FAAH (+/+)] would provide a powerful tool for determining the necessity of peripheral nerves in FAAH blockade of gastric inflammation. We would anticipate a decrease in gastric hemorrhages in FAAH (-/-) mice, which have elevated anandamide levels and have been shown to attenuate ulcerogenesis (Naidu et al., 2009), but not in FAAH-NS mice, which have elevated anandamide levels only in non-neural tissues, indicating that a nervousdependent mechanism is responsible for endocannabinoid-mediated gastroprotection.

\section{Cannabinoids in GI disorders}

In addition to reducing gastric hemorrhages, cannabinoids may be beneficial for other gastrointestinal system disorders. Work from my lab has shown that preclinical use of THC is gastroprotective (Kinsey \& Cole, 2013), and there is substantial evidence that cannabinoids attenuate GI disorders in humans, highlighting the translational potential of cannabinoids in the gut. For example, due to its anti-nausea and appetite stimulating effects, a synthetic, oral 


\section{ENDOCANNABINOID MODULATION OF GASTROPATHY}

preparation of THC, dronabinol, is currently approved by the Food and Drug Administration for the treatment of chronic wasting conditions (Sticht, Rock, Limebeer, \& Parker, 2015). There is also evidence indicating elevated endocannabinoid levels may be involved in reducing nausea in patients (Sticht et al., 2015). The anesthetic, propofol, indirectly increased levels of the endocannabinoid, anandamide, and is associated with a reduction in post-operative nausea in patients (Kumar, Stendall, Mistry, Gurusamy, \& Walker, 2014; Sticht et al., 2015).

Endocannabinoid levels are also implicated in motion-induced nausea. For example, people experiencing motion-sickness had lower blood levels of anandamide and 2-AG, indicating that higher levels of endocannabinoids may be protective against motion sickness (Choukèr et al., 2010). Conversely, the $\mathrm{CB}_{1}$ receptor selective antagonist, rimonabant, increased nausea in humans (Van Gaal, Pi-Sunyer, Despres, McCarthy, \& Scheen, 2008), indicating CB $_{1}$ mediates the anti-nausea effects of cannabinoids.

In addition to gastric disorders, cannabinoids are also active in the gut. For example, inflammatory bowel disease (IBD) encompasses the many forms of chronic inflammation in the gastrointestinal system, such as colitis and Crohn's disease. IBDs cause severe abdominal pain, diarrhea, reduced appetite, and weight loss. Patients with IBD report self-medicating with cannabis in order to relieve these symptoms (Lal et al., 2011). Cannabis use is more likely for individuals within this patient population if there is also a history of chronic analgesic use, which indicates that, at least for some individuals, traditional analgesic are not effective for reducing disease-related pain (Lal et al., 2011). Patients with colitis who used cannabis reported a decrease in diarrhea, most likely stemming from cannabinoid-mediated gastrointestinal hypomotility (Naftali, Mechulam, Lev, \& Konikoff, 2014). A small placebo-controlled clinical trial indicated that THC reduced disease-related pain and increased quality of life in patients with 
ENDOCANNABINOID MODULATION OF GASTROPATHY

Crohn’s disease (Naftali et al., 2013). Endocannabinoids have also been implicated in IBD.

Levels of anandamide are significantly reduced in biopsies of human IBD-inflamed intestine (Di Sabatino et al., 2011). The decrease in anandamide was caused by both an increase in degradation and a decrease in synthesis of the endocannabinoid (Di Sabatino et al., 2011), either of which may alter IBD-related increased intestinal motility. Similarly, prevention of the breakdown of anandamide reduces disease-induced inflammation in a mouse model of colitis (Massa et al., 2004). In a pre-clinical study, IBD increased endotoxins in the blood, intestinal barrier permeability, and inflammation in mice (Alhouayek et al., 2011). Repeated administration of JZL184 (which increases 2-AG levels) normalized IBD mice in disease scores, histology, and inflammation, reduced endotoxins, repaired intestinal barrier permeability, and restored mucosal structure (Alhouayek et al., 2011). Pharmacological blockade of either $\mathrm{CB}_{1}$ or $\mathrm{CB}_{2}$ reversed the effects of JZL184, indicating activation of both receptors mediates the reduction of IBD symptoms (Alhouayek et al., 2011).

The highest expression of the 2-AG producing enzyme, DAGL, in the periphery is found in the stomach and colon (Bashashati et al., 2015; DiPatrizio, 2016). Considering 2-AG slows motility by decreasing acetylcholine release on enteric nerves, using DAGL inhibitors, thus decreasing 2-AG levels, increases motility during pathological state with no basal changes (Bashashati et al., 2015). Therefore, DAGL inhibitors could be a novel therapeutic target for constipation.

\section{Parallel wound healing and pain models}

One limitation of the current study is the acute model of gastric wound healing, in that NSAID-induced ulcers are usually fully healed within $24 \mathrm{~h}$ of NSAID administration (data not 


\section{ENDOCANNABINOID MODULATION OF GASTROPATHY}

shown). However, the risk of death from gastric hemorrhage increases with duration of a

perforated ulcer over $24 \mathrm{~h}$, which is particularly germane for elderly patients (Kocer et al., 2007).

Therefore, I also assessed eCB modulation in a different model of chronic wound healing.

Chronic stress significantly impairs wound healing in humans and other animals. For example, people experiencing chronic psychological stress, such as Alzheimer's Disease caretakers, have slower skin biopsy wound healing than "non-stressed" controls (Head, Farrow, Sheridan, \& Padgett, 2006; Kiecolt-Glaser, Marucha, Mercado, Malarkey, \& Glaser, 1995). Similarly, restraint stress prolongs cutaneous wound healing and induces gastric hemorrhages in mice and other rodents (Liu et al., 1998; Padgett, Marucha, \& Sheridan, 1998). A delay in wound closure is undesirable because open wounds increase exposure to microorganisms, and heighten the risk of secondary insult and infection (Padgett et al., 1998). Similar to gastric hemorrhages, one strategy to increase cutaneous wound healing rate is to attenuate inflammation during the wound healing process (Head et al., 2006; Padgett et al., 1998). Cannabinoids attenuate stress effects (Carrier, Patel, \& Hillard, 2005), have anti-inflammatory properties (Ghosh et al., 2013; Klein, 2005), and enhance in vitro wound healing (Wright et al., 2005). Therefore, the goal of my study was to determine the efficacy of inhibiting MAGL or FAAH to normalize in vivo cutaneous wound healing in mice subjected to repeated restraint stress. Restraint stress significantly delayed cutaneous wound healing, but either manipulation of the endocannabinoid system had no effect on wound closure (data not shown). Thus, the extensive psychological stress induced by restraint may be too advanced for endocannabinoids to overcome in order to rectify wound healing. Furthermore, in vitro effects of cannabinoids on "wound healing” may be model specific and not predictive of in vivo effects. 


\section{ENDOCANNABINOID MODULATION OF GASTROPATHY}

As outlined in the Introduction, chronic high dose JZL184 administration reverses the antiinflammatory and antinociceptive properties of MAGL inhibition, which is most likely due to the irreversible alterations to MAGL. Conversely, reversible enzyme inhibitors have fewer deleterious side effects than irreversible inhibitors (Cisneros et al., 2012; Tuccinardi et al., 2014). In collaboration with a pharmaceutical company, I recently evaluated a novel reversible MAGL inhibitor in an NSAID-model of gastric hemorrhage. Acute administration of the experimental MAGL inhibitor significantly attenuated neuropathic pain in mice. In addition, acute and chronic administration of the reversible MAGL inhibitor blocked the development of NSAID-induced gastric hemorrhages, indicating that the reversible MAGL inhibitor does not undergo tolerance (Crowe, Pink, Peluso, \& Kinsey, in prep). An interesting future direction would be to evaluate the reversible MAGL inhibitor on the pathogenic mechanisms of NSAID-induced ulcers reported in the current study. While the compound is not yet commercially available, this is an exciting new class of MAGL inhibitors.

NSAIDs are used worldwide, especially in chronic pain patients. Thus, decreasing doses of NSAIDs concomitantly reduces the risk of side effects, and therefore may be beneficial to the population. One strategy for reducing drug doses is by combining drugs with different mechanisms of action, to produce greater pain attenuation than individually administered analgesics (Raffa, 2001). Patients taking high doses of an analgesic, who have a higher risk of experiencing negative side effects, could potentially take two drugs in lower doses, thereby decreasing the potential for side effects. Thus, a dual administration approach may allow for subclinical dose of each drug, lessening the side effects of each compound while maintaining adequate pain relief (Josée Guindon, Walczak, \& Beaulieu, 2007). Work from my lab (Grim et al., 2014; Naidu et al., 2009), and others (Sasso et al., 2012; Scarpelli, Sasso, \& Piomelli, 2015), 


\section{ENDOCANNABINOID MODULATION OF GASTROPATHY}

has shown that targeting separate systems (i.e., endocannabinoid degradative enzymes and cyclooxygenases) potentiates analgesia. Expanding on these studies, I recently published that combined inhibition of MAGL and COX enzymes synergistically reduced neuropathic pain in mice (Crowe et al., 2015). In other words, the combined inhibition of MAGL (i.e., using JZL184) and COX (i.e., using diclofenac) enzymes may be beneficial in maximizing analgesia while at the same time reducing NSAID side effects, in particular gastrointestinal ulcers. Interestingly, taken with the results of the current study, even if high doses of NSAIDs are used, pretreatment with a MAGL inhibitor will block NSAID-induced gastric hemorrhages. While this is an exciting outcome, MAGL inhibitors are not currently approved for use in humans, and thus clinical trials are still needed to test the efficacy of these drugs.

\section{Research limitations}

The aims of the current research were to evaluate multiple possible pathomechanisms of NSAID-induced gastric hemorrhages. However, there were some limitations of the study. Patients are prescribed NSAIDs for persistent pain and inflammation and will therefore, use NSAIDs repeatedly. However, the model used in the present study is an acute model of NSAID administration, unlike the chronic use of NSAIDs found in clinical settings. While acute use of NSAIDs does induce gastric damage, the chronic inhibition of COX-1 and COX-2 from repeated NSAID use can increase the incidence of severe, life-threatening gastric hemorrhages. Therefore, a potential future direction may be to evaluate gastric hemorrhages after chronic administration of an NSAID.

While one strength of this study is the evaluation of cytokine signaling in both male and female mice, it is difficult to fully understand the circumstance of the cytokine levels when looking at one time point, as was selected for the design of the present study. Therefore, a 


\section{ENDOCANNABINOID MODULATION OF GASTROPATHY}

potential follow-up study would include evaluating cytokine levels at multiple time points, which would provide a more complete understanding of the relationship between the cytokines analyzed for the present study.

Gastric $\mathrm{pH}$ fluctuates throughout the day and can be affected by food intake, water consumption, and time of day. Therefore, the optimal method to evaluate drug-induced changes in $\mathrm{pH}$ would be to continuously sample gastric contents over an extended period of time in order to limit any environmental- and time-dependent influences on gastric secretions. However, this methodology was not able to be accomplished for the current study. Therefore, a potential follow-up study might use separate cohorts of mice to evaluate gastric contents at multiple time points to fully elucidate the time course of gastric $\mathrm{pH}$ changes due to MAGL inhibition.

NSAIDs have been shown to increase the frequency of stomach contractions, as assessed by pressure changes in the stomach. The gastric motility assay used in the current study focused more on overall stomach emptying function and may not be sensitive enough to investigate alterations of stomach contractions caused by diclofenac. For example, measuring pressure changes using balloon manometry in the stomach may reveal a more subtle change in mucosal compression than can be determined in whole stomach functioning, as measured by gastric emptying in the present study.

\section{Conclusion}

Diclofenac dose-dependently increases gastric hemorrhages in male and female mice, whereas inhibiting the degradation of the endocannabinoid, 2-AG, attenuates NSAID-induced gastric hemorrhage. Three main pathogenic mechanisms, gastric acid, inflammation, and motility, were evaluated to better understand the formation and prevention of gastric hemorrhages. The first potential ulcerogenic mechanism evaluated was gastric inflammation. 


\section{ENDOCANNABINOID MODULATION OF GASTROPATHY}

Diclofenac dose-dependently increased neutrophil infiltration in both male and female mice, indicating that diclofenac induces a cell-mediated inflammatory response. However, JZL184 did not attenuate cytokine and chemokine levels in male or female mice, as hypothesized. Multiple assays were run to further determine inflammatory cytokine signaling in gastric inflammation, however, the results were contradictory and inconclusive. Future studies may focus on cytokine involvement at multiple time points in gastric hemorrhage development and prevention. The second aim of the study was to assess the effects of JZL184 on basal and diclofenac- or pentagastrin-stimulated gastric acid. Neither JZL184 nor diclofenac produced any changes on gastric acid secretions. However, in the pentagastrin-stimulated acid model, JZL184 decreased gastric acid secretions in both basal and stimulated conditions, indicating that JZL184 may be gastroprotective through a transient antisecretory mechanism. Another potential mechanism evaluated in the present study was mechanical compressions of the stomach, or gastric motility. As hypothesized, JZL184 decreased gastric motility, although diclofenac also slowed gastric motility, indicating that diclofenac-induced ulcers most likely do not occur through increased gastric motility, at least not as measured functionally, as in the present study. In light of the present data, NSAIDs are most likely causing gastric hemorrhages through multiple pathways simultaneously. In other words, one potential pathomechanism of NSAID-induced hemorrhages by itself will not likely result in gastric hemorrhages, but it is the combined physiological changes that is prompting ulcer development. Although the gastroprotective mechanisms of JZL184 remain unclear, the present data support the idea that MAGL is a promising target to protect against NSAID-induced gastric hemorrhages in male and female mice. 


\section{References}

Abalo, R., Vera, G., Lopez-Perez, A. E., Martnez-Villaluenga, M., \& Martin-Fontelles, M. I. (2012). The gastrointestinal pharmacology of cannabinoids: Focus on motility. Pharmacology, 90(1-2), 1-10. http://doi.org/10.1159/000339072

Adami, M., Frati, P., Bertini, S., Kulkarni-Narla, A., Brown, D. R., de Caro, G., ... Soldani, G. (2002). Gastric antisecretory role and immunohistochemical localization of cannabinoid receptors in the rat stomach. British Journal of Pharmacology, 135(7), 1598-606. http://doi.org/10.1038/sj.bjp.0704625

Adams, E. H., Breiner, S., Cicero, T. J., Geller, A., Inciardi, J. A., Schnoll, S. H., ... Woody, G. E. (2006). A comparison of the abuse liability of tramadol, NSAIDs, and hydrocodone in patients with chronic pain. Journal of Pain and Symptom Management, 31(5), 465-76. http://doi.org/10.1016/j.jpainsymman.2005.10.006

Ahn, K., McKinney, M. K., \& Cravatt, B. F. (2008). Enzymatic pathways that regulate endocannabinoid signaling in the nervous system. Chemical Reviews, 108(5), 1687-1707. http://doi.org/10.1021/cr0782067.Enzymatic

Aldinger, K. A., Sokoloff, G., Rosenberg, D. M., Palmer, A. A., \& Millen, K. J. (2009). Genetic variation and population substructure in outbred CD-1 mice: Implications for genome-wide association studies. PLOS ONE, 4(3), 2-11. http://doi.org/10.1371/journal.pone.0004729

Alhouayek, M., Lambert, D. M., Delzenne, N. M., Cani, P. D., \& Muccioli, G. G. (2011). Increasing endogenous 2-arachidonoylglycerol levels counteracts colitis and related systemic inflammation. The FASEB Journal : Official Publication of the Federation of American Societies for Experimental Biology, 25(8), 2711-2721. http://doi.org/10.1096/fj.10-176602

Anavi-Goffer, S., \& Coutts, A. A. (2003). Cellular distribution of vanilloid VR1 receptor immunoreactivity in the guinea-pig myenteric plexus. European Journal of Pharmacology, 458(1-2), 61-71. http://doi.org/10.1016/S0014-2999(02)02653-5

Appleyard, C., McCafferty, D.-M., Tigley, A. W., Swain, M. G., \& Wallace, J. L. (1996). Tumor necrosis factor mediation of NSAID-induced gastric damage: role of leukocyte adherence. American Journal of Physiology, 270, G42-G48.

Aviello, G., Romano, B., \& Izzo, a a. (2008). Cannabinoids and gastrointestinal motility: animal and human studies. European Review for Medical and Pharmacological Sciences, 12 Suppl 1(Suppl 1), 81-93.

Bashashati, M., Nasser, Y., Keenan, C. M., Ho, W., Piscitelli, F., Nalli, M., ... Sharkey, K. A. (2015). Inhibiting endocannabinoid biosynthesis: A novel approach to the treatment of constipation. British Journal of Pharmacology, 3099-3111. http://doi.org/10.1111/bph.13114

Bastaki, S. M., \& Wallace, J. L. (1999). Pathogenesis of nonsteroidal anti-inflammatory drug gastropathy: clues to preventative therapy. Canadian Journal of Gastroenterology = Journal Canadien de Gastroenterologie, 13(2), 123-7. Retrieved from http://www.ncbi.nlm.nih.gov/pubmed/10203430 


\section{ENDOCANNABINOID MODULATION OF GASTROPATHY}

Beck, P. L., Xavier, R., Lu, N., Nanda, N. N., Dinauer, M., Podolsky, D. K., \& Seed, B. (2000). Mechanisms of NSAID-induced gastrointestinal injury defined using mutant mice. Gastroenterology, 119(3), 699-705. http://doi.org/S0016508500973098 [pii]

Berthoud, H. R., Carlson, N. R., \& Powley, T. L. (1991). Topography of efferent vagal innervation of the rat gastrointestinal tract. Am J Physiol, 260(1 Pt 2), R200-7. Retrieved from

http://www.ncbi.nlm.nih.gov/entrez/query.fcgi?cmd=Retrieve\&db=PubMed\&dopt=Citation \&list_uids $=1992820$

Bisogno, T., Howell, F., Williams, G., Minassi, A., Cascio, M. G., Ligresti, A., ... Doherty, P. (2003). Cloning of the first sn1-DAG lipases points to the spatial and temporal regulation of endocannabinoid signaling in the brain. Journal of Cell Biology, 163(3), 463-468. http://doi.org/10.1083/jcb.200305129

Blankman, J. L., Simon, G. M., \& Cravatt, B. F. (2007). A comprehensive profile of brain enzymes that hydrolyze the endocannabinoid 2-arachidonoylglycerol. Chem Biol, 14(12), 1347-1356. Journal Article. http://doi.org/10.1016/j.chembiol.2007.11.006

Bouman, A., Jan Heineman, M., \& Faas, M. M. (2005). Sex hormones and the immune response in humans. Human Reproduction Update, 11(4), 411-423. http://doi.org/10.1093/humupd/dmi008

Brand, S. J., Morise, Z., Tagerud, S., Mazzola, L., Granger, D. N., \& Grisham, M. B. (1999). Role of the proteasome in rat indomethacin-induced gastropathy. Gastroenterology, 116(4), 865-73. Retrieved from http://www.ncbi.nlm.nih.gov/pubmed/10092308

Brantl, S. A., Khandoga, A. L., \& Siess, W. (2014). Mechanism of platelet activation induced by endocannabinoids in blood and plasma. Platelets, 25(3), 151-61. http://doi.org/10.3109/09537104.2013.803530

Burdyga, G., Lal, S., Varro, A., Dimaline, R., Thompson, D., \& Dockray, G. J. (2004). Expression of Cannabinoid CB1 Receptors by Vagal Afferent Neurons Is Inhibited by Cholecystokinin. Journal of Neuroscience, 24(11), 2708-2715. http://doi.org/10.1523/JNEUROSCI.5404-03.2004

Burgos-Ramos, E., Martos-Moreno, G. Á., Argente, J., \& Barrios, V. (2012). Multiplexed Bead Immunoassays : Advantages and Limitations in Pediatrics, Advances in Immunoassay Technology. Advances in Immunoassay Technology.

Cai, K. C., Mil, S. van, Murray, E., Mallet, J.-F., Matar, C., \& Ismail, N. (2016). Age and sex differences in immune response following LPS treatment in mice. Brain, Behavior, and Immunity. http://doi.org/10.1016/j.bbi.2016.08.002

Carrier, E. J., Patel, S., \& Hillard, C. J. (2005). Endocannabinoids in neuroimmunology and stress. Curr Drug Targets CNS Neurol Disord, 4, 657-665.

Choukèr, A., Kaufmann, I., Kreth, S., Hauer, D., Feuerecker, M., Thieme, D., ... Schelling, G. (2010). Motion sickness, stress and the endocannabinoid system. PLoS ONE, 5(5), 1-7. http://doi.org/10.1371/journal.pone.0010752

Cisneros, J. a, Björklund, E., González-Gil, I., Hu, Y., Canales, A., Medrano, F. J., ... López- 


\section{ENDOCANNABINOID MODULATION OF GASTROPATHY}

Rodríguez, M. L. (2012). Structure-activity relationship of a new series of reversible dual monoacylglycerol lipase/fatty acid amide hydrolase inhibitors. Journal of Medicinal Chemistry, 55(2), 824-36. http://doi.org/10.1021/jm201327p

Coruzzi, G., Adami, M., Coppelli, G., Frati, P., \& Soldani, G. (1999). Inhibitory effect of the cannabinoid receptor agonist WIN 55,212-2 on pentagastrin-induced gastric acid secretion in the anaesthetized rat. Naunyn-Schmiedeberg's Archives of Pharmacology, 360(6), 715-8. Retrieved from http://www.ncbi.nlm.nih.gov/pubmed/10619190

Coruzzi, G., Adami, M., Guaita, E., Menozzi, A., Bertini, S., Giovannini, E., \& Soldani, G. (2006). Effects of cannabinoid receptor agonists on rat gastric acid secretion: discrepancy between in vitro and in vivo data. Digestive Diseases and Sciences, 51(2), 310-7. http://doi.org/10.1007/s10620-006-3130-2

Costa, M., Brookes, S. J., \& Hennig, G. W. (2000). Anatomy and physiology of the enteric nervous system. Gut, 47(Suppl IV), iv15-19. http://doi.org/10.1136/gut.47.suppl_4.iv15

Crowe, M. S., Leishman, E., Banks, M. L., Gujjar, R., Mahadevan, A., Bradshaw, H. B., \& Kinsey, S. G. (2015). Combined inhibition of monoacylglycerol lipase and cyclooxygenases synergistically reduces neuropathic pain in mice. British Journal of Pharmacology, 172(7), 1700-1712. http://doi.org/10.1111/bph.13012

Crowe, M. S., Pink, M., Peluso, S., \& Kinsey, S. G. (2016). Analgesic and anti-inflammatory effects of a reversible monoacylglycerol lipase inhibitor.

Darling, R. L., Romero, J. J., Dial, E. J., Akunda, J. K., Langenbach, R., \& Lichtenberger, L. M. (2004). The effects of aspirin on gastric mucosal integrity, surface hydrophobicity, and prostaglandin metabolism in cyclooxygenase knockout mice. Gastroenterology, 127(1), 94104. http://doi.org/10.1053/j.gastro.2004.04.003

Darnall, B. D., \& Suarez, E. C. (2009). Sex and gender in psychoneuroimmunology research: Past, present and future. Brain, Behavior, and Immunity, 23(5), 595-604. http://doi.org/10.1016/j.bbi.2009.02.019

De Waal Malefyt, R., Abrams, J., Bennett, B., Figdor, C. G., \& Vries, J. E. De. (1991). Interleukin 10 (IL-10) inhibits cytokine synthesis by human monocytes: An autoregulatory role of IL-10 produced by monocytes. J Exp Med, 174, 1209-1220.

Devi, R. S., Narayan, S., Vani, G., Srinivasan, P., Mohan, K. V., Sabitha, K. E., \& Devi, C. S. S. (2007). Ulcer protective effect of Terminalia arjuna on gastric mucosal defensive mechanism in experimental rats. Phytotherapy Research, 21, 762-767. http://doi.org/10.1002/ptr.2160

Di Marzo, V., Capasso, R., Matias, I., Aviello, G., Petrosino, S., Borrelli, F., ... Izzo, A. A. (2008). The role of endocannabinoids in the regulation of gastric emptying: alterations in mice fed a high-fat diet. British Journal of Pharmacology, 153(6), 1272-1280. http://doi.org/10.1038/sj.bjp.0707682

Di Sabatino, A., Battista, N., Biancheri, P., Rapino, C., Rovedatti, L., Astarita, G., ... Corazza, G. R. (2011). The endogenous cannabinoid system in the gut of patients with inflammatory bowel disease. Mucosal Immunology, 4(5), 574-583. http://doi.org/10.1038/mi.2011.18 


\section{ENDOCANNABINOID MODULATION OF GASTROPATHY}

Dimaline, R., \& Varro, A. (2007). Attack and defence in the gastric epithelium - a delicate balance. Experimental Physiology, 92(4), 591-601.

http://doi.org/10.1113/expphysiol.2006.036483

DiPatrizio, N. V. (2016). Endocannabinoids in the Gut. Cannabis and Cannabinoid Research, 1(1), 67-77. http://doi.org/10.1089/can.2016.0001

Dong, M., Lu, Y., Zou, Z., \& Yang, H. (2015). Monoacylglycerol lipase inhibitor protects primary cultured neurons against homocysteine-induced impairments in rat caudate nucleus through COX-2 signaling. Life Sciences, 138, 64-71. http://doi.org/10.1016/j.lfs.2015.03.006

Duncan, M., Thomas, A. D., Cluny, N. L., Patel, A., Patel, K. D., Lutz, B., ... Sharkey, K. A. (2008). Distribution and function of monoacylglycerol lipase in the gastrointestinal tract. American Journal of Physiology. Gastrointestinal and Liver Physiology, 295(6), G1255-65. http://doi.org/10.1152/ajpgi.90500.2008

Ermund, A., Schütte, A., Johansson, M. E. V, Gustafsson, J. K., Hansson, G. C., \& Schuette, A. (2013). Gastrointestinal mucus layers have different properties depending on location - 1. Studies of mucus in mouse stomach, small intestine, Peyer's patches and colon. American Journal of Physiology. Gastrointestinal and Liver Physiology, 305(5), ajpgi.00046.2013-. http://doi.org/10.1152/ajpgi.00046.2013

Esfandyari, T., Camilleri, M., Ferber, I., Burton, D., Baxter, K., \& Zinsmeister, A. R. (2006). Effect of a cannabinoid agonist on gastrointestinal transit and postprandial satiation in healthy human subjects: A randomized, placebo-controlled study. Neurogastroenterology and Motility, 18(9), 831-838. http://doi.org/10.1111/j.1365-2982.2006.00834.x

FitzGerald, G. A., \& Patrono, C. (2001). The coxibs, selective inhibitors of cyclooxygenase-2. $N$ Engl J Med, 345(6), 433-442. Journal Article. http://doi.org/10.1056/NEJM200108093450607

Fitzpatrick, F. A. (2004). Cyclooxygenase enzymes: Regulation and function. Current Pharmaceutical Design, 10(6), 577-588.

Fuchs, K. H., DeMeester, T. R., Hinder, R. A., Stein, H. J., Barlow, A. P., \& Gupta, N. C. (1991). Computerized identification of pathologic duodenogastric reflux using 24-hour gastric $\mathrm{pH}$ monitoring. Annals of Surgery, 213(1), 13-20. Retrieved from http://www.pubmedcentral.nih.gov/articlerender.fcgi?artid=1358304\&tool=pmcentrez\&ren dertype $=$ abstract

Gaskins, H. R. (1999). Developmental Microbial Ecology of the Neonata GIT. The American Journal of Clinical Nutrition, 69, 1035S-1045S.

Ghosh, S., Wise, L. E., Chen, Y., Gujjar, R., Mahadevan, A., Cravatt, B. F., \& Lichtman, A. H. (2013). The monoacylglycerol lipase inhibitor JZL184 suppresses inflammatory pain in the mouse carrageenan model. Life Sciences, 92(8-9), 498-505. http://doi.org/10.1016/j.lfs.2012.06.020

Goyal, R. K., \& Hirano, I. (1996). The enteric nervous system. The New England Journal of Medicine, 334(17), 1106-1116. 


\section{ENDOCANNABINOID MODULATION OF GASTROPATHY}

Granger, D. N., \& Kubes. (1994). The microcirculation and inflammation: modulation of leukocyte-endothelial cell adhesion. Journal of Leukocyte Biology, 55(May), 662-675.

Grim, T. W., Ghosh, S., Hsu, K.-L., Cravatt, B. F., Kinsey, S. G., \& Lichtman, A. H. (2014). Combined inhibition of FAAH and COX produces enhanced anti-allodynic effects in mouse neuropathic and inflammatory pain models. Pharmacology, Biochemistry, and Behavior, 124, 405-11. http://doi.org/10.1016/j.pbb.2014.07.008

Guindon, J., Guijarro, A., Piomelli, D., \& Hohmann, A. G. (2011). Peripheral antinociceptive effects of inhibitors of monoacylglycerol lipase in a rat model of inflammatory pain. British Journal of Pharmacology, 163(7), 1464-78. http://doi.org/10.1111/j.14765381.2010.01192.x

Guindon, J., Walczak, J. S., \& Beaulieu, P. (2007). Recent advances in the pharmacological management of pain. Drugs, 67(15), 2121-2133. Journal Article. Retrieved from http://www.ncbi.nlm.nih.gov/pubmed/17927280

Gyires, K., Rónai, A. Z., Zádori, Z. S., Tóth, V. E., Németh, J., Szekeres, M., \& Hunyady, L. (2014). Angiotensin II-induced activation of central AT1 receptors exerts endocannabinoidmediated gastroprotective effect in rats. Molecular and Cellular Endocrinology, 382(2), 971-8. http://doi.org/10.1016/j.mce.2013.10.002

Head, C. C., Farrow, M. J., Sheridan, J. F., \& Padgett, D. A. (2006). Androstenediol reduces the anti-inflammatory effects of restraint stress during wound healing. Brain, Behavior, and Immunity, 20(6), 590-596. http://doi.org/10.1016/j.bbi.2006.03.007

Hecken, A. Van, Depre, M., Lepeleire, I. De, Dallob, A., Tanaka, W., Wynants, K., ... Arnout, J. (2000). Comparative inhibitory activity of rofecoxib, meloxicam, diclofenac, ibuprofen, and naproxen on COX-2 versus COX-1 in healthy volunteers. The Journal of Clinical Pharmacology, 40(1), 1109-1120.

Ignatowska-Jankowska, B. M., Ghosh, S., Crowe, M. S., Kinsey, S. G., Niphakis, M. J., Abdullah, R. A., ... Lichtman, a H. (2014). In vivo characterization of the highly selective monoacylglycerol lipase inhibitor KML29: antinociceptive activity without cannabimimetic side effects. British Journal of Pharmacology, 171(6), 1392-407. http://doi.org/10.1111/bph.12298

Izzo, A. A., Mascolo, N., \& Capasso, F. (2001). The gastrointestinal pharmacology of cannabinoids. Current Opinion in Pharmacology, 1(6), 597-603. Retrieved from http://www.ncbi.nlm.nih.gov/pubmed/11757815

Izzo, A. A., \& Sharkey, K. A. (2010). Cannabinoids and the gut: new developments and emerging concepts. Pharmacology \& Therapeutics, 126(1), 21-38. http://doi.org/10.1016/j.pharmthera.2009.12.005

Izzo, Mascolo, N., Borrelli, F., \& Capasso, F. (1999). Defaecation, intestinal fluid accumulation and motility in rodents: implications of cannabinoid CB1 receptors. NaunynSchmiedeberg's Archives of Pharmacology, 359(1), 65-70. http://doi.org/10.1007/PL00005325

Kamada, T., Hata, J., Kusunoki, H., Sugiu, K., Tanimoto, T., Mihara, M., ... Haruma, K. (2006). Endoscopic characteristics and Helicobacter pylori infection in NSAID-associated gastric 


\section{ENDOCANNABINOID MODULATION OF GASTROPATHY}

ulcer. Journal of Gastroenterology and Hepatology (Australia), 21(1 PART1), 98-102. http://doi.org/10.1111/j.1440-1746.2005.04219.x

Kato, S., Aihara, E., Yoshii, K., \& Takeuchi, K. (2005). Dual action of prostaglandin E2 on gastric acid secretion through different EP-receptor subtypes in the rat. American Journal of Physiology. Gastrointestinal and Liver Physiology, 289(1), G64-9. http://doi.org/10.1152/ajpgi.00397.2004

Khan, M. I., \& Khan, M. R. (2013). Gastroprotective Potential of Dalbergia sissoo Roxb. Stem Bark against Diclofenac-Induced Gastric Damage in Rats. Osong Public Health and Research Perspectives, 4(5), 271-277. http://doi.org/10.1016/j.phrp.2013.09.006

Kiecolt-Glaser, J. K. K., Marucha, P. T. T., Mercado, A. M. M., Malarkey, W. B. B., \& Glaser, R. (1995). Slowing of wound healing by psychological stress. The Lancet, 346(8984), 1194-1196. http://doi.org/10.1016/S0140-6736(95)92899-5

Kingsmore, S. F. (2006). Multiplexed protein measurement: technologies and applications of protein and antibody arrays. Nat Rev Drug Discov, 5(4), 310-320.

Kinsey, S. G., \& Cole, E. C. (2013). Acute $\Delta(9)$-tetrahydrocannabinol blocks gastric hemorrhages induced by the nonsteroidal anti-inflammatory drug diclofenac sodium in mice. European Journal of Pharmacology, 715(1-3), 111-6. http://doi.org/10.1016/j.ejphar.2013.06.001

Kinsey, S. G., Long, J. Z., O’Neal, S. T., Abdullah, R. A., Poklis, J. L., Boger, D. L., ... Lichtman, A. H. (2009). Blockade of endocannabinoid-degrading enzymes attenuates neuropathic pain. The Journal of Pharmacology and Experimental Therapeutics, 330(3), 902-10. http://doi.org/10.1124/jpet.109.155465

Kinsey, S. G., Nomura, D., O’Neal, S., Long, J. Z., Mahadevan, A., Cravatt, B., ... Lichtman, A. H. (2011). Inhibition of monoacylglycerol lipase attenuates nonsteroidal anti-inflammatory drug-induced gastric hemorrhages in mice. J Pharmacol Exp Ther, 338(3), 795-802. Journal Article. http://doi.org/10.1124/jpet.110.175778

Kinsey, S. G., Wise, L. E., Ramesh, D., Abdullah, R. A., Selley, D. E., Cravatt, B. F., \& Lichtman, A. H. (2013). Repeated low-dose administration of the monoacylglycerol lipase inhibitor JZL184 retains cannabinoid receptor type 1-mediated antinociceptive and gastroprotective effects. The Journal of Pharmacology and Experimental Therapeutics, 345(3), 492-501. http://doi.org/10.1124/jpet.112.201426

Klein, T. W. (2005). Cannabinoid-based drugs as anti-inflammatory therapeutics. Nature Reviews. Immunology, 5(5), 400-11. http://doi.org/10.1038/nri1602

Kocer, B., Surmeli, S., Solak, C., Unal, B., Bozkurt, B., Yildirim, O., ... Cengiz, O. (2007). Factors affecting mortality and morbidity in patients with peptic ulcer perforation. Journal of Gastroenterology and Hepatology, 22(4), 565-570. http://doi.org/10.1111/j.14401746.2006.04500.x

Kogan, N. M., \& Mechoulam, R. (2007). Cannabinoids in health and disease. Dialogues Clin Neurosci, 9(4), 413-430. Journal Article. Retrieved from http://www.ncbi.nlm.nih.gov/pubmed/18286801 


\section{ENDOCANNABINOID MODULATION OF GASTROPATHY}

Krowicki, Z., Moerschbaecher, J. M., Winsauer, P. J., Digavalli, S. V, \& Hornby, P. J. (1999). Delta9-tetrahydrocannabinol inhibits gastric motility in the rat through cannabinoid CB1 receptors. European Journal of Pharmacology, 371, 187-196.

Kuller, L. H. (2016). Do Proton Pump Inhibitors Increase the Risk of Dementia? JAMA Neurology, 73(4), 379-381. http://doi.org/10.1001/jamaneurol.2015.4931

Kumar, G., Stendall, C., Mistry, R., Gurusamy, K., \& Walker, D. (2014). A comparison of total intravenous anaesthesia using propofol with sevoflurane or desflurane in ambulatory surgery: Systematic review and meta-analysis. Anaesthesia, 69(10), 1138-1150. http://doi.org/10.1111/anae.12713

Kwiecien, S., Brzozowski, T., \& Konturek, S. J. (2002). Effects of reactive oxygen species action on gastric mucosa in various models of mucosal injury. Journal of Physiology and Pharmacology, 53(1), 39-50.

Laine, L., Harper, S., Simon, T., Bath, R., Johanson, J., Schwartz, H., ... Bolognese, J. (1999). A randomized trial comparing the effect of Rofecoxib, a cyclooxygenase 1-specific inhibitor, with that of ibuprofen on the gastroduodenal mucosa of patients with osteoarthritis. Gastroenterology, 117, 776-783.

Laine, L., Takeuchi, K., \& Tarnawski, A. (2008). Gastric Mucosal Defense and Cytoprotection: Bench to Bedside. Gastroenterology, 135(1), 41-60. http://doi.org/10.1053/j.gastro.2008.05.030

Lal, S., Prasad, N., Ryan, M., Tangri, S., Silverberg, M. S., Gordon, A., \& Steinhart, H. (2011). Cannabis use amongst patients with inflammatory bowel disease. European Journal of Gastroenterology \& Hepatology, 23(10), 891-896. http://doi.org/10.1097/MEG.0b013e328349bb4c

Lanas, A. (2009). Nonsteroidal antiinflammatory drugs and cyclooxygenase inhibition in the gastrointestinal tract: a trip from peptic ulcer to colon cancer. Am J Med Sci, 338(2), 96106. Journal Article. http://doi.org/10.1097/MAJ.0b013e3181ad8cd3

Landi, M., Croci, T., Rinaldi-Carmona, M., Maffrand, J. P., Le Fur, G., \& Manara, L. (2002). Modulation of gastric emptying and gastrointestinal transit in rats through intestinal cannabinoid CB1 receptors. European Journal of Pharmacology, 450(1), 77-83. http://doi.org/10.1016/S0014-2999(02)02053-8

Liu, W., Okajima, K., Murakami, K., Harada, N., Isobe, H., \& Irie, T. (1998). Role of neutrophil elastase in stress-induced gastric mucosal injury in rats. Journal of Laboratory and Clinical Medicine, 132(5), 432-439. http://doi.org/10.1016/S0022-2143(98)90114-7

Lodato, F., Azzaroli, F., Turco, L., Mazzella, N., Buonfiglioli, F., Zoli, M., \& Mazzella, G. (2010). Adverse effects of proton pump inhibitors. Best Practice \& Research. Clinical Gastroenterology, 24(2), 193-201. http://doi.org/10.1016/j.bpg.2009.11.004

Long, J. Z., Li, W., Booker, L., Burston, J. J., Kinsey, S. G., Schlosburg, J. E., ... Cravatt, B. F. (2009). Selective blockade of 2-arachidonoylglycerol hydrolysis produces cannabinoid behavioral effects. Nat Chem Biol, 5(1), 37-44. Journal Article. http://doi.org/10.1038/nchembio.129 


\section{ENDOCANNABINOID MODULATION OF GASTROPATHY}

Long, J. Z., Nomura, D. K., \& Cravatt, B. F. (2009). Characterization of Monoacylglycerol Lipase Inhibition Reveals Differences in Central and Peripheral Endocannabinoid Metabolism. Chemistry and Biology, 16(7), 744-753. http://doi.org/10.1016/j.chembiol.2009.05.009

Loria, V., Dato, I., Graziani, F., \& Biasucci, L. M. (2008). Myeloperoxidase: A new biomarker of inflammation in ischemic heart disease and acute coronary syndromes. Mediators of Inflammation, 2008. http://doi.org/10.1155/2008/135625

Ma, L., Elliott, S. N., Cirino, G., Buret, a, Ignarro, L. J., \& Wallace, J. L. (2001). Platelets modulate gastric ulcer healing: role of endostatin and vascular endothelial growth factor release. Proceedings of the National Academy of Sciences of the United States of America, 98(11), 6470-6475. http://doi.org/10.1073/pnas.111150798

Maccarrone, M., Bab, I., Bíró, T., Cabral, G. A., Dey, S. K., Di Marzo, V., ... Zimmer, A. (2015). Endocannabinoid signaling at the periphery: 50 years after THC. Trends in Pharmacological Sciences, 36(5), 277-296. http://doi.org/10.1016/j.tips.2015.02.008

Marquez, L., Suarez, J., Iglesias, M., Bermudez-Silva, F. J., de Fonseca, F. R., \& Andreu, M. (2009). Ulcerative colitis induces changes on the expression of the endocannabinoid system in the human colonic tissue. PLoS ONE, 4(9). http://doi.org/10.1371/journal.pone.0006893

Martin, G. R., \& Wallace, J. L. (2006). Gastrointestinal Inflammation : A Central Component of Mucosal Defense and Repair. Experimental Biology and Medicine.

Martinez, V., Curi, A. P., Torkian, B., Schaeffer, J. M., Wilkinson, H. A., Walsh, J. H., \& Tache, Y. (1998). High Basal Gastric Acid Secretion in Somatostatin Receptor. Gastroenterology, 114, 1125-1132.

Massa, F., Marsicano, G., Hermana, H., Cannich, A., Monory, K., Cravatt, B. F., ... Lutz, B. (2004). The endogenous cannabinoid system protects against colonic inflammation. Journal of Clinical Investigation, 113(8), 1202-1209. http://doi.org/10.1172/JCI200419465

McCallum, R. W., Soykan, I., Sridhar, K. R., Ricci, D. A., Lange, R. C., \& Plankey, M. W. (1999). Delta-9-tetrahydrocannabinol delays the gastric emptying of solid food in humans: A double-blind, randomized study. Alimentary Pharmacology and Therapeutics, 13(1), 7780. http://doi.org/10.1046/j.1365-2036.1999.00441.x

McMenamin, C. A., Travagli, R. A., \& Browning, K. N. (2016). Inhibitory neurotransmission regulates vagal efferent activity and gastric motility. Experimental Biology and Medicine, 241(12), 1343-1350. http://doi.org/10.1177/1535370216654228

Mersereau, W. A., \& Hinchey, E. J. (1982). Prevention of phenylbutazone ulcer in the rat by glucose: Role of a glycoprivic receptor system. Am J Physiol Gastrointest Liver Physiol, 242, G429-G432.

Mössner, J. (2016). The indications, applications, and risks of proton pump inhibitors - a review after 25 years. Deutsches Ärzteblatt International, 113, 477-483. http://doi.org/10.3238/arztebl.2016.0477

Motilva, V., Alarcón De La Lastra, C., Bruseghini, L., Manuel Herrerias, J., \& Sánchez-Fidalgo, S. (2005). COX expression and PGE2 and PGD2 production in experimental acute and 


\section{ENDOCANNABINOID MODULATION OF GASTROPATHY}

chronic gastric lesions. International Immunopharmacology, 5(2), 369-379. http://doi.org/10.1016/j.intimp.2004.10.005

Musumba, C., Pritchard, D. M., \& Pirmohamed, M. (2009). Review article: cellular and molecular mechanisms of NSAID-induced peptic ulcers. Aliment Pharmacol Ther, 30(6), 517-531. Journal Article. http://doi.org/10.1111/j.1365-2036.2009.04086.x

Naftali, T., Bar-Lev Schleider, L., Dotan, I., Lansky, E. P., Sklerovsky Benjaminov, F., \& Konikoff, F. M. (2013). Cannabis induces a clinical response in patients with crohn's disease: A prospective placebo-controlled study. Clinical Gastroenterology and Hepatology, 11(10), 1276-1280.e1. http://doi.org/10.1016/j.cgh.2013.04.034

Naftali, T., Mechulam, R., Lev, L. B., \& Konikoff, F. M. (2014). Cannabis for inflammatory bowel disease. Digestive Diseases, 32(4), 468-474. http://doi.org/10.1159/000358155

Naidu, P. S., Booker, L., Cravatt, B. F., \& Lichtman, A. H. (2009). Synergy between enzyme inhibitors of fatty acid amide hydrolase and cyclooxygenase in visceral nociception. $J$ Pharmacol Exp Ther, 329(1), 48-56. Journal Article. http://doi.org/10.1124/jpet.108.143487

Nakamura, Y., Murai, T., \& Ogawa, Y. (1996). Effect of in vitro and in vivo administration of dexamethasone on rat macrophage functions: comparison between alveolar and peritoneal macrophages. European Respiratory Journal, 9(2), 301-306. http://doi.org/10.1183/09031936.96.09020301

Nalin, D. R., Levine, M. M., Rhead, J., Bergquist, E., Rennels, M., Hughes, T., ... Hornick, R. B. (1978). Cannabis, Hypochlorhydira, and Cholera. Lancet, 2, 859-862.

Nishio, H., Terashima, S., Nakashima, M., Aihara, E., \& Takeuchi, K. (2007). Involvement of prostaglandin E receptor EP3 subtype and prostacyclin ip receptor in decreased acid response in damaged stomach. Journal of Physiology and Pharmacology, 58(3), 407-421.

Nomura, D. K., Long, J. Z., Niessen, S., Hoover, H. S., Ng, S. W., \& Cravatt, B. F. (2010). Monoacylglycerol Lipase Regulates a Fatty Acid Network that Promotes Cancer Pathogenesis. Cell, 140(1), 49-61. http://doi.org/10.1016/j.cell.2009.11.027

Nomura, D. K., Morrison, B. E., Blankman, J. L., Long, J. Z., Kinsey, S. G., Marcondes, M. C. G., ... Cravatt, B. F. (2011). Endocannabinoid hydrolysis generates brain prostaglandins that promote neuroinflammation. Science (New York, N.Y.), 334(6057), 809-13. http://doi.org/10.1126/science.1209200

Orbach, H., \& Shoenfeld, Y. (2007). Hyperprolactinemia and autoimmune diseases. Autoimmunity Reviews, 6(8), 537-542. http://doi.org/10.1016/j.autrev.2006.10.005

Padgett, D. a, Marucha, P. T., \& Sheridan, J. F. (1998). Restraint stress slows cutaneous wound healing in mice. Brain, Behavior, and Immunity, 12(1), 64-73. http://doi.org/10.1006/brbi.1997.0512

Patrono, C., \& Baigent, C. (2009). Low-Dose Aspirin, Coxibs, and other NSAIDs: A Clinical Mosaic Emerges. Molecular Interventions, 9(1), 31-39.

Pazos, M. R., Tolón, R. M., Benito, C., Rodríguez, C. F., Gorgojo, J. J., Nevado, M., ... Romero, J. (2008). Cannabinoid CB1 receptors are expressed by parietal cells of the human gastric 


\section{ENDOCANNABINOID MODULATION OF GASTROPATHY}

mucosa. The Journal of Histochemistry and Cytochemistry, 56(5), 511-6. http://doi.org/10.1369/jhc.2008.950741

Pinto, L., Izzo, A. A., Cascio, M. G., Bisogno, T., HospodarScott, K., Brown, D. R., ... Capasso, F. (2002). Endocannabinoids as physiological regulators of colonic propulsion in mice. Gastroenterology, 123(1), 227-234. http://doi.org/10.1053/gast.2002.34242

Playford, R. J., \& Ghosh, S. (2005). Cytokines and growth factor modulators in intestinal inflammation and repair. The Journal of Pathology, 205(4), 417-25. http://doi.org/10.1002/path.1722

Pohle, T., Brzozowski, T., Becker, J. C., Van Der Voort, I. R., Markmann, A., Konturek, S. J., ... Konturek, J. W. (2001). Role of reactive oxygen metabolites in aspirin-induced gastric damage in humans: Gastroprotection by vitamin C. Alimentary Pharmacology and Therapeutics, 15(5), 677-687. http://doi.org/10.1046/j.1365-2036.2001.00975.x

Raffa, R. B. (2001). Pharmacology of oral combination analgesics: rational therapy for pain. $J$ Clin Pharm Ther, 26(4), 257-264. Journal Article. Retrieved from http://www.ncbi.nlm.nih.gov/pubmed/11493367

Reuter, B., Davies, N., \& Wallace, J. L. (1997). Nonsteroidal anti-inflammatory drug enteropathy in rats: Role of permeability, bacteria, and enterohepatic circulation. Gastroenterology, 112(1), 109-117. http://doi.org/10.1016/S0016-5085(97)70225-7

Rodriguez-Stanley, S., Redinger, N., \& Miner, P. B. (2006). Effect of naproxen on gastric acid secretion and gastric pH. Alimentary Pharmacology and Therapeutics, 23(February), 17191724. http://doi.org/10.1111/j.1365-2036.2006.02897.x

Roncarolo, M. G., Gregori, S., Battaglia, M., Bacchetta, R., Fleischhauer, K., \& Levings, M. K. (2006). Interleukin-10-secreting type 1 regulatory T cells in rodents and humans. Immunological Reviews, 212(1), 28-50. http://doi.org/10.1111/j.0105-2896.2006.00420.x

Rostom, A., Dube, C., Ga, W., Tugwell, P., Welch, V., Jolicoeur, E., ... Lanas, A. (2011). Prevention of NSAID-induced gastroduodenal ulcers. Cochrane Database of Systematic Reviews, (6), 1-62. http://doi.org/10.1002/14651858.CD002296

Rouzer, C. A., \& Marnett, L. J. (2009). Cyclooxygenases: structural and functional insights. $J$ Lipid Res, 50 Suppl, S29-34. Journal Article. http://doi.org/10.1194/jlr.R800042-JLR200

Salgado, R., Benoy, I., Bogers, J., Weytjens, R., Vermeulen, P., Dirix, L., \& Marck, E. Van. (2001). Platelets and vascular endothelial growth factor (VEGF): A morphological and functional study. Angiogenesis, 4, 37-43.

Salvatella, M. A., Rossi, I., Del Valle, J. C., Gutierrez, Y., Pereda, C., Samper, B., \& Feliu, J. E. (2004). Inhibition of acid secretion by the nonsteroidal anti-inflammatory drugs diclofenac and piroxicam in isolated gastric glands: analysis of a multifocal mechanism. American Journal of Physiology-Gastrointestinal and Liver Physiology, 286(5), G711-G721. http://doi.org/10.1152/ajpgi.00305.2003

Samuelsson, B., Morgenstern, R., \& Jakobsson, P.-J. (2007). Membrane prostaglandin E synthase-1: a novel therapeutic target. Pharmacological Reviews, 59(3), 207-224. http://doi.org/10.1124/pr.59.3.1 


\section{ENDOCANNABINOID MODULATION OF GASTROPATHY}

Sasso, O., Bertorelli, R., Bandiera, T., Scarpelli, R., Colombano, G., Armirotti, A., ... Piomelli, D. (2012). Peripheral FAAH inhibition causes profound antinociception and protects against indomethacin-induced gastric lesions. Pharmacol Res, 65(5), 553-563. Journal Article. http://doi.org/10.1016/j.phrs.2012.02.012

Scarpelli, R., Sasso, O., \& Piomelli, D. (2015). A Double Whammy: Targeting Both Fatty Acid Amide Hydrolase (FAAH) and Cyclooxygenase (COX) To Treat Pain and Inflammation. ChemMedChem, 4625, 1-11. http://doi.org/10.1002/cmdc.201500395

Schlosburg, J. E., Blankman, J. L., Long, J. Z., Nomura, D. K., Pan, B., Kinsey, S. G., ... Cravatt, B. F. (2010). Chronic monoacylglycerol lipase blockade causes functional antagonism of the endocannabinoid system. Nature Neuroscience, 13(9), 1113-1119. Journal Article. http://doi.org/10.1038/nn.2616

Schubert, M. L. (2008). Hormonal Regulation of Gastric Acid Secretion. Current Gastroenterology Reports, 10, 523-527.

Schubert, M. L., \& Peura, D. a. (2008). Control of gastric acid secretion in health and disease. Gastroenterology, 134(7), 1842-60. http://doi.org/10.1053/j.gastro.2008.05.021

Shujaa, N., Zadori, Z. S., Ronai, A. Z., Barna, I., Mergl, Z., Mozes, M. M., \& Gyires, K. (2009). Analysis of the effect of neuropeptides and cannabinoids in gastric mucosal defense intitiated centrally in the rat. Journal of Physiology and Pharmacology, (8), 93-100.

Silvestri, C., \& Di Marzo, V. (2013). The endocannabinoid system in energy homeostasis and the etiopathology of metabolic disorders. Cell Metabolism, 17(4), 475-90. http://doi.org/10.1016/j.cmet.2013.03.001

Singh, J., Petter, R. C., Baillie, T. a, \& Whitty, A. (2011). The resurgence of covalent drugs. Nature Reviews. Drug Discovery, 10(4), 307-317. http://doi.org/10.1038/nrd3410

Sinn, D. H., Min, B.-H., Ko, E., Lee, J. Y., Kim, J. J., Rhee, J. C., ... Rhee, P.-L. (2010). Regional differences of the effects of acetylcholine in the human gastric circular muscle. American Journal of Physiology. Gastrointestinal and Liver Physiology, 299(5), G1198G1203. http://doi.org/10.1152/ajpgi.00523.2009

Smecuol, E., Bai, J. C., Sugai, E., Vazquez, H., Niveloni, S., Pedreira, S., ... Meddings, J. (2001). Acute gastrointestinal permeability responses to different non-steroidal antiinflammatory drugs. Gut, 49(5), 650-655. http://doi.org/10.1136/gut.49.5.650

Smith, W. L., Garavito, R. M., \& Dewitt, D. L. (1996). Prostaglandin endoperoxide H synthase (cyclooxygenases) - 1 and -2. The Journal of Biological Chemistry, 271(52), 33157-33160.

Sofia, R. D., Diamantis, W., Harrison, J. E., \& Melton, J. (1978). Evaluation of antiulcer activity of [delta]9-tetrahydrocannabinol in the Shay rat test. Pharmacology, 17(3), 173-177.

Sticht, M. A., Rock, E. M., Limebeer, C. L., \& Parker, L. A. (2015). Endocannabinoid Mechanisms Influencing Nausea. International Review of Neurobiology (1st ed., Vol. 125). Elsevier Inc. http://doi.org/10.1016/bs.irn.2015.09.001

Sung, J. J. Y., Tsoi, K. K. F., Ma, T. K. W., Yung, M.-Y., Lau, J. Y. W., \& Chiu, P. W. Y. (2010). Causes of mortality in patients with peptic ulcer bleeding: a prospective cohort study of 10,428 cases. The American Journal of Gastroenterology, 105(1), 84-89. 


\section{ENDOCANNABINOID MODULATION OF GASTROPATHY}

http://doi.org/10.1038/ajg.2009.507

Takahashi, S. (2011). Vascular endothelial growth factor (VEGF), VEGF receptors and their inhibitors for antiangiogenic tumor therapy. Biol Pharm Bull, 34(12), 1785-1788. http://doi.org/10.1248/bpb.34.1785

Takeuchi, K. (2012). Pathogenesis of NSAID-induced gastric damage: importance of cyclooxygenase inhibition and gastric hypermotility. World Journal of Gastroenterology : WJG, 18(18), 2147-2160. http://doi.org/10.3748/wjg.v18.i18.2147

Takeuchi, K., Ueki, S., \& Okabe, S. (1986). Importance of gastric motility in the pathogenesis of indomethacin-induced gastric lesions in rats. Digestive Diseases and Sciences, 31, 11141122.

Takezono, Y., Joh, T., Oshima, T., Suzuki, H., Seno, K., Yokoyama, Y., ... Itoh, M. (2004). Role of prostaglandins in maintaining gastric mucuscell permeability against acid exposure. Journal of Laboratory and Clinical Medicine, 143(1), 52-58. http://doi.org/10.1016/j.lab.2003.09.004

Tanaka, A., Araki, H., Hase, S., Komoike, Y., Takeuchi, K., \& Komoike, Y. (2002). Upregulation of COX-2 by inhibition of COX-1 in the rat: a key to NSAID-induced gastric injury. Aliment Pharmacology Therapy, 16(2), 90-101. http://doi.org/10.1046/j.13652036.16.s2.22.x

Tanaka, A., Araki, H., Komoike, Y., Hase, S., \& Takeuchi, K. (2001). Inhibition of both COX-1 and COX-2 is required for development of gastric damage in response to nonsteroidal antiinflammatory drugs. Journal of Physiology Paris, 95(1-6), 21-27. http://doi.org/10.1016/S0928-4257(01)00005-5

Tang, E. H. C., Libby, P., Vanhoutte, P. M., \& Xu, A. (2012). Anti-inflammation therapy by activation of prostaglandin EP4 receptor in cardiovascular and other inflammatory diseases. Journal of Cardiovascular Pharmacology, 59(2), 116-23. http://doi.org/10.1097/FJC.0b013e3182244a12

Trevethick, M. A., Bahl, A. K., Clayton, N. M., Strong, P., Sanjar, S., \& Harman, I. W. (1994). Neutrophil infiltration does not contribute to the ulcerogenic effects of indomethacin in the rat gastric antrum. Agents Actions, 43, 39-43.

Tuccinardi, T., Granchi, C., Rizzolio, F., Caligiuri, I., Battistello, V., Toffoli, G., ... Martinelli, A. (2014). Identification and characterization of a new reversible MAGL inhibitor. Bioorganic \& Medicinal Chemistry, 22(13), 3285-91. http://doi.org/10.1016/j.bmc.2014.04.057

Turner, P. V, Brabb, T., Pekow, C., \& Vasbinder, M. a. (2011). Administration of substances to laboratory animals: routes of administration and factors to consider. $J$ Am Assoc Lab Anim Sci, 50(5), 600-613. Retrieved from http://www.ncbi.nlm.nih.gov/pubmed/22330705

Van Gaal, L., Pi-Sunyer, X., Despres, J. P., McCarthy, C., \& Scheen, A. (2008). Efficacy and safety of rimonabant for improvement of multiple cardiometabolic risk factors in overweight/obese patients: pooled 1-year data from the Rimonabant in Obesity (RIO) program. Diabetes Care, 31 Suppl 2, S229-S240. http://doi.org/10.2337/dc08-s258 


\section{ENDOCANNABINOID MODULATION OF GASTROPATHY}

Vandevoorde, S., Jonsson, K.-O. O., Labar, G., Persson, E., Lambert, D. M., \& Fowler, C. J. (2007). Lack of selectivity of URB602 for 2-oleoylglycerol compared to anandamide hydrolysis in vitro. British Journal of Pharmacology, 150(2), 186-91. http://doi.org/10.1038/sj.bjp.0706971

Vane, J. R. (1971). Inhibition of Prostaglandin Synthesis as a Mechanism of Action for Aspirinlike Drugs. Nature, 231(25), 232-235. http://doi.org/10.1038/10.1038/newbio231232a0

Vane, J. R., \& Botting, R. (1998). Mechanism of action of nonsteroidal anti-inflammatory drugs. The American Journal of Medicine, 104(3A), 2S-8S.

Wallace, J. L. (1989). Gastric resistance to acid: is the "mucus-bicarbonate barrier" functionally redundant? The American Journal of Physiology, 256(1 Pt 1), G31-8.

Wallace, J. L. (2001). Pathogenesis of NSAID-induced gastroduodenal mucosal injury. Best Practice \& Research. Clinical Gastroenterology, 15(5), 691-703. http://doi.org/10.1053/bega.2001.0229

Wallace, J. L. (2008). Prostaglandins, NSAIDs , and Gastric Mucosal Protection: Why Doesn't the Stomach Digest Itself? Physiological Reviews, 88, 1547-1565. http://doi.org/10.1152/physrev.00004.2008.

Wallace, J. L. (2013). Mechanisms, prevention and clinical implications of nonsteroidal antiinflammatory drug-enteropathy. World Journal of Gastroenterology : WJG, 19(12), 186176. http://doi.org/10.3748/wjg.v19.i12.1861

Wallace, J. L., Caliendo, G., Santagada, V., Cirino, G., \& Fiorucci, S. (2007). Gastrointestinal Safety and Anti-Inflammatory Effects of a Hydrogen Sulfide-Releasing Diclofenac Derivative in the Rat. Gastroenterology, 132(1), 261-271. http://doi.org/10.1053/j.gastro.2006.11.042

Wallace, J. L., Keenan, C. M., \& Granger, D. N. (1990). Gastric ulceration induced by nonsteroidal anti-inflammatory drugs is a neutrophil-dependent process. The American Journal of Physiology, 259(3 Pt 1), G462-7. Retrieved from http://www.ncbi.nlm.nih.gov/pubmed/2169206

Wallace, J. L., \& Vong, L. (2008). NSAID-induced gastrointestinal damage and the design of GI-sparing NSAIDs. Current Opinion in Investigational Drugs (London, England : 2000), 9(11), 1151-1156.

Wright, K., Rooney, N., Feeney, M., Tate, J., Robertson, D., Welham, M., \& Ward, S. (2005). Differential Expression of Cannabinoid Receptors in the Human Colon: Cannabinoids Promote Epithelial Wound Healing. Gastroenterology, 129(2), 437-453. http://doi.org/10.1053/j.gastro.2005.05.026

Yano, S., Akahane, M., \& Harada, M. A. (1978). Role of gastric motility in development of stress-induced gastric lesions of rats. Japanese Journal of Pharmacology, 28, 607-615. 


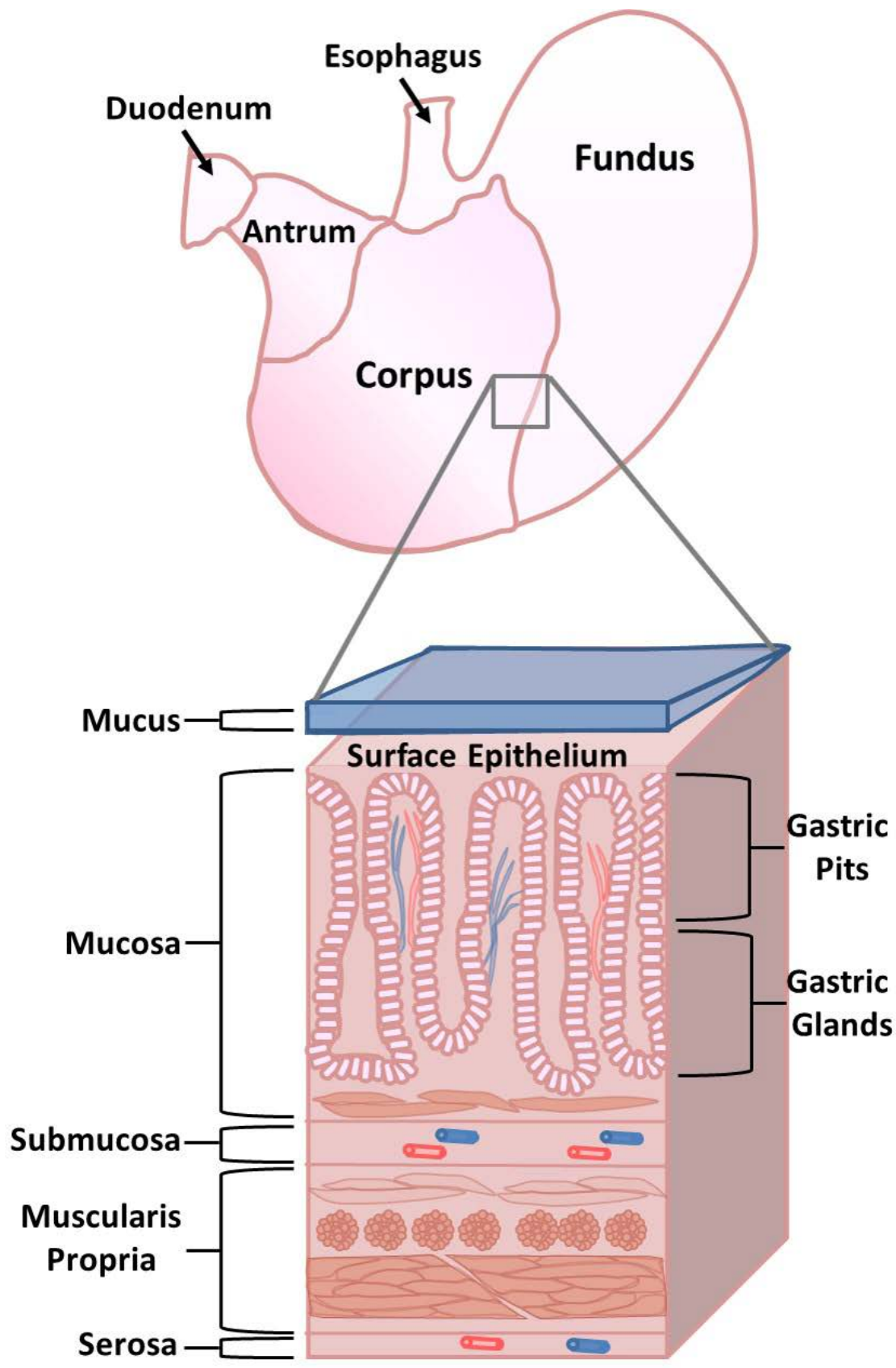

Figure 1. Schematic diagram of stomach organization topographical areas and anatomy. The stomach is subdivided into four layers: mucosa, submucosa, muscularis propria, and serosa. The mucosa layer of the stomach is lined with epithelial cells, which are folded into gastric pits that give the stomach its characteristic "ridged" appearance. Layers of the stomach contain blood vessels, connective tissue, and muscle. 

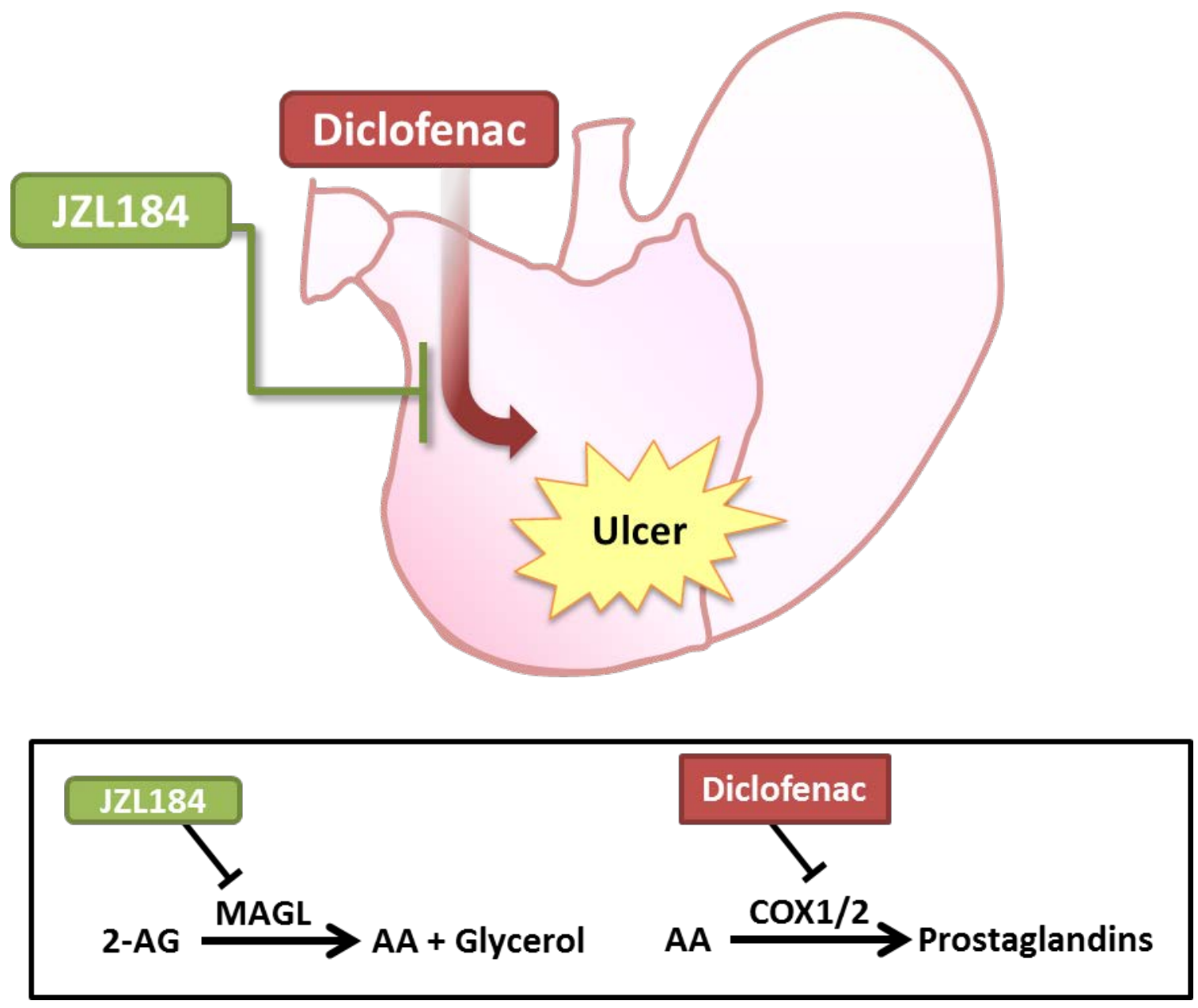

Figure 2. Simplified schematic of the MAGL inhibitor JZL184 blocking diclofenacinduced gastric pathology. JZL184 inhibits monoacylglycerol (MAGL), which catabolizes the endocannabinoid 2-arachidonoylglycerol (2-AG) into arachidonic acid (AA) and glycerol. Thus, JZL184 increases brain, spinal cord, and stomach levels of 2$A G$, in vivo. Diclofenac inhibits cyclooxygenases (COX), thereby decreasing prostaglandin synthesis from arachidonic acid, and inducing gastric inflammation and ulceration. 


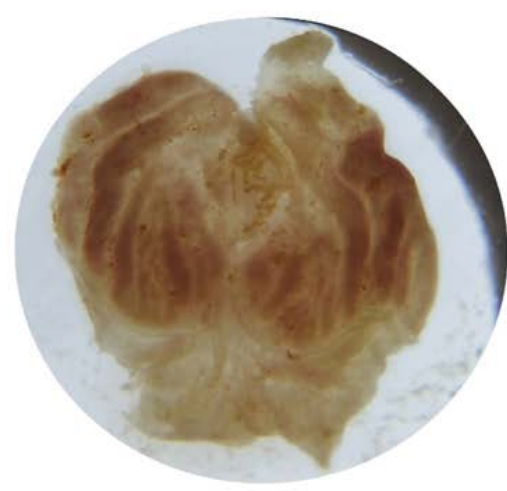

Vehicle

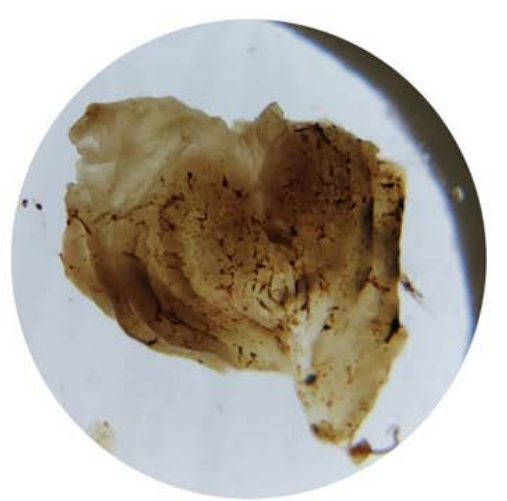

Diclofenac

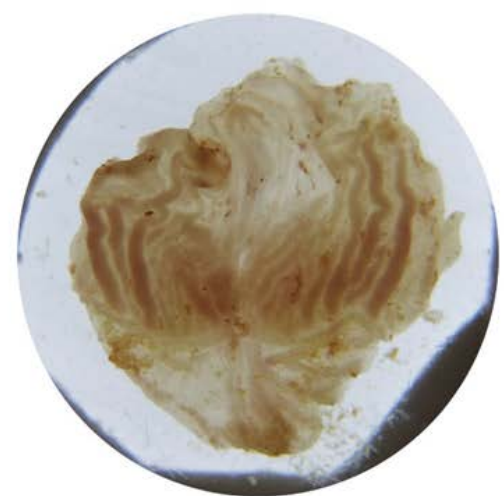

JZL184 + Diclofenac

Figure 3. Representative images of mouse stomachs. Mice were food deprived for $24 \mathrm{~h}$ and then administered diclofenac sodium $(100 \mathrm{mg} / \mathrm{kg}$, po) or vehicle. Gastric hemorrhages were induced by diclofenac (center), whereas the MAGL inhibitor JZL184 (right) prevented diclofenac-induced hemorrhage formation. 


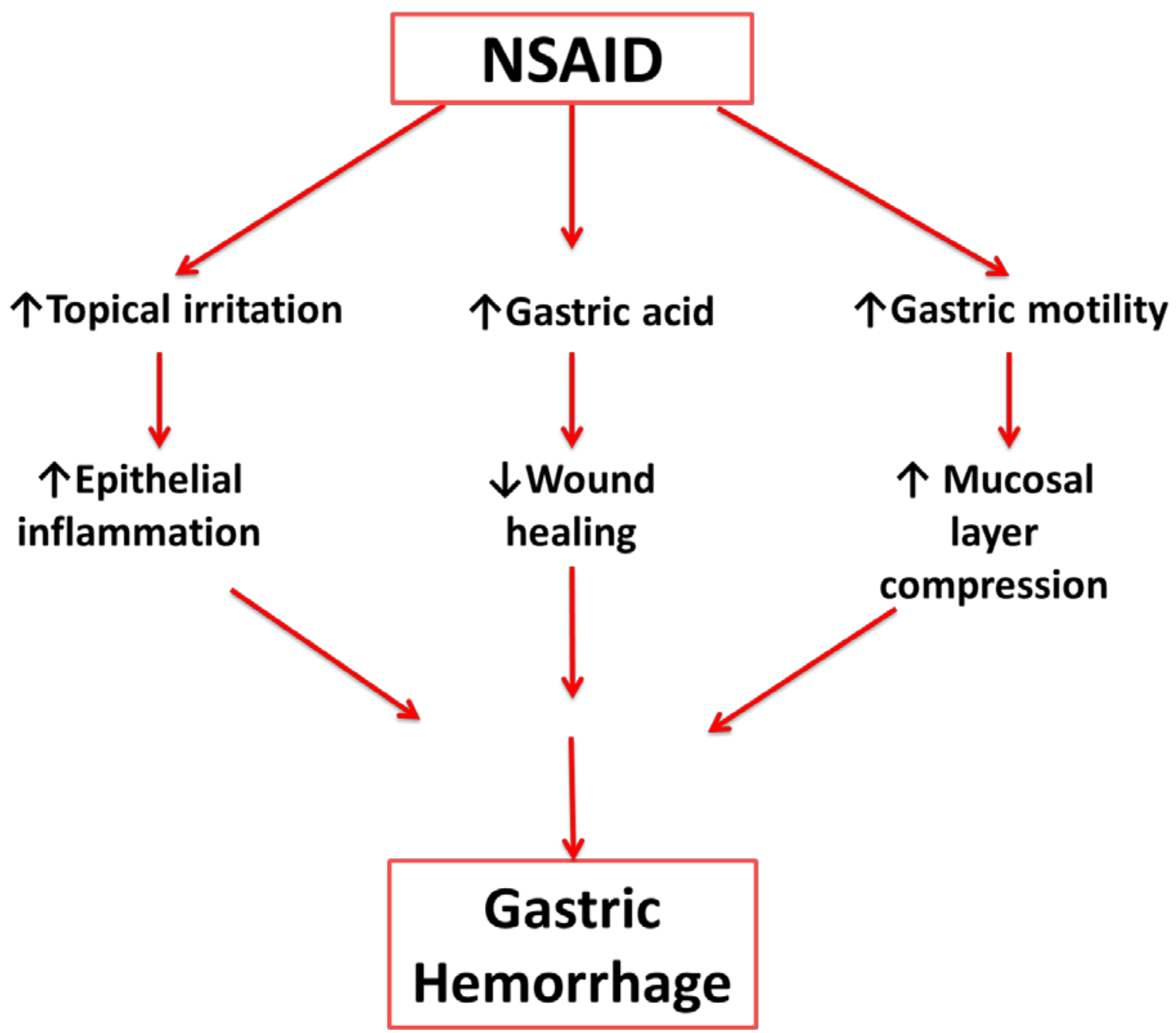

Figure 4. Schematic of potential pathogenesis mechanisms of NSAID-induced gastric hemorrhaging, as evaluated in the current study. The most characterized pathways of NSAID gastropathy are inflammation of the stomach lining, increased gastric acid secretion, and hypermotility. (Adapted from Wallace, 2008) 

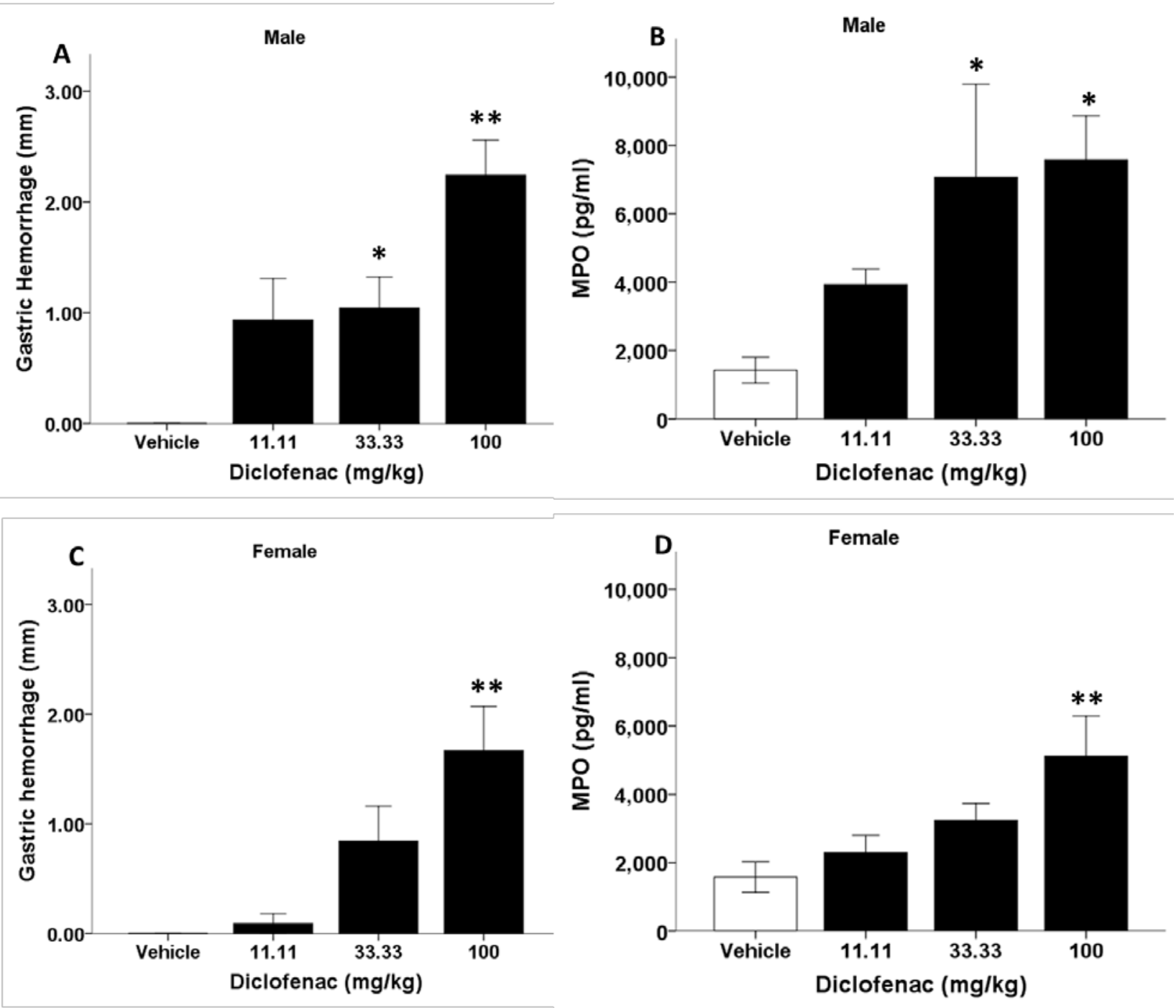

Figure 5. Diclofenac increased gastric hemorrhages and MPO levels. Mice were fasted for $24 \mathrm{~h}$, administered diclofenac (100 mg/kg, po) or vehicle, and stomachs were harvested and mucus collected $6 \mathrm{~h}$ later. In mucus samples, diclofenac dose-dependently increases gastric hemorrhage length and gastric mucus myeloperoxidase (MPO) levels in male ( $\mathrm{n}=$ 8) $(A, B)$ and female $(n=8-9)(C, D)$ mice. Data presented as mean \pm SEM; ${ }^{*} p<0.05$ vs. vehicle; ${ }^{* *} \mathrm{p}<0.01$ vs. vehicle 

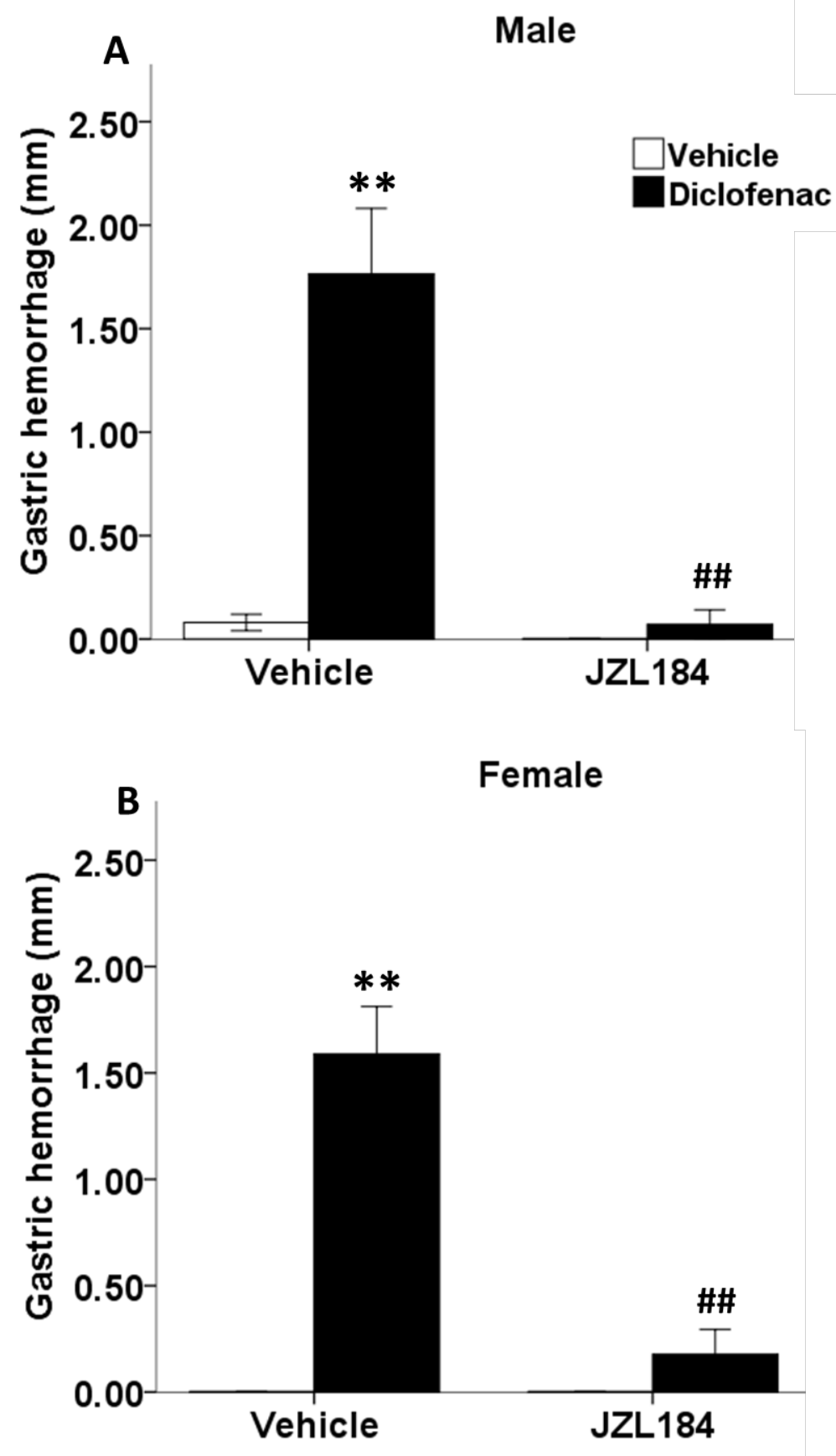

Figure 6. The MAGL inhibitor JZL184 prevents the development of gastric hemorrhages induced by diclofenac in male (A) and female (B) mice. Mice were fasted for $22 \mathrm{~h}$, administered JZL184 (40 mg/kg, ip) or vehicle, then diclofenac (100 mg/kg, po, black bars) or vehicle (white bars) $2 \mathrm{~h}$ later, and stomachs were harvested $6 \mathrm{~h}$ later. Data presented as mean \pm SEM $(\mathrm{n}=7-8) ;{ }^{* *} \mathrm{p}<0.01$ vs. vehicle/vehicle; \#\# $\mathrm{p}<0.01$ vs. vehicle/diclofenac 


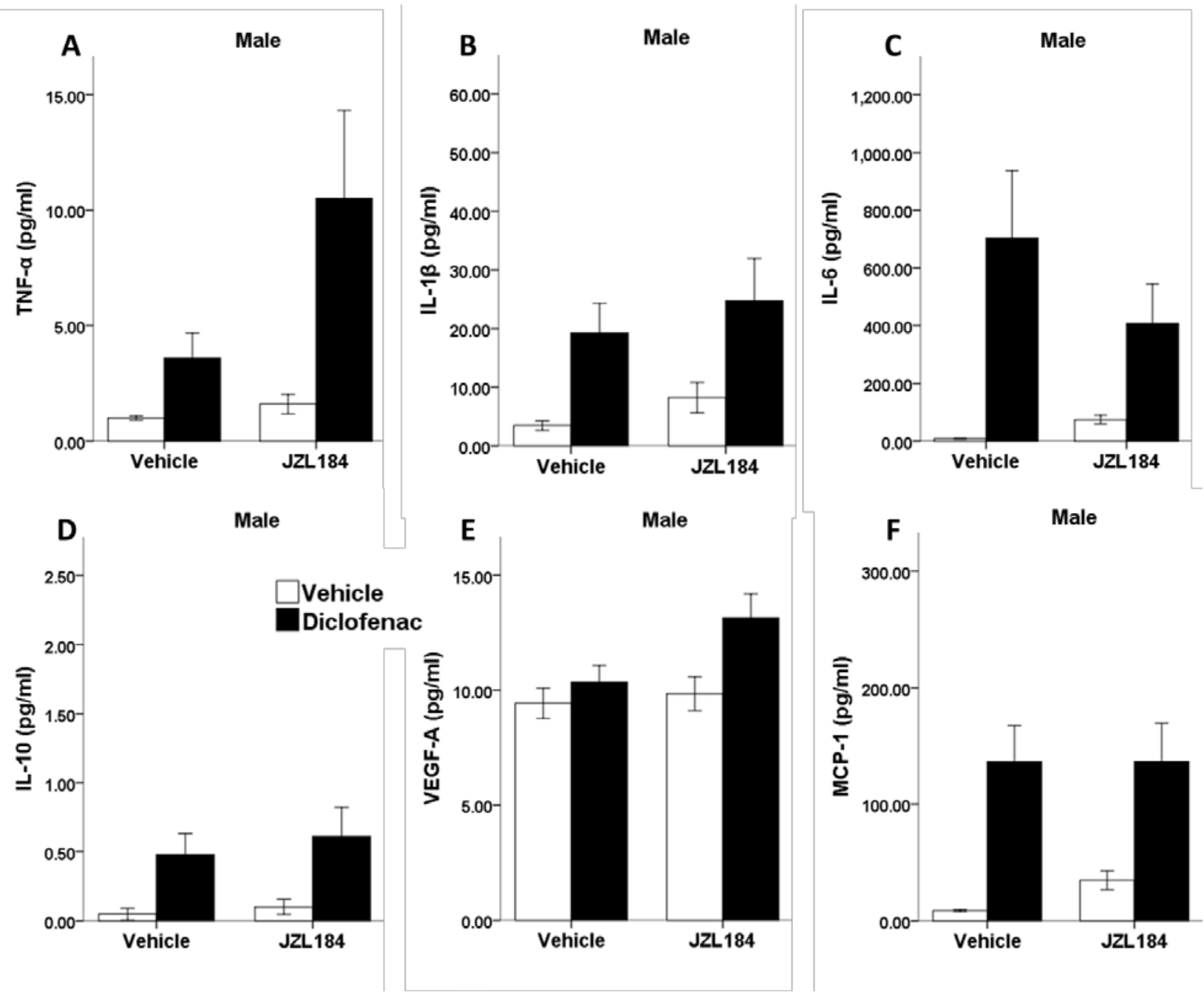

Figure 7. Diclofenac increases inflammatory cytokines in whole stomach in male mice. Mice were fasted for $22 \mathrm{~h}$, administered JZL184 (40 mg/kg, ip) or vehicle, diclofenac (100 mg/kg, po, black bars) or vehicle (po, white bars) $2 \mathrm{~h}$ later, and stomachs were harvested $6 \mathrm{~h}$ later. Cytokines and chemokines were analyzed using a multiplex assay. In whole stomach, diclofenac significantly increases levels of TNF- $\alpha$ (A), IL-1 $\beta$ (B), IL-6 (C), IL-10 (D), VEGFA (E), and MCP-1 (F). JZL184 does not block diclofenac-induced cytokine elevations. Data presented as mean \pm SEM $(n=7-8)$. 


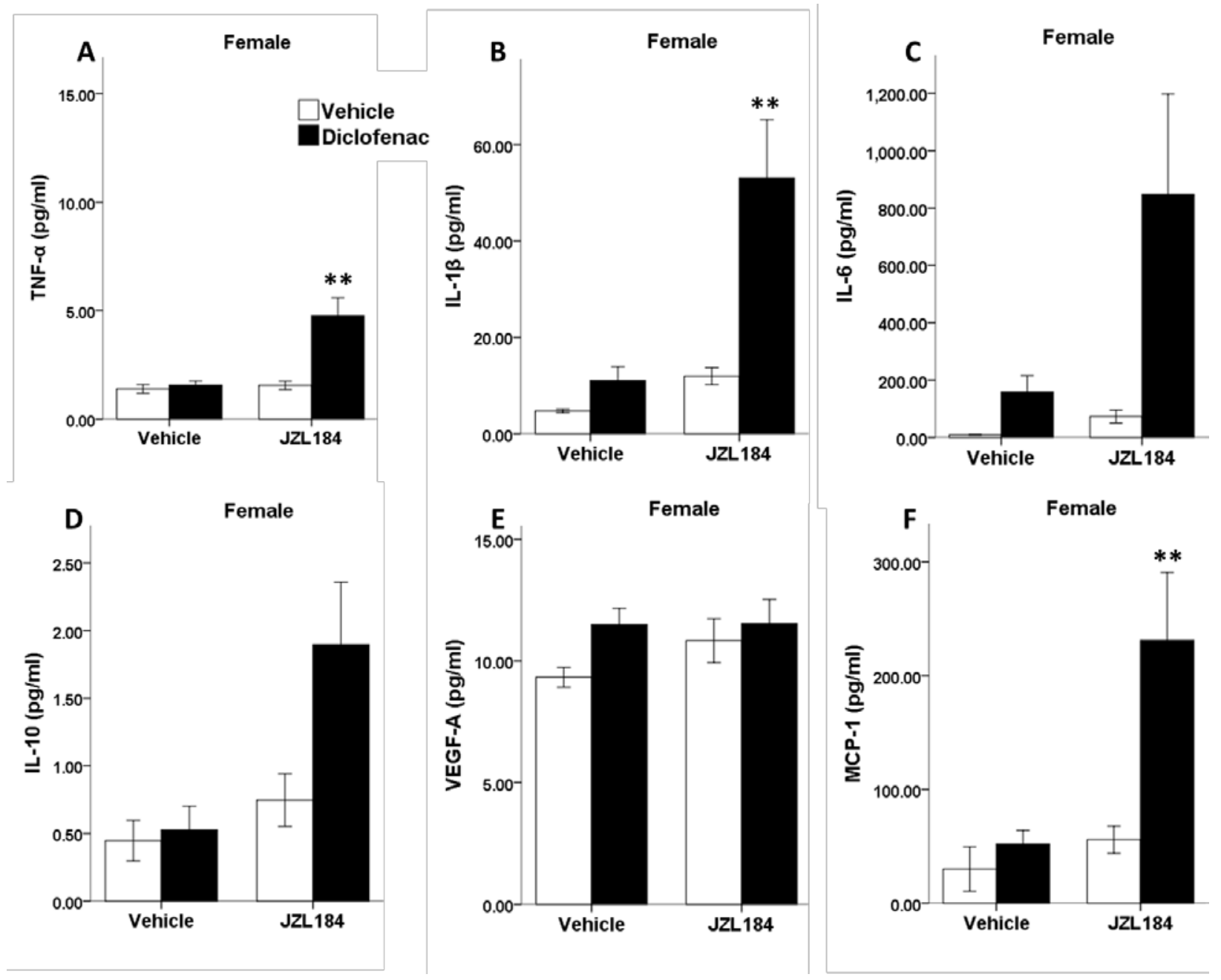

Figure 8. JZL184 administration prior to diclofenac increases inflammatory cytokines in whole stomach in female mice. Mice were fasted for $22 \mathrm{~h}$, administered JZL184 (40 mg/kg, ip) or vehicle, diclofenac (100 mg/kg, po, black bars) or vehicle (po, white bars) $2 \mathrm{~h}$ later, and stomachs were harvested $6 \mathrm{~h}$ later. TNF- $\alpha$ (A), IL-1 $\beta$ (B), IL-6 (C), IL-10 (D), VEGF-A (E), and MCP-1 (F) were analyzed using a multiplex assay. Data presented as mean \pm SEM ( $\mathrm{n}=$ $8) ;{ }^{* *} \mathrm{p}<0.01$ vs. vehicle/vehicle 


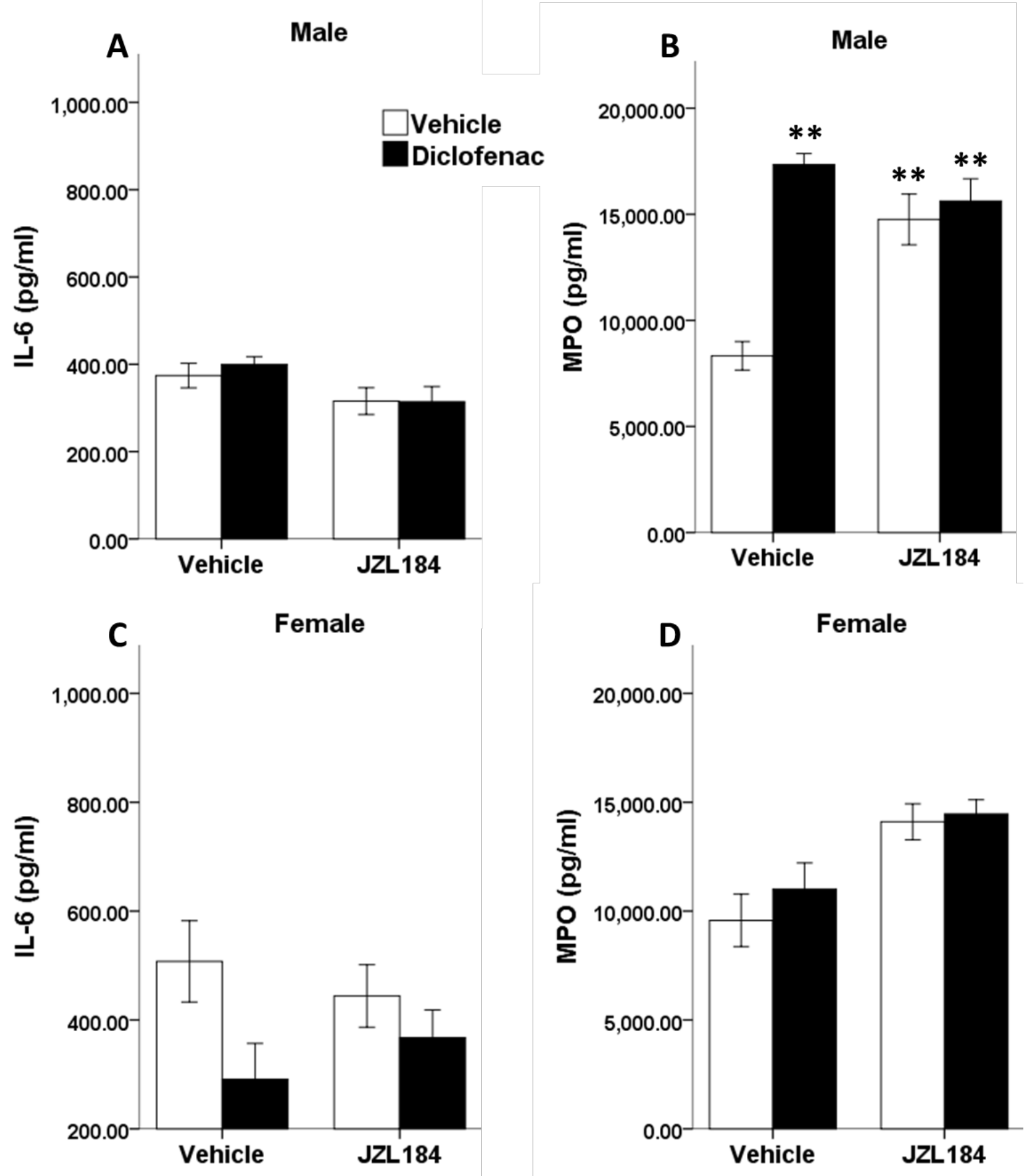

Figure 9. Diclofenac increases gastric MPO levels. Whole stomachs were assayed for IL-6 and MPO using an enzyme-linked immunosorbent assay (ELISA). In male mice, JZL184 (40 $\mathrm{mg} / \mathrm{kg}$ ip) significantly decreases IL-6 (A). JZL184 with and without diclofenac increases levels of MPO (B). In female mice, diclofenac significantly decreases IL-6 (C). JZL184 increases levels of MPO (D). Data presented as mean \pm SEM ( $n=7-8) ;{ }^{* *} \mathrm{p}<0.01$ vs. vehicle/vehicle 

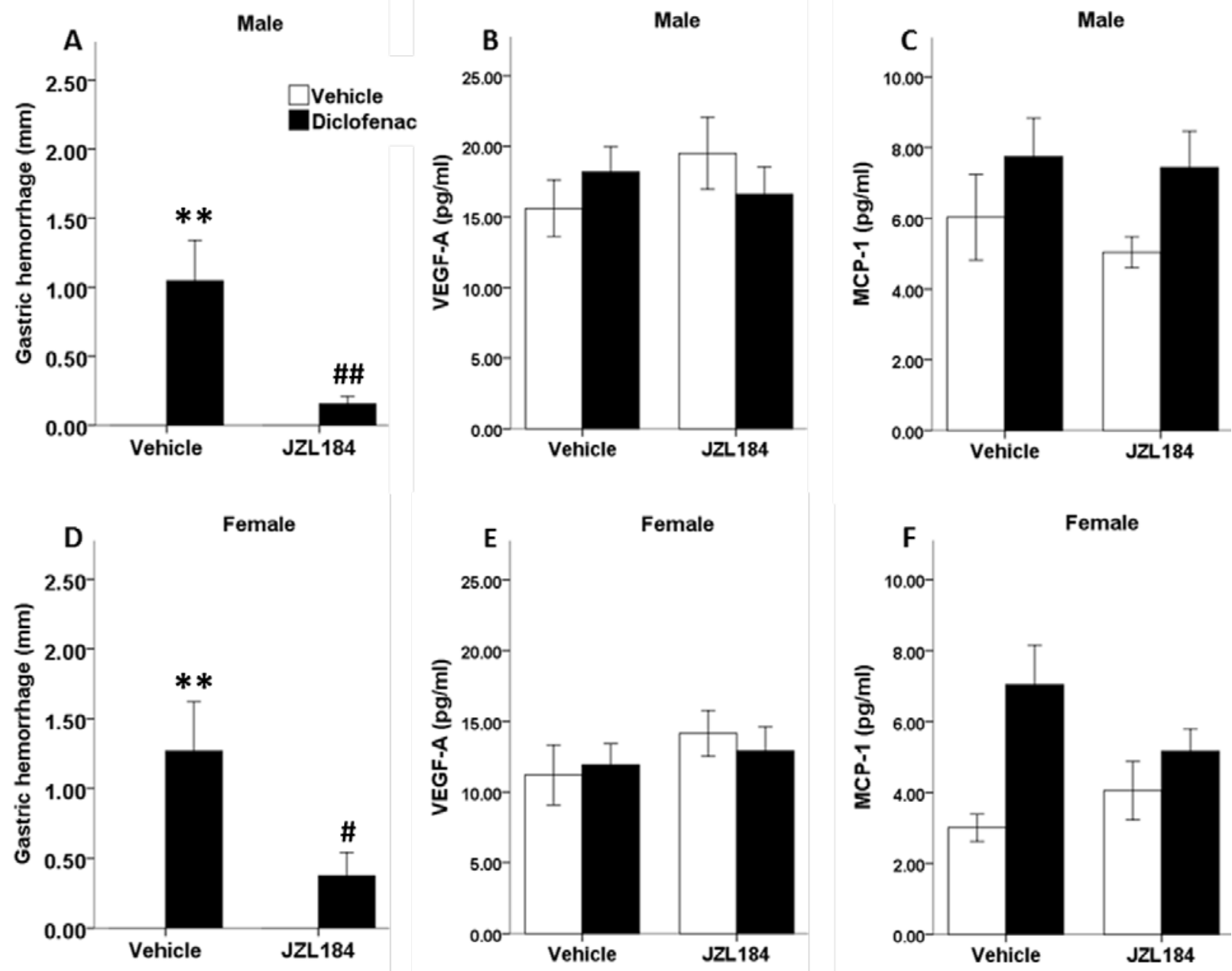

Figure 10. Diclofenac increases the chemokine MCP-1 in stomach mucus. Mice were fasted for $22 \mathrm{~h}$, administered JZL184 (8 mg/kg, ip) or vehicle, diclofenac (100 mg/kg, po, black bars) or vehicle (po, white bars) 2 h later, and stomachs were harvested and mucus collected 6 $\mathrm{h}$ later. The MAGL inhibitor JZL184 prevents the development of gastric hemorrhages induced by diclofenac in male (A) and female (D) mice. Inflammatory markers were analyzed using a multiplex assay. In mucus samples, only VEGF-A and MCP-1 were detected in the assay. There were no treatment differences in VEGF-A in male (B) or female (E) mice. Diclofenac significantly increases MCP-1 in male (C) and female (F) mice. Data presented as mean \pm SEM $(n=9-10) .{ }^{* *} p<0.01$ vs. vehicle/vehicle; $\# p<.05$, \#\# $p<0.01$ vs.

vehicle/diclofenac 

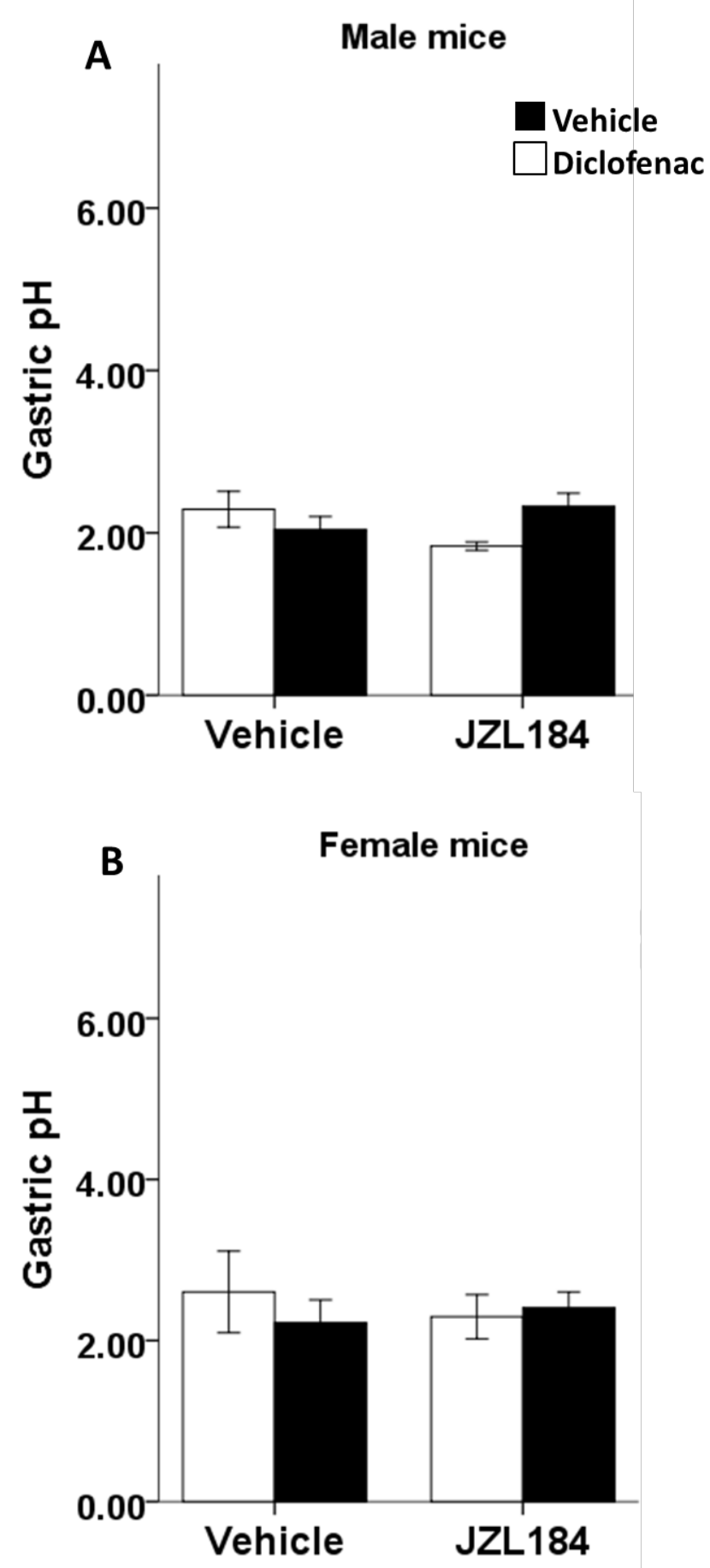

Figure 11. Gastric secretion acidity is unaffected by JZL184 or diclofenac. Mice were fasted for 22h, administered JZL184 (8 mg/kg, ip) or vehicle, diclofenac (100 mg/kg, po, black bars) or vehicle (po, white bars) $2 \mathrm{~h}$ later, and gastric contents were harvested $6 \mathrm{~h}$ later. Diclofenac and JZL184 do not alter gastric acid secretions in either male (A) or female (B) mice. Data presented as mean \pm SEM $(n=10)$ 


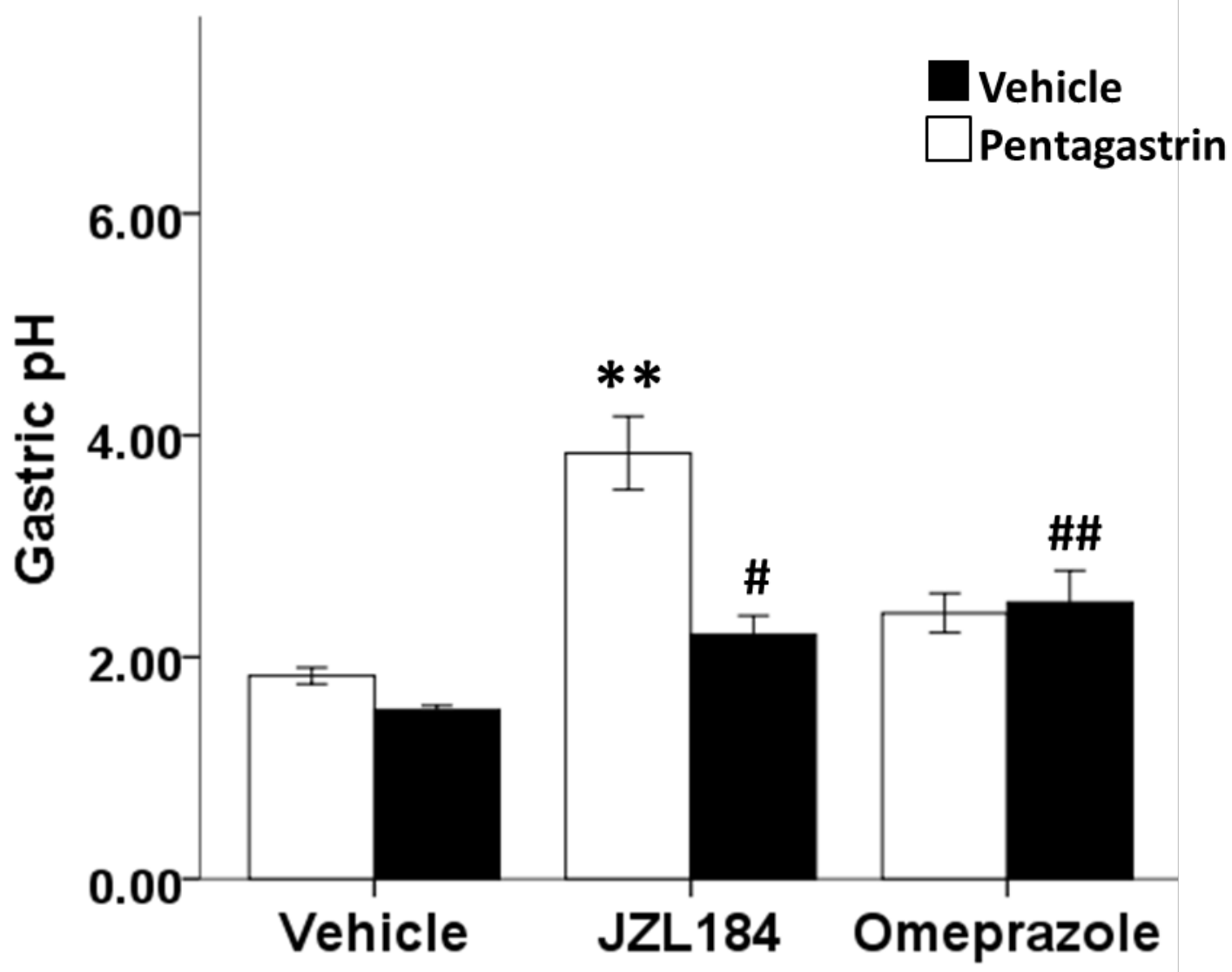

Figure 12. JZL184 increases gastric $\mathrm{pH}$ in basal- and stimulated-acid conditions. Mice were fasted for $22 \mathrm{~h}$, administered JZL184 (40 mg/kg, ip), omeprazole (20 mg/kg, ip) or vehicle (ip), acid secretion was stimulated $2 \mathrm{~h}$ later with pentagastrin $(0.25 \mathrm{mg} / \mathrm{kg}$, sc, black bars) or vehicle (sc, white bars), and gastric contents were collected $1 \mathrm{~h}$ later. Data presented as mean \pm $\operatorname{SEM}(\mathrm{n}=8) ;{ }^{* *} \mathrm{p}<.01$ vs vehicle/vehicle, $\# \mathrm{p}<.05, \# \# \mathrm{p}<.01$ vs vehicle/pentagastrin 


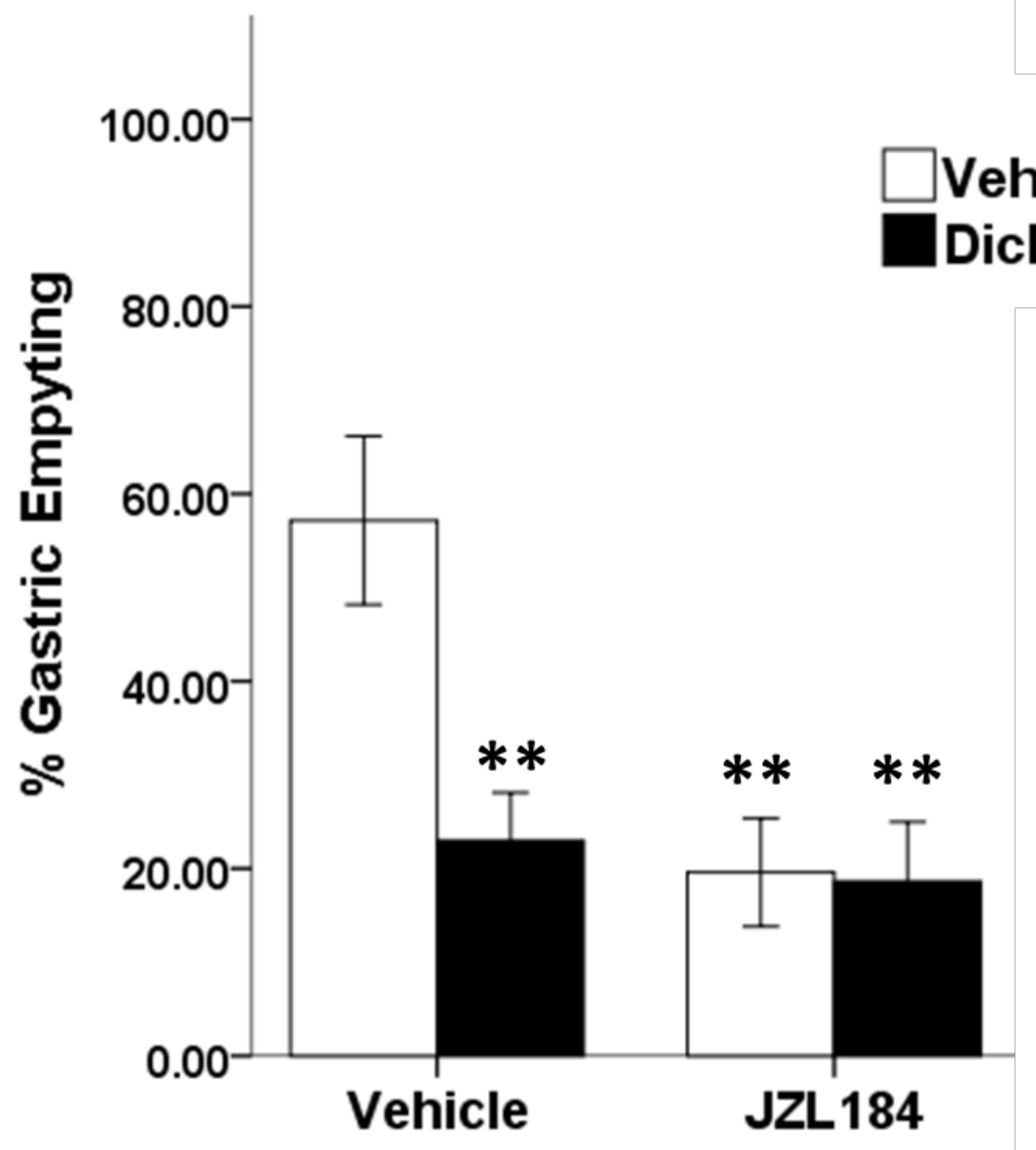

Figure 13. JZL184 and diclofenac decrease gastric emptying. Mice were fasted for $24 \mathrm{~h}$. The mice were administered JZL184 (40 mg/kg) or vehicle, then $2 \mathrm{~h}$ later, diclofenac sodium (100 $\mathrm{mg} / \mathrm{kg}$, po, black bars) or vehicle (po, white bars) was administered $1 \mathrm{~h}$ before oral administration by gavage of phenol red $(0.5 \mathrm{mg} / \mathrm{ml})$. JZL184 and diclofenac significantly reduce gastric emptying of phenol red as compared to control mice. Data presented as mean \pm SEM $(\mathrm{n}=8) ;{ }^{* *} \mathrm{p}<.01$ vs vehicle/vehicle 

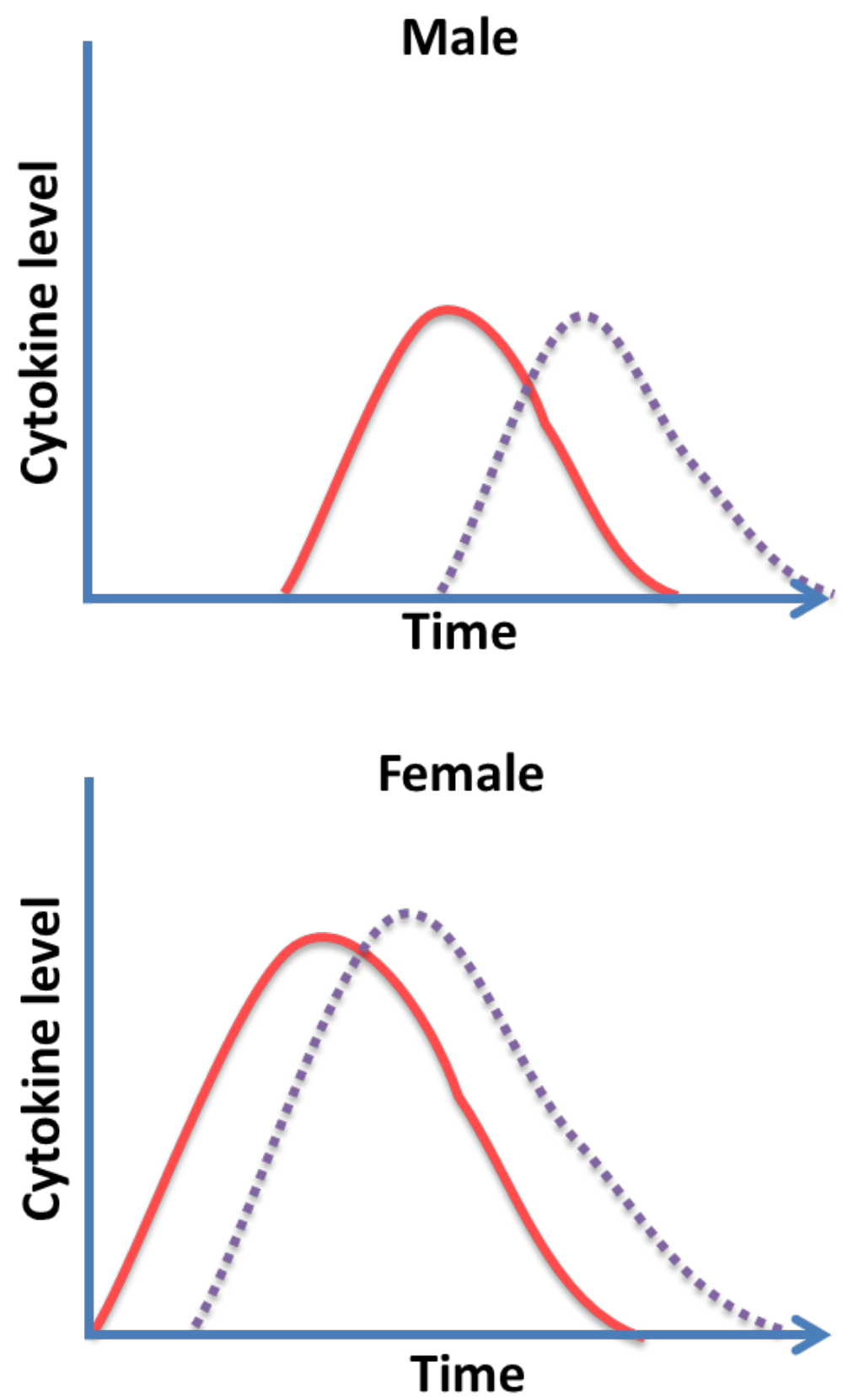

Figure 14. Schematic of possible sex differences in immune response. After mucosal damage, TNF- $\alpha$, IL-1 $\beta$, IL-6, and MCP- 1 are produced and increase inflammation at the site of injury (solid line). These proinflammatory cytokines then stimulate production of the anti-inflammatory cytokine, IL-10, and VEGF-a (dashed line). In the current data, female mice have higher cytokine activity than male mice, which may indicate a more vigorous immune response, as depicted by the cytokine activity peaks, or an earlier cytokine response, as depicted by the shifted timeline. 